University of Louisville

ThinkIR: The University of Louisville's Institutional Repository

Electronic Theses and Dissertations

$5-2020$

\title{
"It's personal": a case study analysis of the strategic management of resources in a historically black University athletic department.
}

Brigitte M. Burpo

University of Louisville

Follow this and additional works at: https://ir.library.louisville.edu/etd

Part of the Business Administration, Management, and Operations Commons, Nonprofit Administration and Management Commons, Organizational Behavior and Theory Commons, Sports Management Commons, and the Sports Studies Commons

\section{Recommended Citation}

Burpo, Brigitte M., "'It's personal": a case study analysis of the strategic management of resources in a historically black University athletic department." (2020). Electronic Theses and Dissertations. Paper 3363.

https://doi.org/10.18297/etd/3363

This Doctoral Dissertation is brought to you for free and open access by ThinkIR: The University of Louisville's Institutional Repository. It has been accepted for inclusion in Electronic Theses and Dissertations by an authorized administrator of ThinkIR: The University of Louisville's Institutional Repository. This title appears here courtesy of the author, who has retained all other copyrights. For more information, please contact thinkir@louisville.edu. 
"IT'S PERSONAL": A CASE STUDY ANALYSIS OF THE STRATEGIC

MANAGEMENT OF RESOURCES IN A HISTORICALLY BLACK UNIVERSITY ATHLETIC DEPARTMENT

By

Brigitte M. Burpo

B.S., Tuskegee University, 2007

M.Ed., Auburn University, 2015

A Dissertation
Submitted to the faculty of the College of Education and Human Development of the
University of Louisville in Partial Fulfillment of the Requirements for the Degree of

Doctor of Philosophy in Educational Leadership and Organizational Development

Department of Educational Leadership, Evaluation and Organizational Development University of Louisville

Louisville, Kentucky

May 2020 
Copyright 2020 by Brigitte Maria Burpo

All rights reserved 

"IT'S PERSONAL": A CASE STUDY ANALYSIS OF THE STRATEGIC MANAGEMENT

OF RESOURCES IN AN HISTORICALLY BLACK UNIVERSITY ATHLETIC DEPARTMENT

\author{
By \\ Brigitte M. Burpo \\ B.S., Tuskegee University, 2007 \\ M.Ed., Auburn University, 2015
}

A Dissertation Approved on

April 17, 2020

By the following Dissertation Committee:

Dr. Meg G. Hancock, Chair

Dr. Meera Alagaraja

Dr. Mary Hums

Dr. Marion Hambrick

Dr. Ishwanzya Rivers 


\section{DEDICATION}

I dedicate this dissertation to the people who helped shape me into the woman that I am, the student that I became, and the professional that I will soon be again. To my mother whose endless sacrifices provided the mental, emotional, and economic means to attain every goal I set for myself, thank you. Your confidence in my ability and relentless reinforcement of that is why I'm here and I cannot thank you enough. Thank you for seeing potential in me even when I did not and my teachers did not. Your unwavering encouragement and support has always been the reason I dream so big and love so hard. I love you and I hope that I make you proud. To my sister, thank you for making me tough throughout the years, and for always being there when I needed you most. Thank you for giving me an academic model to strive to be like. Your friendship, "Are you in the library?" messages and genuine support gave me motivation to work hard on days when I had little energy left. I hope that I have made you proud. I love you. To my closest friends and family in Birmingham, Atlanta, Arlington, New York, New Orleans, Columbia, and Los Angeles, thank you for supporting me on both good days and tearfilled nights, and for giving me refuge when I needed to regroup. You comforted me, allowed me space to achieve this great achievement, and cheered me to victory. You never held it against me when I could not make it to special events and I cannot put into words what that has done for me throughout this process. I am here today because of the strong support from all of you along the way. To all of you, I love you. To the students and alumni of Historically Black Colleges and Universities, you are the best and the 
brightest. Thank you for continuing to preserve our culture and inspiring this research. To the little girls with brown skin who are told that you are not smart enough, the only opinion about you that matters is your own. You are everything you want to be and more. This dissertation is for all of you. 


\section{ACKNOWLEDGEMENTS}

I would like to thank my dissertation chair, Dr. Meg Hancock, for your unwavering support, encouragement, and patience. Thank you for always being available to talk through research, life goals, and to give me encouragement. Thank you for supporting me while holding me accountable, and telling me what was real every time we had difficult conversations. I would also like to thank all of my committee members. Dr. Mary Hums, thank you for seeing my potential from our first conversation about UofL. Your welcoming nature is why I trusted UofL SPAD with my doctoral journey. Thank you for being supportive and always available to talk through anything I was facing. Dr. Marion Hambrick, thank you for allowing your office to become a safe space for me to exist and sometimes cry. You did not judge me and instead motivated me to step my game up, and most importantly, to finish what I started. Dr. Meera Alagaraja, thank you for seeing my vision and setting my passion on fire with the incredible possibilities that qualitative research brings. Thank you for being a sounding board and a confidant when I needed to have transparent conversations. I have learned so much from your guidance both academically and professionally. To Dr. Ishwanzya Rivers, thank you for agreeing to be a part of this journey at the Celebration of Teaching and Learning in 2018. You heard a short overview of my research interests and supported me without question. Thank you for your encouragement and calm nature that always reassured me that everything would be ok. 
I would like to thank the entire SPAD faculty and doctoral students for the wellness checks, opportunities, and fun fellowship. Though I struggled my first year in this process, you all showed me that it is not about how I start, but how I finish. I would like to thank my students in the SPAD program who have cheered me on and reminded me daily why I began this journey. Your fresh minds continue to keep me motivated and I hope that I have been able to show you all that learning can be fun, and we can all be good students when we are motivated and feel supported. Thank you to the Multicultural Association of Graduate Students (MAGS). I had the privilege to serve as your Vice President and meet so many brilliant and supportive students over the past few years. I appreciate you, and it has been my honor to serve you. Thank you all for giving me the environment that I needed to bloom. 


\begin{abstract}
“IT’S PERSONAL”: A CASE STUDY ANALYSIS OF THE STRATEGIC

MANAGEMENT OF RESOURCES IN A HISTORICALLY BLACK COLLEGE

ATHLETIC DEPARTMENT

Brigitte M. Burpo
\end{abstract}

April 3, 2020

This dissertation is a qualitative case study examination of the strategic

management of critical resources in an HBCU athletic program. It begins with a historical overview of HBCUs and HBCU athletic departments focusing on the systemic and societal influences that contributed to the current state of HBCU athletic programs. This dissertation later discusses the influence of a lack of financial resources on HBCU athletic departments further depletes the ability to operate with a competitive advantage.

Chapter One focuses on the historic background of HBCUs and their formation as well as the societal influences that depleted critical resources. Chapter Two covers the theoretical background of resource dependence theory and resource based theory as well as the use of those theories in business and in sport. Chapter Three outlines the methods used for this qualitative case study highlighting the unique elements of the study including the use of photovoice, video observations, and photos to capture evidence of a phenomenon. Results from the study identify and introduce the three themes of satisficing, personal attachment and "village" benevolence management practices found in this study. 


\section{TABLE OF CONTENTS}

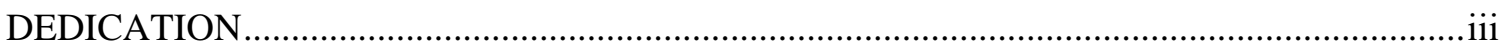

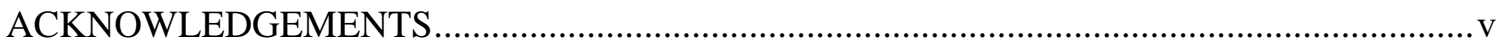

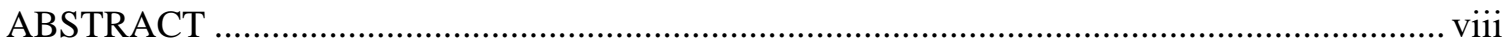

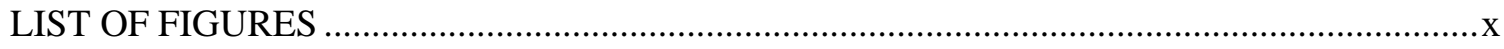

CHAPTER I INTRODUCTION …………………………………………………….

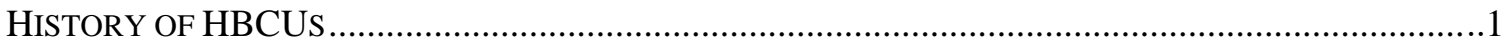

HBCU ATHLETICS HISTORY \& CULTURE …………………..................................................

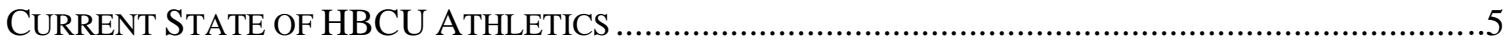

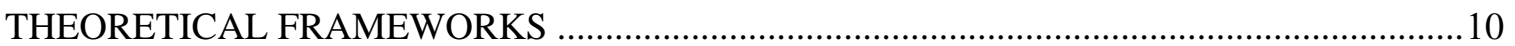

RESOURCE DEPENDENCE THEORY ……………………………………………………1 10

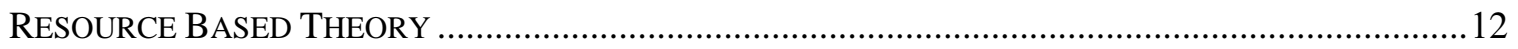

STATEMENT OF THE PROBLEM …………………………………………………....13

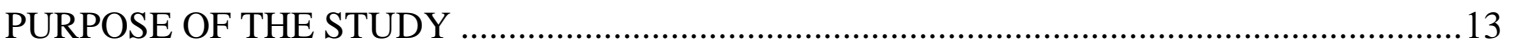

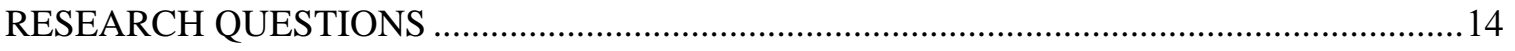

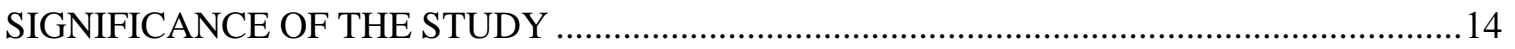

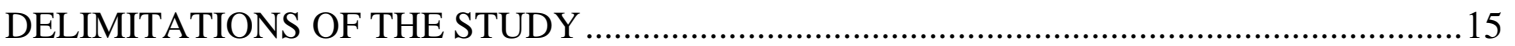

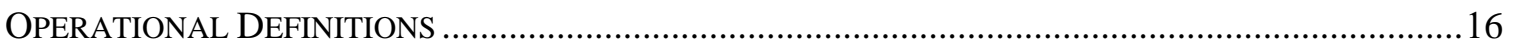

CHAPTER II LITERATURE REVIEW ………………………………………….....19

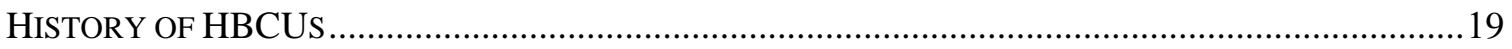

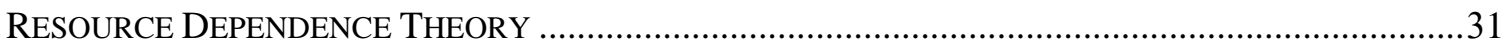

RESOURCE BASED THEORY …………………………………………………………....

CHAPTER III METHODOLOGY.................................................................................. 57

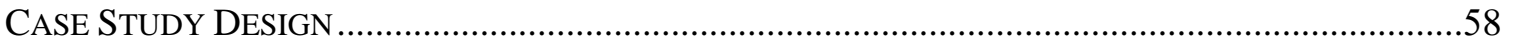

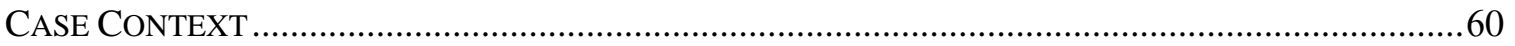

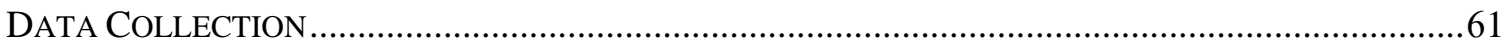

QUALITY OF CONCLUSIONS ……………………………………………………………6

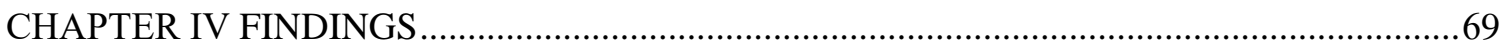

GENERAL DATA COLLECTION METHODS …………………………………………….....

CASE: HILL UNIVERSITY............................................................................................

RQ1: WHAT RESOURCES DO HBCU ATHLETIC DEPARTMENTS MANAGE? ....................................74

RQ2: HOW ARE RESOURCES MANAGED IN HBCU ATHLETIC DEPARTMENTS? ...............................91

RQ 2B: HOW DO HBCU ATHLETIC DEPARTMENTS MITIGATE GAPS IN RESOURCES? …….............104

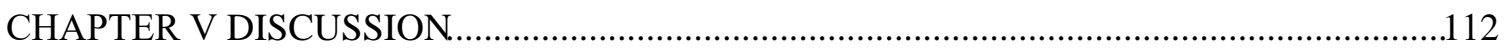

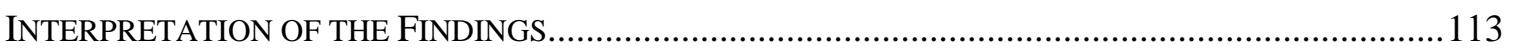

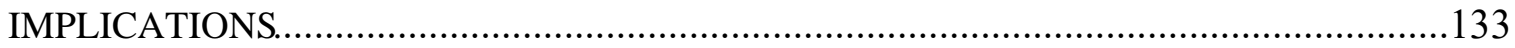




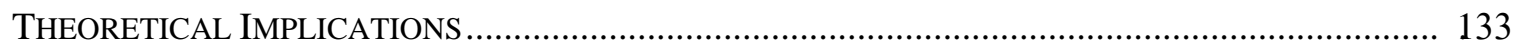

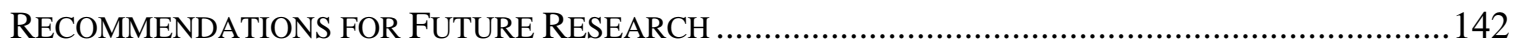

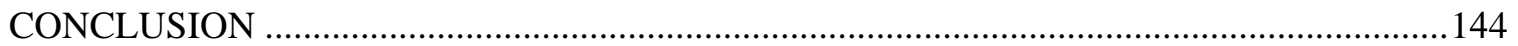

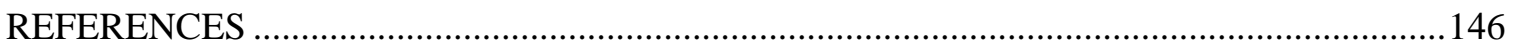

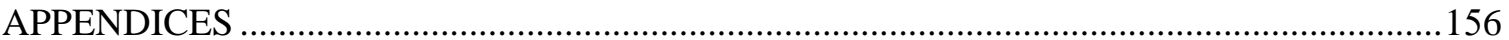

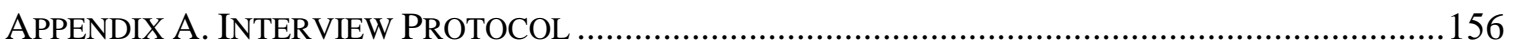

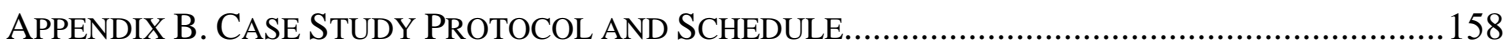

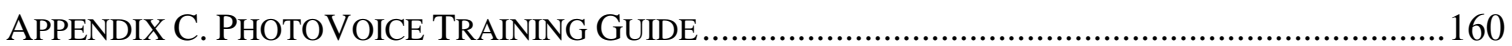

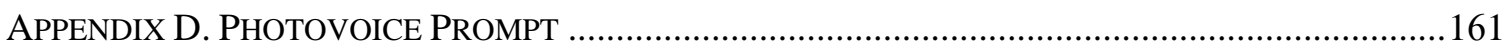

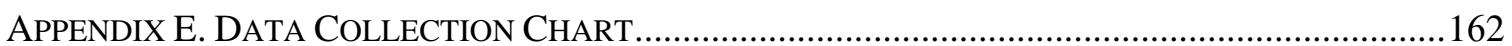

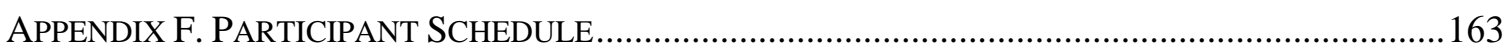

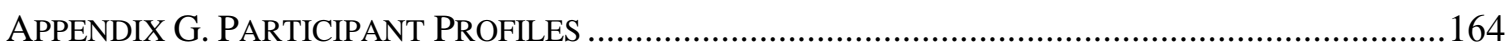

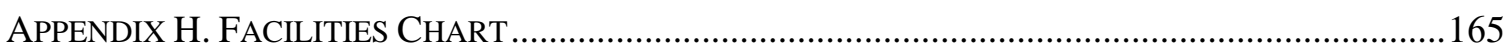

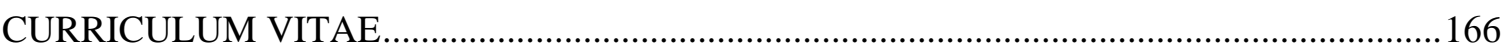




\section{LIST OF FIGURES}

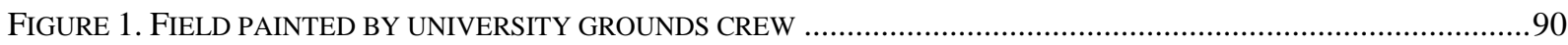

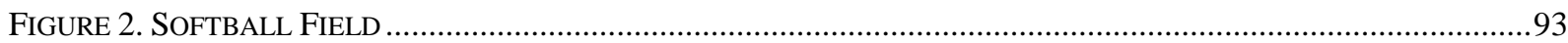

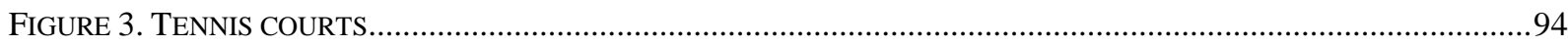

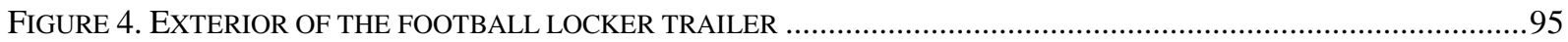

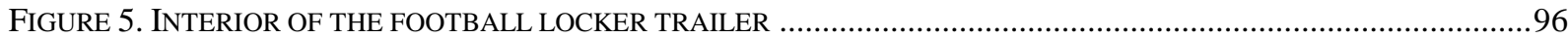

FIGURE 6. PHOTO OF TAILGATING INSIDE OF THE STADIUM TAKEN BY PHOTOVOICE PARTICIPANT ...........................97

FIGURE 7. TAILGATING MARKERS FOR EACH SECTION THAT IS SOLD TO CUSTOMERS...........................................98

FIGURE 8. THREE THEMES AND ELEMENTS OF MANAGEMENT STRATEGIES IN THIS STUDY …................................102

FIGURE 9. HU ATHLETIC SPONSORSHIP WITH A FOODSERVICE ORGANIZATION .....................................................104

FIGURE 10. CURRENTLY OUTDATED EQUIPMENT TAKEN BY THE PHOTOVOICE PARTICIPANT …...............................107

FIGURE 11. THE CURRENT TICKET BOX OFFICE FOR FOOTBALL TICKET SALES.....................................................109

FIGURE 12. PHOTO OF THE TICKET BOOTH FOR BASKETBALL AND VOLLEYBALL TICKET SALES .............................109

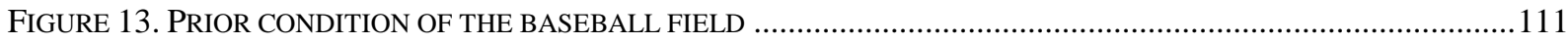

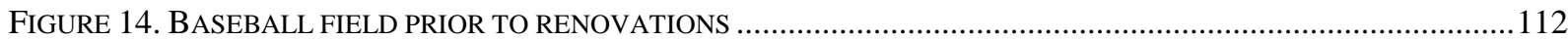

FIGURE 15. STAFF AND VOLUNTEERS WORKING TO REBUILD THE BASEBALL FIELD …….....................................112

FIGURE 16. PHOTO OF VIDEO CONTENT TAKE BY THE PHOTOVOICE PARTICIPANT ……….......................................119 


\section{CHAPTER I}

\section{INTRODUCTION}

The survival of Historically Black Colleges and Universities (HBCUs) has proven difficult in unpredictable political, social, cultural, and financial environments that work against their stability. A series of historic events as outlined in this chapter has had ripple effects on various facets of the HBCU infrastructure, including its athletics departments (Palmer, 2010). Traditionally, HBCU athletics have had limited budgets that affect recruiting, coaching and administrative staff hiring, departmental structure, facilities, and the programs they are able to offer their student- athletes (Cheeks \& Crowley, 2015). To better understand how HBCUs' limited yet overtaxed budgets affect so many aspects of their operation, it is important to understand the historic timeline of HBCUs, their athletics programs, and the current state of HBCUs. Nearly a century of federal and societal actions have impeded the aspirations of HBCUs and in turn, their athletics departments.

\section{History of HBCUs}

In 1865, the Thirteenth Amendment ended nearly three centuries of chattel slavery in the United States. Prior to then, it was illegal in every state south of Tennessee to teach any Black person how to read or write (Gasman \& Hilton, 2011). After the Thirteenth Amendment abolished chattel slavery, Congress established the Freedmen's Bureau in March 1865 to aid formerly enslaved people with acclimation to a life of freedom (United States Senate, n.d.). The bureau provided them with food, clothing, job placement, and educational facilities, which also 
helped with the formation of many Historically Black Colleges and Universities. HBCUs are defined as:

Any historically Black college or university that was established prior to 1964, whose principal mission was, and is, the education of Black Americans, and that is accredited by a nationally recognized accrediting agency or association determined by the Secretary [of Education] to be a reliable authority as to the quality of training offered or is, according to such an agency or association, making reasonable progress toward accreditation (Higher Education Act of 1965, Sec.322.20 U.S.C. 1061).

This definition gives clarity to the differentiation between predominantly Black colleges and universities such as Baton Rouge Community College and Baltimore City Community College and federally designated HBCUs such as Morgan State University, Howard University, and Spelman College. This also differentiates HBCUs from minority-serving institutions (MSI) such as Azusa Pacific University and Barry University (Miami), which were not founded for the purpose of educating Black students but currently serve a large portion of Black and Hispanic students in the United States (Flores \& Park, 2015).

The Morrill Act of 1890 stated that public colleges and universities would forfeit federal funding unless they established agricultural and mechanical universities for the Black population in their state. This not only increased funding for those institutions, but it also increased access to education for Black students. This increase of federal funding aided in the growth of HBCUs (Collins \& Norris, 2015). By the 1930s, 121 public and private HBCUs existed, mostly located in the southeast region of the United States. The HBCU culture then grew to reflect three paradigms outlined by Cavil (2015): racial pride, cultural expression, and Black masculinity. 
This growth in opportunities for education for Black people not only expanded academic offerings at HBCUs, but also increased extracurricular offerings such as athletics.

Today, HBCUs have had financial difficulty given their mission to serve underrepresented populations while facing a history of underfunding and discrimination (Gasman, 2009). Lower tuition and smaller endowments strain operating budgets; an institution's financial structure is further strained by subsidies to support athletics departments. Physical, human, and financial resources are scarce in comparison to larger Power Five institutions (Cheeks \& Crowley, 2015). The athletics departments of HBCUs have also experienced the same struggles.

\section{HBCU Athletics History \& Culture}

HBCUs began to organize athletic competitions between schools through the formation of athletic conferences. The first Black intercollegiate conference was founded in 1906 and was named the Inter-Scholastic Athletic Association of the Middle Atlantic States (ISAA) in conjunction with the racially segregated National Collegiate Athletic Association (NCAA) the same year. ISAA was comprised of all-Black teams and referees for public schools, athletic clubs, churches, and colleges throughout the mid-Atlantic United States. ISAA was also the model for the creation of state athletic associations across the United States. In 1912, the Colored Intercollegiate Athletic Association (CIAA, since renamed as the Central Intercollegiate Athletic Association) was founded on the campus of Hampton Institute (now Hampton University) as the first HBCU conference. The CIAA has since been succeeded by the Southern Intercollegiate Athletic Conference (SIAC) in 1913, the Southwestern Athletic Conference (SWAC) in 1920, and the Mid-Eastern Athletic Conference (MEAC) in 1970 (Cavil, 2015; Hodge et al., 2013). 
Due to segregation laws, HBCUs were not allowed into the NCAA until after 1956. The NCAA then enacted the College Division classification (now known as Division II), which separated HBCUs from historically White institutions that competed in what was then known as the University Division (Cavil, 2015). By the 1970s, the effects of Brown v. Board of Education (1954) and the Civil Rights Act of 1964 had finally started to take their toll on campuses and in the athletic departments of HBCUs. HBCUs were historically underfunded in comparison to historically White institutions; thus, HBCUs were unable to attract top athletic talent due to a lack of resources (e.g., scholarships, facilities, personnel) to compete with top athletic programs in the nation (Jones \& Bell, 2016). As teams competing in the NCAA became more integrated, the Black athletes that would typically participate on HBCU athletic teams were now recruited by predominantly White institutions. The departure of top athletic talent was followed by the resources they once provided (Cheeks \& Crowley, 2015).

The formation of conferences followed by the implementation of HBCU "classic" games soon became a larger part of HBCU culture (Rodgers, 2015). During the early years of HBCU athletics, football was the most popular sport. HBCU Classics are unique games that are regular season competitions between HBCU football teams (Cavil, 2015). The first HBCU Classic was the Turkey Day Classic held in Montgomery, Alabama in 1924 between Alabama State College (now University) and Tuskegee Institute (now University). Classic games are significant contributors to the HBCU experience and the financial stability of many HBCU athletic departments.

The HBCU marching band is also an important facet of HBCU athletic culture. The HBCU marching band has become a fixture in athletics culture although in its inception, 
marching bands did not perform at sporting events (Essoka, 2014). The first recorded HBCU marching band was formed at Tuskegee Normal School 2 in 1890. The band was used as a tool to recruit students as well as raise funds for Tuskegee Normal School. The original HBCU marching band, similar to the inception of intercollegiate athletics, was informal and student led. Now, the HBCU athletic experience is heavily influenced by marching bands with their highenergy performances. A national exhibition for HBCU marching bands occurs every year in Atlanta, Georgia called the Honda Battle of the Bands.

\section{Current State of HBCU Athletics}

Financial resources in HBCU athletics departments began to decline after racial integration due to the ability to recruit the nation's top athletic talent and, thus, a decline in ticket sales (Cheeks \& Crowley, 2015). In recent years, HBCU athletic departments have relied heavily on ticket sales, guaranteed contracts for competition, football classic games, shared revenue from the NCAA, and subsidies from institutional budgets (Cheeks \& Crowley, 2015). The scarcity of financial resources that HBCU athletic departments face has led to the closure of some or all athletic programs at institutions like Spelman College which opted instead to build a health and fitness facility saving the institution \$1 million annually (Cheeks \& Crowley, 2015).

Financial resources. Unfortunately, the current financial status of HBCUs has created limitations for their respective athletic departments. The NCAA has no HBCUs in the top 25, 50, or 100 of the 230 NCAA Division I athletic departments reported in the NCAA Athletic Department Revenue Database (Cheeks \& Crowley, 2015). According to the 2017 NCAA Athletic Department Revenue Database, Prairie View A\&M University had the highest operating budget (\$17.85 million) of all HBCUs reported (ranked 150). Nearly 74\% of Prairie View’s budget is subsidized with funds from the University. Alabama A\&M University (ranked 230) 
ranked lowest with an operating budget of just over $\$ 3.29$ million (Berkowitz \& Schnaars, n.d.). That number pales in comparison to the highest operating budget of all NCAA Division I athletic departments, the University of Texas, with over $\$ 214.8$ million and no subsidies from the University. All of the ranked Division I HBCUs are over 50 percent subsidized while the top 20 athletic departments with the largest operating budgets in the NCAA Division I are less than 12 percent subsidized. Although athletics can add to the alumni support and student recruitment of an institution, if the university is already struggling to maintain academic necessities, an athletic department can add tremendous strain to the general fund. With the heavy burden of securing financial resources to maintain athletic programs, $\mathrm{HBCU}$ athletic departments must make decisions that can help increase their operating budgets.

Guarantee contract games. A search for alternative streams of revenue has led HBCUs to participate in guarantee contract games for financial benefit rather than the purpose of athletic competition. Guarantee contract games represent an opportunity to compete against larger conference teams. This has been seen as a way to increase revenue for the department, but it also adds great risk to student-athletes within those HBCU athletic departments (Gill \& Hart, 2015). The athletes face greater risk of injury, while their athletic departments pursue six-figure payments for participating in out-of-conference games perceived as easy wins for the larger Power 5 conference teams. Participating in guarantee games gives HBCUs the opportunity to gain national exposure, but the exposure is an image of HBCU teams sometimes losing by double-digit margins (Rodgers, 2015). Guarantee contracts are not exclusive to football for HBCUs (Lillig, 2015). Basketball teams also participates in guarantee contract games. Ron Mitchell, athletic director and basketball coach at Coppin State said, "guarantee basketball games buy a lot of baseballs, golf balls, and uniforms" (Gill \& Hart, 2015, pg.191). The dependence on 
this financial source has set a higher value on revenue generation than athletic success and athlete safety (Gill \& Hart, 2015).

HBCU classics. HBCU classics also serve as an alternative form of revenue generation for HBCU athletic programs. As of 2011, over fifty official HBCU classics are held in cities throughout the United States (Cavil, 2015). Classic games are used not only as a tool for recruiting for the institutions, but also as a way to generate significant revenue for them while celebrating racial and cultural pride. For example, the 2016 Magic City Classic held in Birmingham, Alabama generated $\$ 1,917,118$ in revenue. The revenue came from ticket sales, corporate sponsorships, and public contributions from the City of Birmingham and was split evenly between Alabama A\&M University and Alabama State University (Johnson, 2017). Classic games are significant contributors to the HBCU experience and the financial stability of HBCU athletic departments. However, they have not presented a lucratively stable means of long-term surplus resources for HBCU athletic departments.

Alumni giving. Though HBCU athletic programs are heavily subsidized by their institutional general funds, HBCU endowments are at least 70 percent lower than endowments of non-HBCUs (Williams \& Davis, 2019). The inequity of federal and state government funding is evident with HBCU endowments and HBCUs have suffered. In addition to lower endowments, over 70 percent of HBCU students rely on financial aid and scholarships to afford attendance (Saunders, Williams, \& Smith, 2016). Given that HBCUs serve a population traditionally underrepresented with lower average incomes, alumni giving also lacks in strength for these institutions. HBCUs' dominant alumni demographic is Black, and it is important to note that Black Americans give a larger portion of disposable to non-profit organizations than all other racial groups (Drezner, 2009). Alumni are a multifaceted resource in that they can provide 
human, financial, and informational resources to help support HBCUs and their athletic departments. Unfortunately, alumni giving has not been heavily cultivated due to a mentality that it "takes money to make money" (Cohen, 2006). It costs more for an institution to solicit alumni donors than to secure corporate sponsorships so the latter has gained priority for HBCUs.

Legal issues. The ripple effect of minimal resources affects other areas of athletic departments including compliance. For example, Title IX creates hardships on athletic programs that struggle to generate revenue while attempting to equally fund all of their athletic programs. In a 1993 case involving Title IX violations and an HBCU athletic program, former women's basketball coach, Sanya Tyler, filed a suit against Howard University for disproportionate facilities for women's basketball compared to men's basketball and for reduced pay and staffing. Tyler won the case and was awarded \$1.1 million in damages (Flowers, 2015). Athletic departments with scarce financial resources to allocate evenly face repercussions of a Title IX violation which can be even more costly than complying with the federal regulation.

Marketing issues. Marketing is an intricate component to ticket sales and broadcasting efforts for athletic departments. Unfortunately, 75 percent of HBCU athletic departments reported that they do not have a marketing department (Jackson, Lyons, \& Gooden, 2001). The athletic departments without marketing departments also reported a lack of funding and staff to support adding a marketing department. Not having more of an emphasis on marketing of their athletic programs, HBCUs will continue to forfeit significant revenue that proper marketing can provide (Jones \& Bell, 2016). Consumers of color are a growing market in sport and respond to different marketing strategies. In a 2008 study, Armstrong found that sport consumers of color were significantly motivated by the event promotions, family appeal, entertainment, social interactions, and event culture more than Caucasian consumers of sport (Armstrong, 2008). 
Armstrong (1999) posits that Black sport consumers are also highly affected by various streams of media. The researcher stated:

Blacks (a) (particularly Black females) watch more television than the general population, and the shows they watch are more apt to be those about Black people; (b) listen to the radio approximately 3.5 hours daily, which is about 30 minutes longer than White listeners; (c) prefer Black-owned radio stations and listen to AM stations more than Whites do; (d) can be reached with some general magazine publications, but prefer to read Black magazines; and (e) are more affected by advertising than Whites are, particularly when the advertisements contain elements that reflect their lifestyles (Armstrong, 2008, p. 270).

There is an opportunity for HBCU athletics to take advantage of various mediums through a dedicated marketing department to reach more Black sport consumers who would be impressed by the unique culture and social exchange of HBCU sporting events. The lack of resources to pay personnel and promotional inventory prevents these programs from further capitalizing on marketing initiatives for their departments. Losing by large margins in guarantee games adds a difficulty to marketing efforts and reduces the ability of athletic departments to recruit and retain loyal fans that do not have direct ties with the institution (Cheeks \& Carter-Francique, 2015).

Academic issues. HBCU athletic departments also suffer in the realm of academics for their student-athletes. These institutions often lack dedicated academic support services for their athletes. HBCUs are at a disadvantage against other NCAA Division I institutions when they cannot provide tutoring, computer labs, designated study spaces within athletics, and/or full-time academic support staff to work directly with student-athletes (Blackman, 2008). In 2012, the NCAA developed the NCAA Limited-Resource Institutions Directors of Athletics Task Force as 
part of the Accelerating Academic Success Program (NCAA, n.d.). The task force was organized to provide a space for athletic directors from such institutions to discuss strategies to increase academic success for student-athletes, share strategies for the acquisition and use of resources, and to develop ways to showcase the successes of limited-resource institutions and HBCUs (NCAA, n.d.). In the APR report for 2011, 33 of 103 teams sanctioned for poor academic performance were from HBCUs. Eight teams that received postseason bans due to academics were from the SWAC conference (Gill \& Hart, 2015). For the 2018 APR report, 19 percent of HBCU athletic programs were below the 930 APR score compared to just four percent of nonHBCU athletic programs (NCAA APR Report, May 2018). Though APR scores are increasing for HBCU athletic programs, there is still a large gap stemming from a shortage of resources.

\section{Theoretical Frameworks}

Resource is defined as "inputs to the production process" (Grant, 2001, p.118), p.21). For the purpose of this study, the collection of productive resources in management was divided into four main categories: financial, human (administrative and coaching staff), physical (facilities) and information (policies and knowledge). This study employed two theoretical frameworks: resource dependence theory (RDT) and resource based theory (RBT). RDT was used to analyze the strategies and practices stemming from a lack of resources. RBT was used to analyze the existing resources, strategies, and gaps in resources.

\section{Resource Dependence Theory}

RDT is a theoretical framework derived from organizational sociology and developed to better understand the effect of external factors on an organization's behavior (Pfeffer \& Salancik, 1978). RDT seeks to explain the behavior of an organization based on the resources needed to survive. The central idea for RDT is that the control of resources is a form of organizational 
power (Hillman, Withers, \& Collins, 2009). When an organization is unable to obtain resources internally, they seek those resources from external organizations within their network. An organization's behavior is thus influenced by the abundance or lack of resources (e.g., financial, human, physical, and informational). For example, an athletic department deprived of resources may settle for less qualified staff than an organization with the ability to invest in the top staff for its athletic department, or the athletic department with limited resources may participate in activities such as guarantee games in hopes of securing resources that will afford higher skilled staff. The decision for either alternative is motivated by the lack of resources. Four primary concepts explain the basic argument of RDT and the relationships formed through a dependence of resources. Those concepts are

a) Organizations need resources to survive in their environment, and behaviors in those organizations are influenced by the quality and volume of the resources they have or need.

b) These organizations are not autonomous and need to pursue relationships with other organizations within their network to secure those resources.

c) Resources are the foundation for organizational power and dependence. This creates a power dynamic between the organization in need of the resources and the organization that holds those resources.

d) Organizations manage their dependencies either to decrease their own dependence or to increase other organizations' dependence on them (Pfeffer, 1987).

In essence, the premise of RDT is that organizations need resources to survive and when those resources are not available, they can obtain them from other organizations at the expense of their independence and organizational power. 
A secondary concept in RDT is a belief that whoever controls resources has leverage over an organization in need of those particular resources (Nienhüser, 2008). Organizations strategize for resources through alliances with other organizations; in that process, they contract, merge, or join associations (Malatesa \& Smith, 2014). HBCU athletic programs are vulnerable to a loss of organizational power (e.g., making decisions, expanding facilities, expanding departmental faculty, recruiting top athletes, and retaining qualified personnel) due to a lack of resources.

\section{Resource Based Theory}

Resource based theory (RBT) is a framework used in strategic management that integrates both economic and behavioral perspectives of organizations. The use of the RBT framework can add depth to this study's analysis of HBCU athletic departmental resources and their acquisition. RBT is separated into two schools of thought: structural and process (Peteraf, 1994). Structural examines the resources that are surplus-generating and how they influence and create a competitive advantage for an organization. Process examines the ways in which resources are generated, maximized, and preserved for an organization (Peteraf, 1994). Contrary to RDT, which looks at the response to a deficit in resources, RBT examines the potential for a surplus of resources which can create or increase a competitive advantage in the market. RBT has a prescriptive nature; it suggests acquiring resources that are valuable, rare, and inimitable will lead to a competitive advantage for the organization. Thus, RBT is useful for extracting practical implications for organizations to maximize their competitive advantage through efficient use of resources (Galbreath, 2005). For HBCU athletic departments, RBT was useful for identifying appropriate strategies to increase long term survival in the NCAA. 


\section{Statement of the Problem}

HBCU athletics have managed to remain somewhat stable despite limited resources available for operation. The growth of HBCUs in the opposition of Jim Crow Laws and unequal government funding was difficult but successful. Their focus on the cultural experience has branded them exciting and inviting to many Black sport consumers. However, competing with larger and better funded athletic programs for athletic talent halted much of their rapid growth. Along with "new" and unbalanced competition, came the stress of balancing annual budgets with a minimal influx of financial resources. Though extant literature on the state of HBCU athletics has assessed the effects of limited resources on the outputs of the organization, they fall short of empirical evidence of the relationship between resources and strategy.

\section{Purpose of the Study}

The purpose of this study was to explore resources and decision- making practices that stem from a shortage of critical resources of an HBCU athletics department. As depicted in the relationship model below (Graph 1), this study sought to better understand the relationship between resources and the business practices and strategies developed by HBCU athletics departments in the NCAA. Graph 2 further depicts how the theoretical framework was used to examine Graph 1.

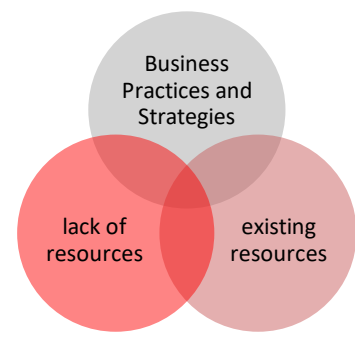

Graph 1 .

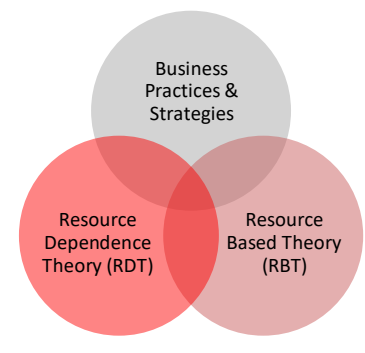

Graph 2. 


\section{Research Questions}

To better understand the relationships between resource limitations and the strategic management thereof, this qualitative study sought to answer the following research questions:

1. What resources do HBCU athletics departments manage?

2. How are resources managed in HBCU athletics departments?

2a. How do HBCU athletics departments manage existing resources?

2b. How do HBCU athletics departments mitigate the gaps in resources?

RQ1 identified what resources the athletics department is directly responsible for in terms of management. RQ2 extracted the strategic management practices for the athletics department based on the resources that are readily available as well as the strategies that formed in response to a lack of critical resources. To answer the research questions and sub-questions, a qualitative case study method was used to explore resource management and strategies of an HBCU athletic department. The HBCU athletic department served as a porthole into the strategic use of resources for the limited resource institution.

\section{Significance of the Study}

The case study research method aided in deep exploration of the resources available to one HBCU athletics department. Resource dependence theory guided the analysis of limitations that the athletics department has resulting from a shortage of resources. Resource based theory aided in the analysis of decision-making practices of the administrators in the case department. The combination of both analyses produced robust findings which will be discussed later in this dissertation. Findings from this study not only give context and understanding to the intricacies of managing resources for HBCU athletic departments, but also give insight for areas of improvement. Findings also reveal the dynamics of the relationship between HBCU athletic programs and the HBCU administrators responsible for allocating funds to support the athletic 
department. The findings of the study were both theoretical and practical. The practical implications explain opportunities to improve or further exploit valuable resources in the department. Theoretical implications further expand what is already known about the role of a depletion of resources and strategic management thereof. The use of both resource dependence theory and resource based theory to analyze the acquisition and management of resources in the intercollegiate athletics realm, specifically $\mathrm{HBCU}$ athletics, expanded the current understanding of both theories.

\section{Delimitations of the Study}

Although a rich description and analysis of $\mathrm{HBCU}$ athletics was desired, time and funding presented initial limitations to the design of a case study for a dissertation. The extent of analysis, descriptive, and summary data was up to the investigator (Stake, 2006). This study also only investigated one university athletics department which competes at the Division II level of the NCAA. Rather than multiple departments to formulate a comparison, this study focuses solely on the resource limitations and strategies of one university. The case institution is also privately funded which presented unique characteristics that may differ from a publicly funded institution. All of these considerations were made prior to conducting this study. This set up a unique context for the study and added richness to the findings and conclusion. The investigation focused on the resources within the athletic departments and how those resources are strategically used within the organization. The scope of the study was related to the resources and strategies of $\mathrm{HBCU}$ athletic departments through collecting data related specifically to those areas such as financial agreements to assess potential financial resources, interviews with administrative personnel focusing on the resources and strategies, photos/visual assessments of 
physical and informational resources, and organizational charts related to human resources. Focusing on resources rather than the institution itself allowed for results and practical implications to hold transferability to another athletics department in a similar situation with limited resources and a heavily subsidized operating budget. Other limitations were related to participants in the study and lack of access to the operating budget for the athletics department. Due to the nature of the study and the possibility of identification in spite of preventative measures caused some participants to be reluctant to share budget information. This was accounted for by assessing how money was received and spent rather than the actual amounts received. This focus on "how" aligned with the research questions and allowed for transferability to other organizations without regard to their specific budget size.

\section{Operational Definitions}

The following terms have been applied to the context of this study: Classics - unique games that are regular season competitions between HBCU football teams (Rogers, 2015).

De Jure Segregation - legal separation of people based on law (Brown, 2013).

External resources - resources available outside of the organization (Nemati et al., 2010) Guarantee Games - contractual agreements between two institutions for athletic competition in which payment is received by a lower ranking athletic program to compete against a higherranking athletic program (Rogers, 2015).

Heterogeneous resources - resources that can be strategically used for multiple purposes rather than reliance on a singular resource or use (e.g., a facility used for its primary purpose of athletic competition, as well as subsidiary uses such as leasing the space for public or private events) (Barney \& Clark, 2007). 
Historically Black Colleges and Universities (HBCUs) - Any historically Black college or university that was established prior to 1964 , whose principal mission was, and is, the education of Black Americans, and that is accredited by a nationally recognized accrediting agency or association determined by the Secretary [of Education] to be a reliable authority as to the quality of training offered or is, according to such an agency or association, making reasonable progress toward accreditation. (Higher Education Act of 1965, Sec.322.20 U.S.C. 1061).

Homogenous resources - resources that can only be used for one purpose (e.g. weight training equipment). (Barney \& Clark, 2007)

Internal resources - resources that belong to or can be created within the organization (Nemati et al., 2010)

Jim Crow Laws - state and local laws that enforced legal segregation in the southern United States from 1877 to 1965 (88 years) (Gasman \& Hilton, 2012).

Market Orientation - the planning and implementation of marketing strategies for an organization in reflection of the explicit or implied needs and wants of consumers to have a significant effect on business performance (Uncles, 2000).

Power - organizational control which can be coercive, referent (respect), expert, or positional (hierarchical) (Hillman, Withers, \& Collins, 2009).

Power Five (5) - five athletic conferences (SEC, ACC, Big 12, Big 10, Pac-12) whose member institutions compete in the Football Bowl Subdivision of the Division I level of the NCAA (National Collegiate Athletic Association [NCAA], n.d.).

Resources - "inputs to the production process" (Grant, 2001, p.118), p.21). For this study, the term "resources" is divided into four main categories: financial, human, physical, and informational. 
Satisficing - a business decision making strategy in which decisions are made to reach a satisfactory outcome rather than an optimal outcome (Parker et al., 2007).

VRIO Model - based in Resource-based theory, a model that assesses the value, rarity, inimitability and organization of resources (Cardeal \& António, 2012). 


\section{CHAPTER II}

\section{LITERATURE REVIEW}

HBCU athletic programs currently have a short-term focus on survival due to historic underfunding and limitations with financial development (Cohen, 2006). Serving students of color who traditionally have lower socioeconomic status in addition to unequal funding in comparison to their traditionally white counterparts creates an environment of constrained human, financial, physical, and informational resources for HBCUs. This significantly affects their heavily subsidized athletic programs. In order to remain viable in the current intercollegiate athletics environment, HBCU athletic administrators must assess ways in which resources are managed in order to create greater stability for their departments. In the following review of literature, resource dependence theory (RDT) and resource- based theory (RBT) will be explored as the framework for this study. RDT and RBT will serve as appropriate models to further analyze the current state of HBCU athletic programs as a result of limited resources and possible under-utilization of existing resources.

\section{History of HBCUs}

HBCUs were established over 180 years ago and have since been a pillar in the African American community for its role in education and professional training (Crawford, 2017). Because of systemic racism and consistent discrimination, HBCUs have served a more important role for Black culture and their surrounding communities than historically white institutions have (Gasman, Spencer, \& Orphan, 2015). While the core of higher education is teaching, research, and public service, HBCUs also have a 4th competency of social justice (Gasman, Spencer, \& 
Orphan, 2015). Six specific goals of HBCUs are: a) Nurture and curate Black history, culture, and traditions; b) Provide leadership for Black community matters; c) Increase economic mobility and function in the Black community; d) Supply role models who understand the effects of social, political, and economic dynamics on Black populations; e) Produce college graduates with the unique cultural competence to respond to issues and concerns between minority and majority populations; and f) Produce Black graduates for specialized research, higher learning, and the distribution of pertinent information for Black and other minority populations (Nichols, 2004). There are currently 53 private and 49 public HBCUs in the United States and US Virgin Islands. HBCUs represent less than three percent of colleges and universities in the United States, yet currently produce 23 percent of Black college graduates. These institutions produce Black graduates at higher rates than other types of higher education institutions. Of all Black dentists and physicians, 70 percent graduated from HBCUs. They are also responsible for producing 50 percent of Black professors at non-HBCU institutions, 50 percent of Black lawyers, and 80 percent of Black judges. Of Blacks who earn PhD level degrees, 43 percent are alumni of HBCUs (Nichols, 2004). The significance of HBCUs for Black citizens in the US has been paramount.

HBCUs were created to fulfill the abrupt need of educating formerly enslaved people. Prior to emancipation, learning to read and write was a criminal offense for enslaved people for several centuries (Collins \& Norris, 2015). These individuals were forbidden to learn how to read and write for fears of this population gaining the ability to economically compete with white citizens in the United States (Gasman \& Hilton, 2012). Religious institutions joined the charge to educate formerly enslaved people by helping form institutions of higher education for this new demographic of students. The first HBCU was the Institute for Colored Youth (ICY), now 
known as Cheyney University, in 1837 in Delaware County, Pennsylvania. ICY was established by a Quaker named Richard Humphreys. Two other HBCUs were established the same year, Lincoln University in Pennsylvania and Wilberforce College in Ohio. Wilberforce College was the first HBCU controlled by Black administrative and academic leadership. These three institutions of higher education were established prior to the Emancipation Proclamation of 1865 which freed enslaved people in the US. This likely occurred because of their geographical location in northern US cities. In 1860 only 28 Black people were awarded college degrees from both HBCUs and historically white institutions prior to the start of the Civil War (Gasman \& Hilton, 2012).

The US government made an effort to assist with transitioning enslaved people into society as free men, women, and children through an initiative called the Freedmen's Bureau. The role of the government-sponsored Freedmen's Bureau was to formally establish and fund other institutions of higher education formed to educate formerly enslaved people and their children. The Freedmen's Bureau made a federal commitment to provide them with food, clothing, schools, supplies, jobs, and land during and one year after the end of the Civil War. The initiative officially ended aid to freedmen in 1872. Many HBCUs formed in the late 1800s were established through missionary groups that believed Blacks would be a menace to society without formal education and Christian values. Of those formed, a large number of HBCUs were established as normal colleges to train teachers who would educate this new generation of free Blacks in the US.

The Hatch Act of 1887 called for equal distribution of funding for both historically white institutions and HBCUs in each state. However, the caveat to the Act was state officials could make the decision not to divide the funding equally between Black and white colleges, which 
southern states chose not to do (Gasman \& Hilton, 2012. The federal government made an effort to require states to disperse funding equally, yet lacked the ability to do so in southern states.

By the year 1890, there were more than 200 HBCUs in the United States of America and Caribbean. The Morrill Act of 1890 was passed in alignment with federal regulations to increase access to formal education for formerly enslaved people in southern states. This was the second Morrill Act, also known as the Land Grant College Act, which funded state institutions of higher education with agriculture, education, and military science programs and required states to extend this funding to schools that enrolled Black students as well. Southern states formed HBCUs to fulfill the requirements needed to receive federal funding through the Morrill Act of 1890 rather than to desegregate historically white institutions (Brown, 2013). The Morrill Act thus created the formal execution of "separate but equal" in higher education because southern states formed public HBCUs to receive federal funding while maintaining segregation. This did not create equal footing for HBCUs however. They continued to be intentionally underfunded for many years in spite of US federal mandates to help close the gaps in access to funding for Black students.

History of HBCU resources. HBCUs served a population of students from families newly receiving compensation for their work. Thusly, the cost of attendance needed to meet the needs of students with lower socioeconomic status than their white counterparts. Plessy $v$. Ferguson was the 1896 landmark Supreme Court case that upheld legal segregation in the United States under the premise of "separate but equal," which made Jim Crow laws a common way of life for Black citizens in the United States. Because of this, HBCUs continued to go underfunded in comparison to their white counterparts. Cumming v. Richmond County Board of Education (1899) further supported de jure segregation of races in schools. This also solidified the separate 
status of HBCUs (Gasman \& Hilton, 2012). Brown v. Board of Education (1954) declared separate but equal in schools as unconstitutional and this became the catalyst for school desegregation. This legislation did not immediately urge institutions of higher education to integrate. Prior to 1964, the United States did not legally have equal protection for all citizens to be treated equally and receive equal access to federally funded opportunities and programs, and this encouraged the unequal treatment of HBCUs serving a predominantly Black population of students. The Civil Rights Act of 1964 established protection from legal discrimination for all federally sponsored programs for all US citizens regardless of race, color, or national origin. It was not until the Higher Education Act of 1965 that the federal government earmarked funding for institutions serving low-income students. Through Title III, HBCUs received funding previously withheld or allocated to their white counterparts. Title III of the Higher Education Act of 1965 helped HBCUs continue to serve Black students through federal funding. However, due to vague language in legislation, 23 percent of Title III funds was given to community colleges serving white students because it was difficult to pass legislation that specifically mentioned race (Gasman \& Hilton, 2012). Though Title III increased funding for HBCUs, the Higher Education Act of 1965 also created incentives for predominantly White institutions (PWIs) to increase their minority student population. This created an environment where HBCUs began to compete with higher resourced institutions for Black student enrollment (Collins \& Norris, 2015).

The low socioeconomic status of many students makes for difficult budgeting at HBCUs. A large demographic of HBCU students (75 percent) rely on Pell Grants to fund their education (Crawford, 2017). This makes it difficult for institutions to increase their tuition and fees to offset increasingly limited government appropriations (Crawford, 2017). This has led to lower endowments at HBCUs. For context, all HBCU endowments combined are less than $\$ 2$ billion 
while Harvard University's endowment alone is nearly $\$ 35$ billion. The only HBCUs whose endowments exceed \$100 million are Howard University, Hampton University, Morehouse College, and Spelman College (Cole, 2008). Dismal endowments for many HBCUs have made recruiting students and faculty a difficult effort.

HBCUs face financial barriers in increasing their endowments and obtaining government funding while attempting to maintain lower tuition rates that accommodate students of lower financial means (Coupet, 2010). This creates further limitations in organizational efficiency as well as challenges with maintaining accreditation standards. Coupet and Barnum (2010) sought to measure the efficiency of HBCUs and PWIs using a valid efficiency indicator and estimating the effects of endowment on the HBCU efficiency scores. The study revealed HBCUs are no less efficient than their PWI counterparts and suggested they may even be more so due to operating more efficiently with fewer resources. Increasing endowments might allow HBCUs to become even more efficient with an increase of employees to manage tasks such as processing financial aid applications. HBCUs should focus more on increasing endowments and wise use of investments in human resources to further increase adequate productivity.

The environment of meager endowments, competition for students and employees, declining budgets, and increased assessment measures leaves many HBCUs challenged to remain financially stable. Institution leaders have an opportunity to look to business college deans and faculty for more marketing and business expertise to increase this acumen needed to secure a portfolio of revenue. Because faculty roles tend to be the pipeline for HBCU leadership, there is a lack of entrepreneurial-based leadership for these institutions (Andrews et al., 2016). Institution leaders have an opportunity to look to business college deans and faculty for more marketing and business expertise to increase this acumen needed to secure a portfolio of revenue. HBCU 
business deans were asked in a 2013 study to rank five factors that are a great threat to the stability of HBCUs (Andrews et al., 2016). Participants ranked funding as the greatest threat to stability and suggested that strategic partnerships, fundraising and development, and brand marketing were viable ways to increase funding for HBCUs.

Historically HBCUs were victims of discriminatory funding practices due to racial inequality in higher education in their states. Sav (2000) sought to explore the potential existence of disparate state funding for HBCUs. She/he found that although PWIs received greater state funding on average, they were larger in terms of student population size and physical plant size. The results from the study also revealed PWIs depended more on tuition funding and also generated more revenue from corporate athletic funding, federal funding, auxiliary enterprise, and philanthropic dollars than HBCUs. Results from the study showed 16.7 percent of the $\$ 39.3$ million average state funding differential between PWIs and HBCUs was not related to the characteristics of the institutions, but rather to differential funding based on allocations from their states (Sav, 2000). This percentage represented \$6.6 million in differential treatment that could assist HBCUs financially. Over time, this incongruity in funding has left a large gap between the financial stability of PWIs and HBCUs. This also suggests a great need for HBCUs to increase their corporate athletic partnerships as well as philanthropic and auxiliary enterprise to maximize their financial stability.

Sav (2010) extended the 2000 study findings by revisiting discriminatory funding for HBCUs, assessing whether the disparate funding practices had lessened over time. Results from the 2010 study revealed differential funding had decreased from 16.7 percent to 12.5 percent in 2006. This indicates that though slow, progress towards equal funding is being made. While this 
may be true, there is a need to shift dependence from government funding to other sources of revenue.

Serving a population with a traditionally lower socioeconomic status in the US, HBCUs historically were hesitant to solicit development funding from alumni. HBCUs make up only three percent of all colleges and universities in the US, but more than 20 percent of all African American college graduates (Tatum, 2010). Alumni support is dependent on factors such as income, age, alumni activity, marital status, affiliation with a sorority/fraternity, and graduating with an engineering degree (Cooper, Cavil, \& Cheeks, 2014). African American alumni give at lower amounts annually than their white counterparts (Wallace, 2012). This makes for a less reliable financial resource for HBCUs (Gill \& Hart, 2015).

History of HBCU athletics. The beginning of intercollegiate sport at HBCUs was significantly later than institutions in the NCAA at the time (Cavil, 2015). HBCU athletics departments were established during the late 1800 s, close to the same time period when historically white institutions began to commercialize their athletic programs. HBCUs created their own space for athletic competition in sports such as football, baseball, and track and field. Due to segregation, HBCUs were not allowed to join the NCAA (Cavil, 2015). Thus, these institutions created their own governance structures such as the Georgia-Carolina Athletic Association founded in 1910 as the first Black collegiate sport association. HBCUs then competed against each other until their acceptance to the NCAA in 1965 (Cavil, 2015).

Though HBCUs lagged behind chronologically, a period of athletic and monetary success occurred during the enforcement of Jim Crow Laws because Black athletic talent was relegated to HBCU athletic programs such as baseball, football, basketball, and track and field. Baseball was a popular sport within the African American community and spread throughout HBCU 
athletics during the late 1800s (Cavil, 2015). Many players in the Eastern Colored Leagues and the Negro National Leagues also played baseball for HBCUs during their off seasons. Track and field was also a prominent sport for HBCUs, particularly Tuskegee Institute (now Tuskegee University). Cleve Abbott started the Tuskegee Relays and increased women's athletic competition in HBCU sport. This event became the largest of all HBCU Relays and the third largest behind the Penn Relays by 1929 (Cavil, 2015). Tuskegee University sent four women (Alice Coachman, Mabel Walker, Nell Jackson, and Theresa Manual) to compete in the 1948 Summer Olympics where Coachman became the first Black woman (from any nation) to win an Olympic medal. In 1949, Paul Younger became the first HBCU athlete to play in the NFL, paving the way for other HBCU athletes such as Walter Payton, Jerry Rice, and Doug Williams (Hodge, Bennett, \& Collins, 2013).

Even after joining the NCAA, HBCUs were still not allowed to compete against larger traditionally white institutions. The NCAA created the College Division (currently known as Division II) for HBCUs to compete in a separate division. In 1965, Tennessee Agricultural and Industrial University (now Tennessee State University) tied in competition with Ball State, and then won the Mideast Region Grantland Rice Bowl game in 1966. Morgan State won the East Region Tangerine Bowl the same year. HBCU football programs had success in the NCAA College Division regional bowl system in the NCAA between 1964 to 1972 (Cavil, 2015).

During the 1960s, the resistance to integrating intercollegiate athletic programs allowed for a maturation of HBCU athletics with top athletic talent. HBCUs were homes to highly competitive athletic programs that cultivated athletes who matriculated to professional sports (Hodge, Collins, \& Bennett, 2013). Prior to the 1970s, HBCU athletic programs were home to top athletic talent due to limited access to traditionally white institutions of higher education. The 
reluctance of PWIs to recruit and enroll Black students allowed an era of success in enrollment and athletic competition for HBCUs. In 1970, the all-white University of Alabama football team lost to an integrated University of Southern California football team. Black athletes' success and talent led to an increase of PWIs recruiting Black players for more competitive teams. The 1970s thusly ushered in an exodus of elite Black athletes from HBCUs to PWIs' revenue-generating football and basketball programs which is still evident today with majority Black teams and white head coaches at schools that historically did not welcome students of color (Hodge, Collins, \& Bennett, 2013). This migration to PWIs left HBCUs destabilized in their ability to recruit and retain students and athletes with far fewer resources than their white higher education counterparts. HBCUs and their athletic departments have since had the lofty task of attracting athletic talent in competition with larger and better funded PWIs with more national media coverage. Thus, the migration of Black athletes to PWIs introduced a decline in enrollment as well as attention to sports for HBCUs.

History of HBCU athletic resources. Armstrong (2002) found that cultural affiliation played a vital role in Black sport consumption, and the history of HBCU sport is no outlier for this assertion. The HBCU culture is rooted in racial pride and cultural expression (Cavil, 2015). One significant cultural element of HBCU sport culture that displays racial pride and cultural expression is the HBCU classic. HBCUs created classics during football seasons in 1924 and a bowl system for postseason games in 1928 (Cavil, 2015). Though the bowl system did not last beyond 1936, classics continued to present day. By 2011, there were upwards of 50 official HBCU classics in the United States, which assist in revenue generation and recruiting efforts for participant institutions. Currently, those classics serve as a means to subsidize athletic programs and institution general funds for HBCUs. Though classics are a desirable way to increase 
revenue for HBCUs, guarantee games have become an appealing alternative. Guarantee games between HBCUs and Power Five conference teams have attractive six-figure payouts for participation (Rodgers, 2015). However, participation in guarantee games comes at the expense of losing by large margins, affecting HBCUs Rating percentage index (RPI), which is calculated with teams' winning percentages (Lillig, 2015). A lower RPI not only affects the coaching staff and program success, but it also makes recruiting top talent even more challenging.

In addition to the reliance on classics and guarantee games, HBCU athletics departments rely heavily on university general fund subsidies. In 2011, SWAC athletics departments had subsidies ranging from $\$ 2.4$ million to just over $\$ 8$ million. With government subsidies already decreasing general funds for HBCUs and increasing pressure on academic and operation development campaigns, having the burden of athletics departments as another large expense places a strain on university budgets. All HBCU athletic programs are subsidized by college and university general funds. The highest ranked HBCU athletic department revenue in 2017 was Prairie View A\&M University (ranked \#149) with just over $\$ 17$ million and subsidized by over 83 percent. The second highest HBCU athletic department revenue the same year was Delaware State University (ranked \#177) which was subsidized over 80 percent (Berkowitz \& Schnaars, 2018). This heavy dependence on subsidies from the university can become taxing to general fund budgets. The same year, the University of Texas was ranked \#1 with upwards of \$217 million in revenue and zero subsidies.

HBCU conference revenues ranked highly overall in conference revenues for the NCAA Division I Football Championship Subdivision (FCS) (Gill \& Hart, 2015). The MEAC ranked the highest with just over $\$ 5.9$ million and the SWAC ranked fourth with just over $\$ 4.85$ million. For Football Bowl Subdivision (FBS) conferences such as the Southeastern Conference (SEC), 
conference revenues were upwards of $\$ 70$ million the following year. This great disparity in revenue at the conference level further demonstrates the limitations of resources for athletic programs outside of the FBS, including HBCUs. Furthermore, two HBCUs have left HBCU conferences in hopes for higher competition and revenue generating opportunities.

HBCUs are significant for Black professionals working in athletic administration. Black men and women make up ten percent of Athletic Directors in the NCAA. Of that ten percent, 40 percent are from HBCU athletic programs. NCAA affiliated HBCU athletic programs also employ 33 percent of all Black head coaches. The total representation of Black head coaches in the NCAA is only nine percent (six percent at non-HBCUs). Though HBCUs give great opportunity for career advancement for Black intercollegiate sport professionals, HBCUs have struggled to attract and retain top talent. This is often due to lower wages, higher workloads, and fewer resources to complete tasks within these roles (Cheeks \& Crowley, 2015). Unfortunately, this difficulty in staffing efficiently also affects the marketing of HBCU athletic departments.

HBCUs lack human resources that can strengthen their long-term stability such as marketing and development. Only 25 percent of HBCU athletic departments reported having a dedicated marketing staff member (Jackson, Lyons, \& Gooden, 2001). HBCUs have a unique product that resonates with a growing sport consumer demographic, yet lack the infrastructure to market their athletic programs effectively.

\section{Summary}

The aforementioned events that have resulted in declining resources for HBCUs has also trickled down to their athletic departments. HBCU athletic departments have also suffered from historic and intentional underfunding, low endowments, and high competition for talent. The narrow budgets and limited resources HBCUs face affect the decisions these athletic departments 
make to survive. Historically Black Colleges and Universities have developed strategies to survive under the constraints of meager operating budgets and growing expenses. While some athletic departments make do with what they have available internally, others seek available resources within their network through classics and guarantee games with top tier PWI athletic programs. The action of sourcing within their network is an example of resource dependence and shows how a lack of resources affects many facets of their operation.

\section{Resource Dependence Theory}

Decreasing government subsidies and low alumni donations for HBCUs increase the strain on institutional budgets. Consequently, limited institutional budgets also strain budgets for HBCU athletic departments, which often depend on supplemental financial resources from the school's general budget (Cheeks \& Crowley, 2015). As a result, HBCU athletic departments have had to find unique ways to generate revenue to support the stability of their athletic programs. Resource dependence theory (RDT) can be used as a framework to analyze the decisions made by athletic administrators to help HBCU athletics programs thrive with limited resources. RDT is primarily used in business to analyze intercorporate relations and organizational behavior stemming from a shortage of resources. This shortage, typically financial, is often seen in non-profit organizations or public organizations (Malatesa \& Smith, 2014). Furthermore, RDT is useful to examine the interdependency of intercollegiate athletic programs because the NCAA is a non-profit organization and the HBCU- affiliated institutions are classified as non-profit as well.

Assumptions of resource dependence theory. RDT is a theoretical framework derived from organizational sociology and developed to better understand the effect of external factors on an organization's behavior (Pfeffer \& Salancik, 1978). RDT seeks to explain the behavior of 
an organization based on the resources needed to survive. The central idea for RDT is that the control of resources is a form of organizational power (Hillman, Withers, \& Collins, 2009). When an organization is unable to obtain resources internally, they seek those resources from external organizations within their network. An organization's behavior is thus influenced by the abundance or lack of resources (e.g., financial, human, physical, and informational). For example, an athletic department deprived of resources may settle for less qualified staff than an organization with the ability to invest in the top staff for its athletic department, or the athletic department with limited resources may participate in activities such as guarantee games in hopes of securing resources that will afford higher skilled staff. The decision for either alternative is motivated by the lack of resources. Four primary concepts explain the basic argument of RDT and the relationships formed through a dependence of resources. Those concepts are

a) Organizations need resources to survive in their environment, and behaviors in those organizations are influenced by the quality and volume of the resources they have or need.

b) These organizations are not autonomous and need to pursue relationships with other organizations within their network to secure those resources.

c) Resources are the foundation for organizational power and dependence. This creates a power dynamic between the organization in need of the resources and the organization that holds those resources.

d) Organizations manage their dependencies either to decrease their own dependence or to increase other organizations' dependence on them (Pfeffer, 1987). 
In essence, the premise of RDT is that organizations need resources to survive and when those resources are not available, they can obtain them from other organizations at the expense of their independence and organizational power.

A secondary concept in RDT is a belief that whoever controls resources has leverage over an organization in need of those particular resources (Nienhüser, 2008). Organizations strategize for resources through alliances with other organizations; in that process, they contract, merge, or join associations (Malatesa \& Smith, 2014). HBCU athletic programs are vulnerable to a loss of organizational power (e.g., making decisions, expanding facilities, expanding departmental faculty, recruiting top athletes, and retaining qualified personnel) due to a lack of resources. Because of this, athletic directors of these programs utilize strategies such as guaranteed contract games with higher-ranked athletic programs or through the implementation of Classics with municipalities and other HBCU programs.

RDT gives managers a model for strategy analysis by focusing on long-term survival through acquiring resources that meet short-term needs (Malatesa \& Smith, 2014). This often means depending on other organizations to secure those resources. Managers are further charged with the responsibility of reducing the unreliability that comes with dependencies on other organizations (Malatesa \& Smith, 2014). Their role is heavily influenced by the surplus or shortage of resources. For HBCU athletic programs, though there is a surplus of informational resources such as culture and traditions, their shortage of financial resources then bleeds into other critical resource areas such as facilities and personnel. The potential for increasing financial stability exists if $\mathrm{HBCU}$ athletic administrators can exploit all viable streams of revenue for their programs. In order to further understand the central premise of RDT, it is important to examine the extant literature grounded in this framework. 
RDT and organizational behavior. Many empirical studies regarding resource dependence focus on the organizational behaviors of nonprofit organizations that have limited resources and tend to rely on other organizations and agencies to operate effectively. These resources, both tangible and intangible, can originate from internal and external factors such as government regulations and market orientation. They may also vary in their relative importance to the organizations. Responses to those factors have been explored in several different facets of organizational behavior as outlined in this review of literature.

Most HBCUs are located in the southern United States, which have historically been the sources of de jure segregation and racism. Within this context, HBCUs were underfunded for a significant portion of their existence. Because $\mathrm{HBCU}$ athletic programs are heavily subsidized, they also tend to operate in a centralized management structure in which college and university presidents as well as board members have control of decisions for athletic departments including resource allocations (Gill \& Hart, 2015). Thus, the relationship between government entities and HBCUs has been stressed. Saidel (1991) used resource dependence theory to analyze the relationship between governmental and nongovernmental entities that operate public programs. With dwindling sizes of public organizations and a growing need for their programs and services, a better understanding of the interdependence of government and non-government agencies can benefit practitioners seeking to decentralize their program offerings. This can allow more autonomy for organizations, or in this case athletic departments, to make sound decisions based on specific needs and departmental objectives.

Saidel (1991) explored how resources flow e between nonprofit organizations and government agencies. Examples of resources that flow between government agencies and nonprofit organizations include expertise and information, revenues, access to policy processes, 
and validation. In the case of HBCUs, revenues and policy flow between the institutions and the local and state governments. Saidel (1991) found three dimensions of resource dependence between the organizations and government agencies: importance, availability of alternatives, and "ability to compel provision" of resources. Importance referred to the need the organization had for the specific resource in order to operate effectively and continue to deliver programs. In terms of the availability of alternatives, Saidel found dependence decreased when there was an alternative available in the exchange network. The ability to compel or pressure an organization to contribute resources needed to operate and continue to provide public programs caused one organization to become more dependent on the other. This was found in regulatory sanctions placed on the organizations to comply with the provisions. Other aspects of resource dependence that emerged in this study were the magnitude of the dependence and how the resources were distributed. Most of the magnitude of interdependence for the nonprofit organizations was reported at the moderate level (Saidel, 1991).

This particular dynamic between government/governing agencies and nonprofit organizations can be seen in HBCU athletics when there is a dependence on government subsidies for HBCU general funding. As stated earlier, HBCUs were often founded with public money as state agricultural schools. Athletic administrators at HBCUs place importance on financial resources in order to continue to offer athletic programming on HBCU campuses. Searching for alternatives is a way HBCU athletic programs can decrease such dependence on financial support from government agencies.

Both internal and external resources and their uses can be affected by strategic decisions made by the organization's leadership. Those decisions then affect the long-term organizational stability and success. Examples of internal resources are human capital, finances, 
technology and equipment, and systems used by the organizations. External resources include the external networks and organizational behavior in those networks. Nemati, Bhatti, Maqsal, Mansoor, \& Naveed (2010) set out to explore the impact of certain resources on decision making. The findings from this study indicated that when an organization has scarce resources, the management team takes uncertainty into consideration when making strategic decisions. A lack of resources also has an effect on board members' recruitment, production strategies, and external organizational links. The findings from the study suggest that organizations develop some strategies based on how they will need to use their internal resources, and other strategies related to external resources are developed to put the organization in a better position. Therefore, the premise of RDT that an organization's behavior is built on the resources it has or needs was evident in this study. Relationships built with Power Five teams and municipalities that host HBCU Classics are a response to the need for financial resources desired to support the advancement of other critical resources such as facilities and equipment, student athlete support programs, staff, and marketing initiatives.

In a study on the appropriate perspectives for examining organizations and their strategies, Ulrich and Barney (1984) found similarities among the resource dependence, efficiency, and population perspectives. The research revealed that the three perspectives were similar in terms of what internal and external business transactions existed, how they navigated issues with scarce resources, and how they addressed looming issues of organizational survival. The analysis found that instead of competing, the perspectives actually worked together in a sense to explain how organizations address the aforementioned aspects of operation. This means that each of the three perspectives assessed (resource dependence, efficiency, and population) were essential in understanding inter-organizational relationships (Ulrich \& Barney, 1984). 
When exploring the financial limitations and actions of HBCU athletic programs, one could possibly consider the same three perspectives. The lack of resources combined with concerns of long-term stability can motivate HBCU athletics directors to make more efficient financial and operational decisions.

The dependence on certain resources by private and public-sector institutions to explain wage structures was explored by Pfeffer and Davis-Blake (1987). The researchers sought to better explain and understand how attributes of some professional positions affected the wages associated with that position. Their argument centered around the premise that some positions viewed as more important were paid higher than others of lesser perceived importance.

Leadership positions related to development, admissions, and alumni affairs paid higher wages at private institutions than at public institutions, which was attributed to the perceived importance of those positions at private institutions in terms of institutional survival. Thus, the positions were seen as more critical at private institutions and were compensated higher than at public institutions (Pfeffer \& Davis-Blake, 1987).

The results stated that the need for certain positions and their perceived importance to the institution were factors in wage structures. This also implied that wages are linked to resource dependency due to the nature of the type of institution. A private institution which depends more heavily on donations and fundraising efforts compensates professional positions in related areas higher than public institutions because those positions are perceived as having high importance to the stability of the institution (Pfeffer \& Davis-Blake, 1987). This perspective can also be applied to the allocation of funding for HBCUs and their athletic programs. For example, the allocation of funding from the general university budget can possibly be tied to how important a university deems its athletics programs. Paying for personnel (e.g., administrators, coaches, 
support staff) in athletic departments is often the largest percentage of an athletic department's operating budget and HBCUs with low endowments have to prioritize the importance of maintaining athletic programs. Additionally, $\mathrm{HBCU}$ athletic departments tend to be understaffed with personnel performing multiple roles. Employee wages may become even more important when this type of working condition is in place.

Macedo and Pinho (2006) examined the extent to which the degree of market orientation is affected by resource dependence for donors to nonprofit organizations. Market orientation is the planning and implementation of marketing strategies for an organization in reflection of the explicit or implied needs and wants of consumers. Resource dependence theory attributes organizational behavior to the organization's response to its resource dependencies. The researchers sought to discover the extent to which decisions made in response to resource dependence affected the market orientation for nonprofit organizations (NPOs) (Macedo \& Pinho, 2006). The study suggested organizations that diversified their strategies to generate revenue have a greater donor/user orientation than organizations that have one revenue source. As mentioned earlier, HBCU alumni can be an important factor in strengthening financial resources for athletic departments through development support.

Significant resource dependence can also impact the ability of organizations to operate autonomously. This spurred research conducted by Verschuere and De Corte (2014) in which they analyzed the autonomy of NPOs in their strategic decision making when they are publicly funded. While public funding can increase an organization's ability to increase its programming through financial support and political legitimacy, the dependence on resources from government agencies can restrict programming the organization is allowed to offer. The dynamic of the dependent relationship thus gives the government entity a sense of power over the nonprofit 
organization (Verschuere \& De Corte, 2014). Generally speaking, the NPOs had varying levels of autonomy and high levels of cooperation with the government entities. However, the level of autonomy of the NPOs was associated with the amount of public income provided to them. This suggests that increased funding is associated with some decrease in autonomy for the nonprofit organization. In the case of autonomy, HBCUs that engage in guarantee contract games sacrifice some level of autonomy to receive the resources that are available through those financial partnerships.

RDT and organizational behavior in sport. Understanding the nature of nonprofit organizations and the strategic decision-making processes that managerial teams use can assist in better understanding the dynamic of resource dependence within HBCU athletics departments. The lack of resources and competing interests of stakeholders can affect the strategic decisionmaking process for HBCU athletic departments. The use of resource dependence theory in sport organizations is very similar to that of nonprofit service organizations and small firms. Inglis (1991) utilized RDT to explore the influence of internal and external resources on Canadian intercollegiate athletics programs. The results of the study showed high levels of influence for four external agencies attributed to the structural connections that the organizations had to the Ontario university athletic programs. The internal influence from athletic administrators was rated high which was linked to the proximity and access to decision making for those personnel (Inglis, 1991). Influence from outside entities in this particular study was only strong when the agency had direct governing control over the athletic department. The nature of this case study assessed the decision-making process for HBCU athletic administrators. Their internal influence in making decisions for their departments was further explored to assess how strategies were formulated and later assessed for effectiveness by those in charge of the organization. 
RDT reveals how relationships with external sources can have an impact on the internal operations of an organization. Papadimitriou (1998) used RDT to further analyze the relationships between specific external sources and various internal organizational dependencies related to national sport organizations (NSOs). Hellenic NSOs operate in a centralized resource structure and are required to comply with a set of standards set by the government (the General Secretariat of Sport [GSS]) in order to qualify for funding. The study sought to explore institutional influences that external agencies have on the internal environments of sport organizations. The researchers found significant influence from the GSS. Interviewees described a working relationship with the GSS that was cooperative but dependent. The results from the study showed a high level of resource dependence on the GSS for the Hellenic NSOs. This heavy dependence caused NSO administrators to focus on activities that led to procuring resources rather than improving performance and efficiency. A similar focus on securing resources rather than the improvement of performance and efficiency is also evident in HBCU athletics departments where administrators participate in activities that meet short-term needs without addressing the long-term stability of the programs.

Informational resources such as processes are an important part of strategic management. Processes are a form of informational resource and can serve as the action aspect of strategy. Canadian national sport organizations (NSOs) transformed when their government initiated a process called the Quadrennial Planning Program (QPP) (Slack \& Hinings, 1992). QPP expedited organizational processes related to professionalism and bureaucratization and was viewed as an effective structure to reduce the dependence on volunteer support. Changing organizational dependencies gave organizations the ability to standardize their systems and programs. This change in organizational behavior also changed the ability of the organizations to 
centralize their decision-making and specialize positions for professional personnel. Essentially, reduction of volunteer dependence increased organizational control.

Also looking at human resources within sport organizations, Wicker and Breuer (2011) sought to analyze the resources of German non-profit sport clubs and how they were characterized by their limited resources. The results indicated that sport clubs in Germany perceived human resources as a larger issue for them than financial or structural resources (Wicker \& Breuer, 2011). Facilities were also a scarce resource, but the resource of volunteers was perceived to have higher scarcity because of the heavy reliance on human resources to continue operations. Many HBCU athletic departments are understaffed which affects their ability to further acquire new resources such as corporate sponsorships (Cheeks \& Crowley, 2015).

Wicker et al. (2013) used RDT to explain whether sport clubs that have strained resources are likely to build relationships with other non-profit sport clubs, schools, or corporate partners. The driving concept from RDT that influenced this study was "the need for scarce resources would be the main drivers for inter-organizational relationships of non-profit sport clubs" (p. 32). Six problem areas were ranked based on the participants' perceptions of how severe the problem was for their club. Those six areas were a) member recruitment and retention, b) volunteer recruitment and retention, c) coaching staff recruitment and retention, d) the availability of sport facilities, e) the condition of those facilities, and finally, f) the financial circumstances at their club (Wicker et al., 2013). The study showed evidence that organizations with scarce resources will form relationships with other organizations to alleviate their lack of resources. For HBCU athletic programs, those relationships have taken form in guarantee contracts with larger conference teams and various city municipalities for Classics. 
Due to limited resources, some organizations are at the mercy of other organizations within their network that can provide resources to them. Morrow and Robinson (2013) studied this concept in their work on the resource dependence of the Financial Times Stock Exchange (FTSE)-British Olympic Association (BOA) Initiative. The Initiative is a partnership between numerous FTSE 100 companies and the Olympic National Governing Bodies (NGBs) in the United Kingdom. Resource acquisition varied by partnership and trended toward intangible resources such as improved policies and procedures, marketing support, and access to other organizations for possible sponsorships or business relationships. The researchers also found that power and effectiveness were imbalanced because the Olympic NGBs gained more benefit than the corporate partners. The NGBs needed the relationships more than the FTSE organizations which provided them with critical resources (Morrow \& Robinson, 2013). Though there was a dependence present for the Olympic NGBs, it was not a primary concern for the corporate partner. The magnitude of their dependence was evident in this particular study which supported the power of RDT to explain the relationship between organizations with a high level of resource dependence and their more powerful partners who provide those resources. Resources provided in these relationships are valuable whether tangible or intangible (Morrow \& Robinson, 2013). The magnitude of dependence is also evident with HBCU athletic programs like Coppin State basketball which participates in three to five guarantee contract games annually at the rate of $\$ 50,000$ to $\$ 80,000$ each game (Gill \& Hart, 2015). They have also lost all of those guarantee contract games. The appeal to participate in guarantee games is high for Coppin State as they are ranked the lowest in terms of revenue.

Government funding and the influence from its financial contribution can create a financial resource dependence for sport clubs (Vos et al., 2011). In addition to governmental 
influence, corporate partnerships have also begun to influence the organizational behavior of voluntary sport clubs. Governments set rules for these sport club organizations and, because they hold the purse strings, are able to exert their influence on compliance with those rules in order to obtain the subsidies (Vos et al., 2011). When external influences hold access to vital resources an organization needs, those external influences limit the dependent organization's power and autonomy.

\section{Summary}

Applying RDT to HBCU athletics makes it important to identify which resources are limited and what control the departments have to increase those resources. Actions HBCU athletics departments take are likely due to the lack of resources the organizations must acquire. HBCU athletic departments rely on university subsidies, alumni support, sponsorships, and ticket sales (among other revenue generating resources) to remain in operation. Those resources are scarce for HBCUs in comparison to larger predominantly White Power Five institutions. The scarcity of financial resources that HCBU athletics departments face has led to the closure of some or all of athletics programs at institutions like Spelman College which opted instead to build a health and fitness facility, saving the institution \$1 million annually (Cheeks \& Crowley, 2015). For HBCU athletics departments, their network of resources includes other HBCUs and their athletic programs, other FCS programs, corporate partners and sponsors, and the FBS teams seeking to enter guarantee contract games with them. The resources available through guarantee contract games are dictated by the FBS teams with adequate financial resources to pay HBCU athletics for participation. Thus, HBCUs utilize other organizations within their network to secure the resources they need to cover short-term responsibilities. Resource based theory can 
help further assess a more long-term approach to meeting the needs of $\mathrm{HBCU}$ athletic organizations.

\section{Resource Based Theory}

The context of HBCU athletics is often presented from a deficit perspective; this perspective does not include the analysis of the resources and strategies that HBCUs have in place to combat the shortage of other resources. Resource based theory (RBT) is a framework used in strategic management that integrates both economic and behavioral perspectives of organizations. The use of the RBT framework adds depth to this study's analysis of HBCU athletic departmental resources and their acquisition.

RBT is separated into two schools of thought: structural and process (Peteraf, 1994).

Structural examines the resources that are surplus-generating and how they influence and create a competitive advantage for an organization. Process examines the ways in which resources are generated, maximized, and preserved for an organization (Peteraf, 1994). Contrary to RDT, which looks at the response to a deficit in resources, RBT examines the potential for a surplus of resources which can create or increase a competitive advantage in the market. RBT has a prescriptive nature; it suggests acquiring resources that are valuable, rare, and inimitable will lead to a competitive advantage for the organization. Thus, RBT is useful for extracting practical implications for organizations to maximize their competitive advantage through efficient use of resources (Galbreath, 2005). For HBCU athletic departments, RBT will be useful for identifying appropriate strategies to increase long term survival in the NCAA.

The role of resources in RBT. The major assumptions of RBT are organizations rely on tangible and intangible resources to operate. Those resources must be diverse and immobile, and align with a model that assesses the value, rarity, inimitability, and organization of the company 
to exploit resources (VRIO model) in order to obtain or maintain a competitive advantage (Barney \& Clark, 2007).

Tangible and intangible resources. An organization's tangible resources include buildings, supplies, land, and employees. Thus, resources that hold a financial or physical value are tangible for an organization (Galbreath, 2005). In athletics, tangible resources would also include facilities, alumni, coaches, administrators, and student athletes. Tangible resources, however, do not create a strong competitive advantage as others in the same market can also acquire those resources (Barney \& Clark, 2007). This does not devalue the resources, but they are not enough to sustain a competitive advantage which is the purpose of RBT. Tangible resources (e.g., facilities, finances, and personnel) are often seen as primary resources and rarely thought of in the context of a supporting role for intangible resources (e.g., marketing, policies, and culture) (Schriber \& Löwstedt, 2015). For example, the HBCU marching band has served as a vital supporting role to the branding of $\mathrm{HBCU}$ athletic program events.

Galbreath (2005) posited that all resources are interrelated to develop a competitive advantage. Thus, a competitive advantage is obtained through the use of both intangible and tangible resources. Numerous scholars of RBT presume that intangible resources lead to the strongest competitive advantage for an enterprise. However, Galbreath's study led to the revelation that tangible resources do play an active role in the success of an organization to some extent. Three implications were developed from this study:

1. Organizational assets, such as culture, human resources management policies, and corporate structure can significantly impact a firm's success.

2. Reputational assets are among the most important the firm can develop. 
3. Tangible assets, in contrast to traditional resource-based theory beliefs, may still have a viable place in the performance of firms (Galbreath, 2005, pg. 985).

Resources and the success of an organization are not linear in nature. They are interlinked to a combination of tangible and intangible resources.

Intangible resources are those that are fixed with the organization and provide stronger competitive advantage when leveraged efficiently. These resources, such as trademarks, brand images, management strategies (e.g., hiring, procedures, or marketing implementation) and informational properties, do not usually show up on the departmental budget and cannot be easily bought by competitors (Galbreath, 2005). Intangible resources can further be divided into two categories: assets (what an organization has) and skills (what an organization does) (Hall, 1992). Intangible assets for an HBCU athletic department are their brand images, culture, and logos. Intangible skills are the ways in which the department administrators strategize to use various resources. Leveraging both intangible assets and skills can strengthen their stability and competitive advantage.

Therefore, an exploration of the full portfolio of resources for HBCU athletic departments is important for the proposed study because intangible resources alone will not necessarily lead to a competitive advantage. This study will also explore a full range of resources including athletics personnel, facilities, branding and marketing, practices, finances, and culture. The examination of a strategic mix of these resources will allow a better understanding of what has been done and what can be done to further increase the competitive advantage of $\mathrm{HBCU}$ athletic departments.

Heterogeneous and immobile resources. Heterogeneous refers to resources as well as the strategic use of those resources. Introducing heterogeneity to strategic uses of resources can 
increase revenue generation as well as alleviate the burden of cost for owning certain assets such as sport facilities and equipment. RBT posits that organizations create a competitive advantage with a mixture of resources (e.g., the combined use of appropriate physical, financial, and human resources needed to successfully host an athletic competition) or resources that can be strategically used for multiple purposes rather than relying on a singular resource or use (e.g., a facility used for its primary purpose of athletic competition as well as subsidiary uses such as leasing the space for public or private events) (Barney \& Clark, 2007). Kunc and Morecroft (2010) sought to extend RBT by focusing on the decision-making processes for the management of homogenous resources which RBT states cannot create a strong competitive advantage. Results of the study support the notion that decision-making patterns focusing on building heterogeneous resources were better for the overall performance of an organization (Kunc \& Morecroft, 2010). Thus, it is important for managers to find multiple uses of resources to increase competitive advantage.

Immobile resources cannot easily be moved to a different industry. Immobility of resources is also essential for competitive advantage and refers to resources that are fixed within an organization (Barney \& Clark, 2007). Immobile resources like the HBCU marching band style and culture tend to be intangible, therefore creating a stronger competitive advantage because competitors cannot purchase them easily and they are stable within the organization. HBCU band culture is so immobile, in fact, that many times HBCU sport is associated with the marching bands rather than the athletic competitions. Information and processes are also immobile and intangible and can further strengthen the ability of organizations to generate a surplus, thus, creating a competitive advantage. 
VRIO model of RBT. An assessment of the resources that an organization has access to can help with determining the competitive advantage that an organization can develop. The VRIO model of RBT refers to the value, rarity, inimitability, and organization of a department's resources. The VRIO model further assesses the value and potential of resources identified within the organization. Because value is subjective in nature, leadership within an organization may view a certain resource as holding greater value than someone with an outside perspective. For example, an athletic department may view human resources as having a high value because of a high level of dependence on personnel to operate, however, the personnel may not provide a competitive advantage. The value of resources in the VRIO model is determined by how the organization can use the resources to efficiently and effectively implement strategies (Cardeal \& António, 2012). If a resource has the potential to be valuable, but the organization does not have the capability to use it in a valuable way, its value remains concealed until it is further exploited by the firm (Newbert, 2008). For example, if an athletic department has a strong alumni base to solicit for development funding but lacks the appropriate personnel for development, the alumni resource will remain concealed until that potential is utilized through organized development efforts. Rarity of resources holds a similar position as value of resources. Competitors can have comparable resources; however, the ways in which the resources are used can be rare (Cardeal \& António, 2012). An example of this is the HBCU marching band. Many universities within the NCAA have marching bands that also perform at athletic competitions; however, the use of the band for HBCUs is very different in style and purpose. The marching style incorporates a trivium of dancing, singing, and instrumentals to create a unique experience for spectators. The HBCU marching band provides such a unique experience that the Honda Battle of the Bands, hosted 
annually in Atlanta, GA, features HBCU marching bands and spectators from all over the United States.

Inimitability is related to how easily a resource can be recreated by competitors.

Resources can be inimitable if: (a) they are informed by past knowledge or experience, (b) there is a relationship between the resources and ways of exploitation, (c) other organizations within the network are unable to manipulate them because they are socially compounded, (d) the organization owns legal rights to the resources, and (e) it would take too long for the resources to be imitated (Cardeal \& António, 2012). An inimitable resource for HBCU athletics is the culture that centers on a celebration of Blackness and emphasizes the marching band. The salient culture of HBCU athletic competitions, such as Classics and homecomings, creates a unique environment that is difficult to recreate because the environment is so heavily tied to the social culture of Black Americans and HBCUs. This inimitability added to organizing the use of Classics to further increase revenue leads to the final point of the VRIO model, organization.

Organization in the VRIO model refers to the ways an organization uses their strategic and non-strategic resources to operate (Pan et al., 2007). The processes within an organization that lead to the efficient and effective use of resources make up the dynamic capability of the organization and can lead to the long-term sustainability of the firm (Cardeal \& António, 2012). Athletic departments can improve their organization through updating processes and routines over time. Failing to assess and update practices, depending on the needs and conditions of their environment, weakens the competitive advantage of the organization (Cardeal \& António, 2012). Therefore, this study seeks to further explore the processes and routines of the HBCU athletic department. Extant RBT literature and the VRIO model support this assessment of the HBCU athletic department as an organization and its ability to reassess needs over time. 
Strategic management of resources. Athletic administrators play a key role in determining the strategic use of resources through the decisions they make for their departments. While access to certain resources may pose difficulty, the use of available resources should be optimized. Thus, it is important for managers to find multiple uses of resources to increase competitive advantage.

Marketing is an example of a heterogeneous resource because of its unique nature that incorporates both tangible and intangible resources to implement strategy. A strong marketing mix incorporates the use of financial, human, informational, and physical resources to further promote a brand. Marketing is an under-exploited resource in HBCU athletics which can be an additional barrier to their competitive advantage. Kamboj, Goyal, and Rahman (2015) found that marketing is an intricate aspect of forming a competitive advantage. Marketing is an intangible resource and the efficient use of this resource can develop a strong competitive advantage which also increases the financial performance of an organization. With only 25 percent of $\mathrm{HBCU}$ athletic departments reporting that they have a dedicated marketing department and marketing personnel (Jackson, Lyons, \& Gooden, 2001), they are at a significant disadvantage in intercollegiate athletics. Investing in marketing efforts can have a positive long-term effect on an organization.

Sponsorships are multifaceted resources in that they can often be a means to provide other resources aside from the relationship itself. Sponsorships for HBCU athletic departments can be explained by both RDT and RBT. Acquiring sponsorships provides sport organizations with a heterogenous resource through intangible brand image usage and tangible sponsorship activations (Amis, Pant, \& Slack, 1997). Sport sponsorships are also inimitable because each 
sponsorship should be tailored to meet the mutual needs of the sport organization and sponsor organization.

Jensen, Cobbs, and Turner (2016) used the resource-based perspective to explain how RBT can be used by sponsorship firms in order to gain a competitive advantage. Through a case study analysis of Visa's sponsorship relationship with the Olympic Games, the researchers developed a conceptual model to assist sport marketers with identifying and leveraging sponsorships. This perspective of the sponsoring firm can be valuable to sport marketers seeking to sell a valuable relationship and potential for a competitive advantage when the sport firm is able to offer that mutually beneficial relationship. However, with HBCUs lacking marketing staff to develop and then manage those relationships, this uniquely tangible and intangible resource is difficult to acquire and sustain.

Though extant literature on RBT discusses what is needed to obtain a competitive advantage, it failed to address how an organization achieves this. Thus, Cardeal and Antonio (2012) examined the ways in which an organization can obtain a competitive advantage through the strategic use of resources. According to the study, dynamic capabilities (DC) served as the "O" (i.e., organization) in the VRIO model. Dynamic capabilities refer to shifting of focus from external forces of an organization (e.g., university subsidies, governance policies, and societal trends) to internal controls such as workforce development and capital investments. To validate this, the researchers employed a case study method which assessed four main sources of data from a Portuguese footwear manufacturer (interviews, internal records, observations, and press articles). The results from the study suggested that the integration of a set of critical resources result in capability of the organization. None of an organization's resources are valuable until they are combined with other resources which is consistent with literature on dynamic 
capabilities (Cardeal \& António, 2012). This further suggests in a practical sense the importance of bundling resources to create stronger inimitability. For example, Classics utilize bundling through integrating HBCU culture, popular culture, and Black consumerism to create an inimitable experience.

Along the lines of bundling resources, Anderson and Kheam (1998) analyzed the relationship between resources and growth strategies. RBT asserts that diversification is needed to form a competitive advantage; the researchers sought to assess the extent of RBT's ability to predict strategies for growth outside of diversification. CEOs from Norwegian exporting firms were surveyed about their perceptions of future growth strategies, market conditions, and firm capabilities. The results suggested that management and marketing capabilities predicted a stronger firm growth than diversification of resources when combined (Anderson \& Kheam,1998). Because management and marketing are both intangible resources, this further confirms the RBT assertion that intangible resources and bundling lead to a stronger competitive advantage.

Newbert (2008) sought to fill a gap in RBT literature that failed to address the relationship among value, rarity, competitive advantage, and performance. The researcher found that competitive advantage can be obtained through rarity in the combinations of resources. The study also suggests that an organization's competitive advantage is an important factor in performance and competitive advantage must be related to performance. The findings also indicate that value and rareness are related to competitive advantage and performance even when competitive advantage is not present (Newbert, 2008). Thus, HBCU athletic departments are able to perform well, even when competitive advantage is not obtained. Performance could be tied to winning seasons for an athletic program or strong branding within the market. 
Human resources (HR) hold the knowledge, information, and abilities of an organization. Pesic, Millic, and Stankovic (2012) explored the role of HR in strategy formation to obtain a competitive advantage. Because human resources are the only "thinking" resource, human resources are also an intangible resource for an organization. Humans have the ability to both think and perform making them a dynamic resource for organizations. The results from this study implied that if an organization is innovative and efficient, it can provide a sustainable advantage. However, commitment and involvement are needed with all personnel. A twodirectional flow of information is the best channel to increase innovation and efficiency. Thus, a holistic management of HR can lead to a competitive advantage.

RBT in HBCU athletics. Athletics departments operate within the higher education. Such a setting comes with influences from resources as well as institutional control. Gallaro and Navarro (2003) explored this dual influence to develop a model for universities in their complex environment. The researchers identified resource related influences of the organization as the core competencies of the institution, the acquisition of assets, the internal structures, and external networks. The institutional related influences were identified as the historical context and regulatory controls. The model the researchers developed showed how both resource-based determinants and institutional determinants affect processes for the institution (Gallaro \& Navarro, 2003). This model is also appropriate for assessing HBCU athletic departments which have enacted strategies resulting from historical contexts in US higher education, regulatory controls of the NCAA, and internal resource-based determinants.

In intercollegiate athletics, RBT has been used to predict competitive advantage based on various criteria. For instance, Omondi-Ochieng (2018) used RBT to predict team competitiveness based on physical, human, and organizational resources. More specifically, the 
researcher assessed coaches' salaries, total revenue, and home attendance as predictors for competitive advantage in terms of wins and losses. The study found that the aforementioned predictors do assist with developing a competitive advantage. However, the study utilized winloss records as an indicator of competitive advantage rather than as a predictor of performance. This misaligns with RBT which separates competitive advantage and performance of an organization (Newbert, 2008). The researcher also asserted that coaching staff and game attendance predict team success, but not a reciprocal relationship between the two factors. The study also fails to address the relationship between the identified resources and the overall success of the athletic department.

Smart and Wolfe (2000) also assessed the competitive advantage of intercollegiate football programs using RBT. The premise of competitive advantage for this context was related to winning averages, finances, graduation of student athletes, and ethics of the football programs (e.g., no major scandals). The researchers proposed that if a football program performed well, the athletic department would also perform well (Smart \& Wolfe, 2000). The resources that were found to be most valuable for the success of the football programs were related to the coaching staff as a human resource who could provide other capital resources such as history, relationships, trust, and culture. Again, the scope of the study fell short of developing a better understanding of how the use of departmental resources leads to competitive advantage regardless of wins and losses.

Practical application of RBT. Grant (1991) defines resources as "inputs into the production process" (p. 118). This simplifies how resources should be viewed in order to better capture what organizations have in their possession to strategically exploit for a competitive advantage. Assessing resources in a realistic way is imperative, especially for HBCUs. This includes 
avoiding wishful thinking and reliance on past glories when assessing existing resources and the network needed to defeat a shortage of resources (Grant, 1991). Under the process perspective, RBT can be utilized to make this assessment and formulate strategies through a series of five steps:

1. Identify and categorize the organization's resources, compare the strengths and weaknesses of those resources to those of competitors, and then identify ways to better utilize those resources.

2. Identify the organization's capabilities and how the organization can better perform in comparison to its rivals.

3. Assess the resources that have the potential to generate rent and the capabilities of the organization.

4. Select a strategy to best use the organization's resources and capabilities.

5. Identify gaps in resources that need to be filled (Grant, 2001).

This model for strategy formation adds to the practical value of RBT in strategic management. The RBT process perspective is valuable for this study to qualitatively examine HBCU athletic departments resources that can be better utilized. RBT will also assist in identifying any gaps in resources that the athletic departments need to fill in order to maximize and preserve existing resources.

Many studies have extracted applicable meaning from RBT. The evaluation of intangible and tangible goods, the bundling of resources, the importance of human resources, and the use of sponsorships all provide new opportunities for HBCU athletic programs seeking to move beyond survival into a position of thriving. HBCU athletic programs have an opportunity to develop long-term strategies that can assist in the long-term sustainability of their organizations. While 
short-term remedies have allowed many athletic departments to survive in their current environment, short-term remedies have not served long-term survival needs.

Though much extant literature has shown the use of RBT in assessing resources and strategies, it has fallen short in athletics research to explore how the strategic use of resources can increase other resources. Literature has also missed an opportunity to address the operational side of intercollegiate athletics business with the RBT lens. This study seeks to further address the gaps in literature on RBT as well as add meaningful practical knowledge that supports the long-term survival of HBCU athletic programs working within the confines of the NCAA. 


\section{CHAPTER III}

\section{METHODOLOGY}

The purpose of this study was to explore resources limitations and decision- making practices of HBCU athletics departments that stem from a shortage of critical resources. This qualitative study sought to answer the following research questions:

1. What resources do HBCU athletics departments manage?

2. How are resources managed in HBCU athletics departments?

To further analyze how resources are managed in HBCU athletics departments the following sub-questions were developed:

RQ2a. How do HBCU athletic departments manage existing resources?

RQ2b. How do HBCU athletic departments mitigate the gaps in resources?

In order to explore the relationships between resources and strategic management for athletic programs at HBCUs, a qualitative design was utilized. This allowed an in-depth empirical look at the current state of HBCU athletics. Qualitative research involves understanding "how people make sense out of their lives, delineate the process of meaning-making, and describe how people interpret what they experience" (Merriam \& Tisdell, 2016, p. 15). This study sought a better understanding of how athletics' personnel make sense of their decisions for the department and described how they interpret their management of resources. The research questions for this study were related to how the lack of resources can impact the organizational behavior of HBCU athletic departments and how those departments can better utilize their resources. 
Resource dependence theory (RDT) and resource-based theory (RBT) explains how resources are acquired, allocated, and exploited within an organization. For the purpose of this study the investigation focused on three specific relationships to formulate a conceptual framework in order to answer the research questions. Those relationships were: a) the relationship between a lack of resources and how organizations strategize to acquire them; b) the relationship between perceptions of resources (value) and how those resources are strategically managed; and c) the relationship between the strategic management of resources and the ability or inability of the organization to create a surplus from them.

\section{Case Study Design}

A case study was most appropriate because the investigation was of a current phenomenon on site in its actual context (Yin, 2018). A case study was also appropriate because the case study has a constructivist paradigm in that it states that truth is dependent on the perspective of the individual (Yin, 2003). Therefore, examining an HBCU as singular organizations within a larger category with varying perspectives created a more accurate depiction of the experiences of that institution's athletics department. HBCUs are not a monolith in that what may be a phenomenon at one institution, may not be generalizable about all HBCU athletic departments (Glesne, 2011). This research inquiry was an illustrative case study that described a phenomenon in HBCU sport in order to fill the dearth of understanding in our field related to this population in intercollegiate athletics (Yin, 2018). The study described all factors that may influence the case including the organization type, size, people involved, location, goals, and events that have taken place. 
Case participants. For a case study, there are three main criteria for selection of cases: relevancy of the case to the study, provision of diversity across contexts, and opportunities to learn more about the context of the study (Stake, 2006). This set of criteria has determined the terms of participation for this study. The participant institution met the following criteria: 1) a privately funded or publicly funded institution that holds the federal designation of Historically Black College or University (HBCU) in the mainland United States of America, and 2) has an NCAA affiliated athletic program at the Division I or Division II level. This institution was identified through network sampling for the specified criteria (Glesne, 2011). Utilizing a network within HBCU athletics allowed access to the desired case study participants for the purpose of empirical data collection. The network consisted of athletics professionals who served as gatekeepers to senior level athletic directors at an HBCU program fitting the eligibility criteria. There were several reasons why a single case study was the appropriate methodology for this study. A single case study allowed for a deeper understanding of the case while extracting meaningful interpretation of the data. Because the case study design involves more than two forms of data collection, a single case study allowed for a richer analysis of the data. The single case study design also allowed for this dissertation research to fit within the constraints of time needed to complete the data collection and reporting process. The data collection process involved travel, time on site, and a more extensive data analysis process. The single case study allowed for greater time management as well as for the data to be exploratory and not comparative which would be the nature of a multiple-case study. 


\section{Case Context}

Hill University (HU) is an HBCU located in the southeastern United States and is an NCAA member institution that operates at the Division II level. This privately funded institution has an average enrollment of under 4,000 students at the undergraduate through doctoral education levels. The athletic department supports twelve athletic programs. There are currently seven athletic administrators and nine head coaches. The department utilizes four athletic facilities including a football stadium, arena, tennis courts, and baseball field. The current athletic director of $\mathrm{HU}$ is also the head football coach. He served as interim athletic director for one year after the departure of the previous athletic director. His experience in intercollegiate athletics has been primarily in coaching. The associate athletic director for marketing has over ten years of experience working in athletic administration and works closely with the athletic director in decision making.

This institution is an ideal specimen for this study because not only does it meet established criteria for the study, but the athletic department also actively shows how a lack of specific resources influences the decisions made by the organization as suggested by RDT as well as how a more efficient use of resources can increase long term stability for an athletic department as suggested by RBT. The current athletic director at HU is also the head coach, and the department is 100 percent subsidized by the university general fund. HU also has a rich history of athletic success. This case study answered the research questions for this study, but also allowed for a plethora of other insightful information about decision making to present itself in the research process as well. 


\section{Data Collection}

Multiple forms of data must be collected for case study methodology (Yin, 2018). The data for this study consisted of interviews, observations, and document analyses to provide a holistic understanding. Several sources of evidence were analyzed to answer the research questions: 1) What resources do HBCU athletics departments manage? 2) How are resources managed in HBCU athletics departments?

One-on-one and in-person interviews with athletic administrators and coaching staff, documents such as photographs, direct observations, and archival records such as departmental agreements, provided insights about the two HBCU athletic departments. Data will be further captured through videography, photography, and audio recordings of interviews, events, and facility tours. The multiple forms of data will assist in giving a rich description needed for this illustrative case study design while also answering the research questions in a robust way.

Individual participant interviews. Incorporating interviews served as an addition to the robustness of the data by further answering the "how" and "why" of the phenomenon of decision making (Yin, 2009). Individual participants were deemed appropriate for interviews if they met the following criteria: (a) currently hold a position within athletics at the HBCU case site, (b) have decision-making power for one or more areas of operations, and (c) have experience working with resources and strategy formation for the current athletic department. Of the four possible participants who met the criteria for the study, three administrators agreed to participate from the case institution. Those participants are the Athletic Director, the Assistant Athletic Director for Marketing and Communications, and the Director of Compliance (Appendix G). 
Interviews derived from questions related to theory and the study's research questions, and will focus on documenting: (a) the acquisition and management of resources, (b) strategies formed to exploit existing resources (c) perceptions of what interviewees consider to be valuable resources, and (d) perceptions of how resources should be exploited within the department (Appendix A). Examples of research questions are as follows: "What is your role in the department? How many staff members perform multiple roles within the department? What resources would you say your department has enough of? Describe a time when a limitation of resources (human, physical, or financial) influenced a decision that you made. How do you evaluate available resources prior to making a decision? What resources do you have or have previously had access to outside of your department? How would you describe the role of (physical, financial, or human) resources within the department?" Interviews were semi-structured, in person, and took between 30 to 60 minutes to complete. The interviews were audio recorded for the purpose of a more accurate transcription process. After transcription, interview transcripts were sent to individual participants for member checks.

Visual data collection. Visual representations are common in society and the inclusion of visual data can provide some societal context that other forms of data collection may not provide (Banks, 2007). Visual data has increased in society as a form of communication and can provide a better understanding of other cultures, geography, and societal phenomenon as can be seen with platforms such as YouTube, Facebook, and Instagram. The use of visual data for this study provided a similar understanding of HBCU sport culture and departmental phenomenon by showing visual representations of actual events in their own context. Visual data that was 
collected included videography of athletic events and field observations, departmental documents, and photographs taken from the perspective of the athletic director. Visual data will also add to the triangulation of data for this study.

Videos. Journaling was used as a form of reflective learning as I observed throughout each day on site. Video journaling was the desired journaling method because of its ability to capture both verbal and nonverbal communication as I processed my field observations. Video journaling has not been mentioned in extant literature on empirical studies regarding resources for an organization. However, with society's increase of video content in media and communication, this added data added to the robustness of the study. Gibbs (1988) model for diary keeping will serve as a guide for the video journaling process. The following steps will be used from the model: 1) describe what happened, 2) examine thoughts related to what was observed, 3) evaluate both the positive and negative related to the observation, 4) further analyze what happened to make sense of the phenomenon, 5) draw a conclusion about what can be done, and 6) action planning if needed. Due to the lack of literature on video journaling field observations, Gibbs' 1988 model served as an appropriate model to process thoughts. Also, for the purpose of piloting this method with the study, I worked exclusively with the first five of the steps as applicable. Each step aided in keeping a more consistent journaling process and data analysis process. The use of video journaling was unique and introduced a less common form of journaling as a researcher on sight reflecting on the phenomenon observed.

Photovoice. Photovoice is a method that allows participants to have an active role in the collection of important data that the investigator may not have otherwise captured (Hergenrather, Rhodes, Cowan, Bardhoshi, \& Pula, 2009). An intricate component of photovoice is the 
participant(s) taking photos of their reality in response to a prompt from the investigator (Wang, Yi, Tao, \& Kathryn, 1998). The stages of the photovoice method are to conduct training with the participant, develop themes from the theoretical model, allow the participant to take pictures, and then discuss the photos with the participant. The participant in this case will be the athletic director. For this study, prompts for photovoice were derived from the VRIO model (value, rarity, inimitability, and organization) and included "Based on your experience in leadership, what resources do you think that your department use well?", "Based on your experience leading this department, what are your most valuable resources?", "Based on your experience leading this department, what resource makes your department most unique?", and "What use of resources is unique to your department?". This added richness of the data collected and accounted for researcher bias.

Documents. Documents collected are also considered visual data for this study and consisted of departmental agreements, unofficial organizational charts, and printed marketing materials. While organizational charts formally tell us what the structure of an organization is intended to look like, the actual execution of job responsibilities, reporting systems, and day to day structures may differ. This created an important source of data to see how the organization is intended to operate versus how it operates in truth. The institution is privately funded and therefore public access to budget documentation was difficult to obtain. This will add ease in procuring budget information as well as further develop interview questions and an understanding of the financial resources available for this athletic department.

\section{Data Analysis}


In order to converge the various forms of data collected from the case site, pattern matching and linking data to theoretical propositions were used for analysis (Baxter \& Jack, 2008). Constant comparative analysis was also used for the data analysis (Merriam, 2016). First, the researcher used structural coding to organize and arrange the data to reflect the conceptual framework related to a dearth of resources and the processes that athletic administrators have in place because of that shortage. Structural coding was deemed appropriate in order to ensure that each research question was answered during the data analysis process (Saldana, 2012).

According to Saldaña (2012), structural coding allows for more focus on the data directly related to the study and the research questions asked. With such a large amount of data needed for this study, structural coding provided the needed focus and organization for analyzing a vast amount of data. This initiated the process of developing categories and subcategories related to the framework and research questions, and assisted in finding emergent themes in the data. Next, the researcher organized the categories through pattern coding (Saldana, 2012). Pattern coding was necessary for a second round of coding which identified data that gave meaning and developed the major themes in the data.

Positionality. As a researcher, my positionality is one of intimate involvement with HBCUs and the athletics department. I was introduced to intercollegiate sport through the Magic City Classic football game in Birmingham, AL. My family members have graduated from various HBCUs around the nation. As a member of a family with a long history of attending and graduating from HBCUs, I was deeply entrenched in HBCU culture at an early age. I graduated from Tuskegee University where I participated in the marching band, a central element of HBCU sport culture. We practiced in the same facilities as athletics. We attended and performed 
simultaneously with athletic teams at sporting events. I worked for the Tuskegee University athletics department during my undergraduate education. While working for athletics, I learned about the financial strains for the Tuskegee University athletic department. There was limited money for basic operations and a great need for updated facilities and an increase in administrative staff.

As a young professional, I volunteered with the Southwestern Athletic Conference (SWAC) for Media Days conducting interviews with HBCU head coaches and athletic directors. While volunteering, I had conversations with coaches about recruiting challenges related to financial limitations for scholarships and facilities. I also was fortunate to see how actions taken at the conference level, such as sponsorship and broadcasting deals, affected operations for the affiliated institutions.

As a graduate student, I worked as an administrative intern with the Tuskegee University athletic department to form a development plan and assist with creating more efficient ways to operate in the NCAA environment. During my internship, I came to a realization that there is a relationship between the lack of financial resources and organizational behavior for Tuskegee University. There was sense of fatigue for administrators who were stretched between two professional roles in the department. I witnessed how having leadership that the departments could afford rather than who was highly qualified affected the operational decisions within the department as well.

As a doctoral student and new researcher in the subject of intercollegiate athletics, my curiosity regarding the state of $\mathrm{HBCU}$ athletics and how a lack of finances affects the operational success of the programs have been met with a shortage of empirical evidence to support or refute 
my assumptions. The search for answers that had not yet been addressed further influenced my research inquiry. Therefore, the purpose of this research was both personal and professional in nature.

\section{Quality of Conclusions}

Objectivity and confirmability. My personal and professional attachments to this area of research could have encouraged me to seek data that supported my own hypothesis and presumptions regarding this field. Researcher positionality was monitored through member checks and a peer audit and debriefing following data collection (Glesne, 2011). Photography and videography was also used as a means of visual triangulation to ensure that the data collected is without my own personal biased interpretation. Credibility was strengthened through analyzing multiple forms of data within the participating athletic department. This allowed each data form to confirm other data that was collected in order to better formulate themes, and develop a conclusion that was grounded in the multiple forms of data (Yin, 2018).

Reliability and dependability. To ensure reliability of the study, I took additional measures to create a consistent study conducted with reasonable care. The research questions reflect lay language that was understood without a full understanding of the theoretical framework. My communication with the athletic director of the selected site was transparent and my role as the researcher was made clear prior to, during, and after the study. The data in this study was collected on site with respondents who were able to give insight that answered the research questions. Member checks were conducted with interview participants, and archival data was reviewed with the athletic director who was able to validate that the information 
presented was accurate. As a doctoral student conducting dissertation work, a committee of faculty was also formed to further review and assess the study.

Transferability of the study. While case studies are not generalizable, the analysis focused heavily on areas that are transferable to similar organizations. Report findings specified any limitations related to the sample selection as well as overall congruency with the theoretical framework. Rich descriptions of the data collected and results gave needed context for possible future studies to be conducted within a similar environment. 


\section{CHAPTER IV}

\section{FINDINGS}

HBCU athletic departments, such as that of this case study, have managed to remain somewhat stable despite the limited resources that they have available to operate. The growth of HBCUs in the opposition of Jim Crow Laws and unequal government funding was difficult but successful. Their focus on the cultural experience has branded them exciting and inviting to many Black sport consumers. However, competing with larger and better funded athletic programs for athletic talent halted much of their rapid growth (Cavil, 2015). Along with "new" and unbalanced competition, came the stress of balancing annual budgets with a minimal influx of financial resources. Therefore, the purpose of this study was to explore resource limitations, allocations, and decision- making practices of an HBCU athletic department stemming from a shortage of critical resources.

Resource is defined as "inputs to the production process" (Grant, 2001, p.118). For the purpose of this study, resources were divided into four main categories: financial, human (administrative and coaching staff), physical (facilities) and information (policies and knowledge). This study employed two theoretical frameworks: resource dependence theory (RDT) and resource based theory (RBT). RDT was used to analyze the strategies and practices stemming from a lack of resources. RBT was applied to analyze the existing resources, strategies, and gaps in resources in order to develop better strategies for resource generation. This investigation explored the relationship between resources and how HBCU athletic departments operate with limitations or an abundance of resources. This qualitative study sought 
to answer the following research questions: 1) What resources do HBCU athletic departments manage? And 2) How are resources managed in HBCU athletic departments? To further analyze how resources are managed in HBCU athletic departments the following sub-questions were developed:

a. How do HBCU athletic departments manage existing resources?

b. How do HBCU athletic departments mitigate the gaps in resources?

\section{General Data Collection Methods}

To answer the research questions and sub-questions, a qualitative case study method was used to explore resource management and strategies of an HBCU athletic department. A single case study allowed for a deeper understanding of the case while extracting meaningful interpretation of the data. The researcher spent 7 days on the campus of an HBCU collecting multiple forms of data. The data for this study consisted of interviews, observations, and document analyses. Data included: one-on-one, in-person interviews with athletic administrators; direct observations of administrators and athletic department operations; and, documents, including photographs and agreement forms, and archival records such as departmental budgets, press releases, reports, and organizational charts were analyzed. Data was also captured through videography, photography, and audio recordings of interviews, events, and facility tours. The multiple forms of data assisted in giving a rich description needed for this illustrative case study design while also answering the research questions in a robust way.

The study took place on the campus of "Hill University" (HU). A series of interviews with the Athletic Director, Assistant Athletic Director/Sports Information Director, and Compliance Director/Senior Woman Administrator were recorded and transcribed verbatim with identifiers removed to protect the identities of participants. The Photovoice method was also used with an 
athletics employee who served as both the video coordinator and a member of the football coaching staff. Documents such as the University's Annual Report stating the economic state of HU, marketing materials, development solicitation materials, as well as photos and researcher observations assisted in triangulation of the data collected through interviews and Photovoice. Structural coding allowed for initial themes to emerge in an organized manner from the vast amount of data that was collected from "Hill University".

\section{Case: Hill University}

"Hill University" (HU) is an HBCU located in the southeastern United States. HU is an NCAA member institution that operates at the Division II level. This privately funded institution has an average enrollment of just under 4,000 students and awards undergraduate, graduate, and doctorate degrees. In summer 2018, HU inaugurated its first woman president. "Hill University" has an endowment of $\$ 129$ million and is one of only 6 HBCUs with endowments above $\$ 100$ million. Alumni giving for the university is reported to be seven percent and HU also received $\$ 35,201,470.86$ in federal grants and funding in 2018 .

The following is an excerpt from observations gathered from the researcher while on the campus of Hill University in November 2019. It provides historical and current context for the present environment at Hill University:

"Well-groomed flowers and shrubs frame the main entrance to the university encapsulated by iron gates and a brick wall with the university logo. A security guard sits in a small building while he monitors pedestrians and vehicles entering the gates at the main entrance on campus. After entering through the gates, red brick buildings a similar shade as the entrance wall, trimmed in white with historic names line the main streets of the campus. Each building has been well-kept and maintained the aesthetic of the original buildings that students and faculty 
built themselves in the late 1800s. The interior of each building has a more modern appeal from renovations and are filled on a daily basis with students who are various shades of brown and have varying accents from different cities across the United States, Caribbean, and Africa. One building in particular located in the center of campus is tall and regal with uneven stairs laid by the students who built the school in its inception. This central structure is home to the dining hall, mail room, game room, and snack bar. Students enter and exit through each door of the building dressed in their school colors. The campus is quiet and small with students and faculty walking about on a Monday morning, yet the history of each building makes the campus feel much larger.

"Monday morning the president of the university gave her State of the University address via satellite video due to scheduling obligations for an accreditation meeting. Faculty and staff across campus watched the address intently from their offices. I watched the address on my tablet from the lobby of the engineering building across the street from the arena. The president addressed students, faculty, alumni, and other stakeholders cheerfully to report the endowment and enrollment progress that has been made. The president reported that the university operating budget was $\$ 125$ million and fall undergraduate enrollment was 2,900 which was 232 students less than the goal of 3,132 students. She explained that this created a \$4.6 million negative budgetary impact. Fundraising for the university increased by 13.5 percent from 2018 to 2019 raising the fundraising for the year to $\$ 7.9$ million. The average for alumni giving at the university is 7.4 percent which is below the national average of 11 percent for alumni giving. She then charged alumni to increase their support in the next year to 10 percent to increase university rankings and grant opportunities as well as to increase academic scholarships for students at the university. Her address to alumni was sincere and direct. I observed a staff member who 
commented on how 'sad' the low level of alumni giving has been in the past and then discussed possible reasons why with another staff member and several current students. The 14-minute address then culminated with information regarding the current university priorities: 1) Increasing student retention, 2) Improve research infrastructure, 3) Renovating campus residence halls to living learning centers, 4) Leverage research to address global concerns, 5) Partner to improve community medical services, and 6) Author a new 10-year strategic plan. Athletics was not mentioned in the state of the university address.

"Across the street from the main campus, nestled in the top floor of a historic gymnasium that was recently renovated is the athletic department. Even this historic gymnasium has the red brick and white trim with modernized interior of the other structures across campus. Inside of this facility is a Hall of Fame showcasing the rich athletic prowess of many generations of student-athletes. Numerous banners, trophies, and plaques with championship accolades fill the room and glass cases. In two hallways adjacent to the Hall of Fame are the athletic personnel offices. Each door was closed and a muffled sound of phone calls, football film, and shuffling papers can be heard from the outside. Monday mornings usually start with a staff meeting to discuss athletic operations, yet this week was homecoming and that morning meeting was dedicated to the football coaching staff to strategize and plan before the big game in six days. Football coaches sat in a glass conference room with the head football coach who has a dual role as the athletic director leading the meeting. Students walked through the athletic office in team apparel and quietly said 'hello' as they passed. The office was calm and everyone who entered smiled and walked with no urgency to visit coaching and administrative staff."

This was day one of a seven-day study of the athletic department at the university that will be referred to as "Hill University" (HU) throughout this dissertation. The first day on site 
consisted of meeting with the athletic director (AD) to discuss the parameters of the study and respond to questions that he had regarding the department's anonymity and boundaries that the staff would be comfortable with. We discussed the current state of the university and the athletic department over lunch in the hotel and conference center located on the main side of campus. The AD talked about the different changes that have taken place at HU including the transition of three presidents within the last ten years. He talked about how the culture of the university and the priority that athletics receives has also fluctuated with each change in administration. The discussion over southern cuisine on the campus of this Historically Black University gave a glimpse into the days to come through observations, interviews, and photos. (See Appendix B for additional observation dates and brief descriptors.)

\section{RQ1: What resources do $\mathrm{HBCU}$ athletic departments manage?}

The Hill University athletics department currently manages all of the four critical resources central to this study. Each resource (financial, human, physical, and informational) is further explained below in addition to circumstances related to management of those resources.

Financial resources. Financial resources consist of all monetary capital that the athletics department is responsible for, including but not limited to monetary donations, budget allocations, payments received for participating in guarantee contracted games, and payments made for the purpose of operating. The HU athletics department is 100 percent subsidized by the HU general fund. This means that all money received by the athletic department comes directly from the HU general fund after approval from the Chief Financial Officer (CFO). This also means that all money received by the athletics department goes directly back to the HU general fund. The athletics department at HU currently generates revenue for the university through 
guarantee game payments, tailgating sales, ticket sales, game day program ads, and game day vendor agreements (Appendix E).

This current funding structure for the athletics department is relatively new. Prior to the newest HU President, the athletic department had a "small" operating budget (AD). Under the new President, the previously allocated athletics operating budget was redistributed to other areas of the university; the athletics department moved to a zero-dollar operating budget. This resulted in the athletics department becoming dependent on the budgetary decision-making of the President's cabinet; thus, this has also created an interesting dynamic for decision-making and management of resources in the athletic department. The Athletic Director, Baldwin, explained that the Hill University general fund provides most of the operating budget for the athletics department:

"Well, our athletic department, the whole athletic department is basically financed by the school. There are outside sources for certain instances, but the bulk, the bulk of financial needs are taken care of by the school."

In other words, the athletic department is dependent on subsidies from the university general fund to operate. Baldwin further explained the current funding model for HU athletics:

"Every single dime we get is handed to us by the university. They set our budget. As a result of that, when there are payday games, for example, we played our archrival at the beginning of the season, that check does not come to the department it goes to the university because the university at the beginning of the fiscal year gave us $x$ amount of dollars to get through the athletic season. So every time you get a payday [game] check it goes back over to the general fund." 
Baldwin's explanation of the current financial model for the $\mathrm{HU}$ athletics department explains not only the process of acquiring financial resources. He also provides insight into the additional financial resources that were received as a result of the athletic department (i.e., two contract classic games and two monetary sponsorships) yet were not allocated to the HU athletics department. To put this in to context, one of the classics in which HU participated attracted more than 28,000 fans. The HU athletic department did not receive direct revenue from this game. Moreover, $\mathrm{HU}$ average attendance at football games topped out at more than 11,000 people per game. Ticket prices range from $\$ 10$ to $\$ 25$. Thus, a home football game may generate between $\$ 110,000$ to $\$ 275,000$ in ticket sales alone. $\mathrm{HU}$ also offers car tailgating (starting at $\$ 100 /$ game), RV tailgating (\$125/game), and parking (\$10/game). At Homecoming, prices for tickets, tailgating, and parking increase. The dependence on university subsidies further creates barriers within the department such as supporting student groups. For example, Associate AD Swan serves as the Student Athlete Advisory Committee advisor and described the difficulty that financial resources cause for the student group:

"Because we don't really have financial resources in order to do things that we really want to do... We don't have it in our budget, so we have to go and do different fundraisers to try to generate revenue in order to try to generate funds." The lack of financial resources available to the athletics department is a nexus for limitations of other essential resources in the department, particularly human resources.

Unfortunately, specific and quantifiable information regarding financial resources was not made available to the researcher. While the $\mathrm{AD}$ instructed the business manager to allow the researcher access to budget and salary documents, the business manager refused. She also 
refused to be interviewed for the study after stating that she did not report to the AD, but reported instead to the HU's chief financial offer; therefore, the business manager did not have to allow access to the documents. When confirmed with the AD about who is the business manager's direct supervisor, AD stated that he is her supervisor. This disregard for AD's authority and position within the department suggested not only the dependence on resources from the general fund under the current budget structure, but also an organizational power dynamic with regard to reporting lines and decision making authority. Additionally, it illustrates the complicated relationship and reliance on human resources management as well. The following section will further explain the HU athletics department's human resources and the influence dependence has on management thereof.

Human Resources. The HU athletic department supports 12 athletic programs, 6 men's teams and 6 women's teams. There are currently 7 athletic administrators and 16 coaching staff members (Table 1).

\begin{tabular}{|l|l|}
\hline Athletic Director & $\begin{array}{l}\text { Oversees all operations in the department, } \\
\text { responsible for hiring and terminating } \\
\text { employees, and serves as the official figure } \\
\text { head for the department }\end{array}$ \\
\hline Assistant Athletic Director for Marketing and & $\begin{array}{l}\text { Oversees the marketing, communications } \\
\text { (sports information, statistics, and PR), and } \\
\text { development for the athletics department }\end{array}$ \\
\hline Director of Compliance & $\begin{array}{l}\text { Oversees compliance for all athletic } \\
\text { programs }\end{array}$ \\
\hline Academic Advisor & \begin{tabular}{l} 
Advises student athletes for six sports \\
\hline Academic Advisor
\end{tabular} \\
\hline Athletics Business Manager & $\begin{array}{l}\text { Advises student athletes for six sports } \\
\text { Manages accounts payable and accounts } \\
\text { receivable for the department. Works } \\
\text { closely with the CFO to reconcile accounts }\end{array}$ \\
\hline Manager of Facilities and Transportation & $\begin{array}{l}\text { Manages all athletics facilities for the } \\
\text { department as well as logistics for game }\end{array}$ \\
\hline
\end{tabular}


day operations

Table 1. Administrative positions and their roles within the Hu athletics department

Hill University athletics has a flat organizational structure, meaning that all employees of the athletics department report directly to the Athletic Director. AD supervises 16 coaches and 7 administrators in the department. The two academic advisors on staff have split the 12 athletic programs to each advise six programs. The advisors work with other academic units on campus to facilitate tutoring and advising needs for student athletes. Human resources for Hill University athletics is further affected by the aforementioned lack of financial resources. Because the athletics' operating budget has been reduced to zero, hiring staff to support administrative structures or coaching personnel has been also affected. AD discussed how there are limited funds to pay for adding more staff positions to his department. This has led to the AD, Assistant $\mathrm{AD}$, and several coaches serving in multiple roles within the department. For example, the AD also serves as the head football coach. The Assistant AD is responsible for marketing and communications, and has taken on the role of development as well. The head track and field coach is also on football staff, as is the head baseball coach. Two other football coaches also serve as assistant coaches for baseball and track and field.

In response to inquiry about the recruitment and hiring process for human resources, $A D$ noted: “...there are many steps that you have to take to get somebody hired. That's why it takes a while to get somebody hired, which is a concern because we're going to have to replace some positions here soon.” The athletics department must utilize the Hill University human resources department to post, interview, and hire athletics professionals. The timeline for hiring is reflective of academic schedules rather than sport career schedules, which often operate on a shorter timeline. 
Baldwin's experience with larger and better resourced athletic programs in his career give him a comparative perspective regarding human resources at $\mathrm{HU}$. He frequently mentioned the need for more staff not just at the administrative level, but also for roles directly related to day to day operations for athletic programs. He explained,

"The major resource that we're lacking is having an official grounds crew. We've got people that do the work, but are they trained seasoned grounds crew workers and that's their only job? No. Because a lot of them you'll find are doing work for buildings and grounds and maintenance. So, while they are actively over here painting the field for a game this Saturday (Figure 1), as a result of them doing that, there's probably major needs campus side that's not getting done because those same individuals double roles with buildings and grounds."

The lack of a grounds crew is particularly important to Baldwin because of his previous experiences with better resourced athletic programs that have staff who are dedicated to the upkeep of athletic facilities. He understands the specific needs of those types of physical resources and how maintenance is critical for the safety of players, but also to recruitment of players, coaches, and staff.

Concerning administrative positions, Baldwin focused on the need for more funding and noted:

"I feel like a broken record when I say this, but the athletic department needs its own development officer and that's someone to assist in fundraising needs... It could be a joint effort with capital projects, but you need a development officer that can help us with fundraising needs because our department has a zero-operating budget." 
Baldwin asserts that the current budgeting model for $\mathrm{HU}$ athletics increased the importance of a dedicated development staff member to assist with generating revenue for the department.

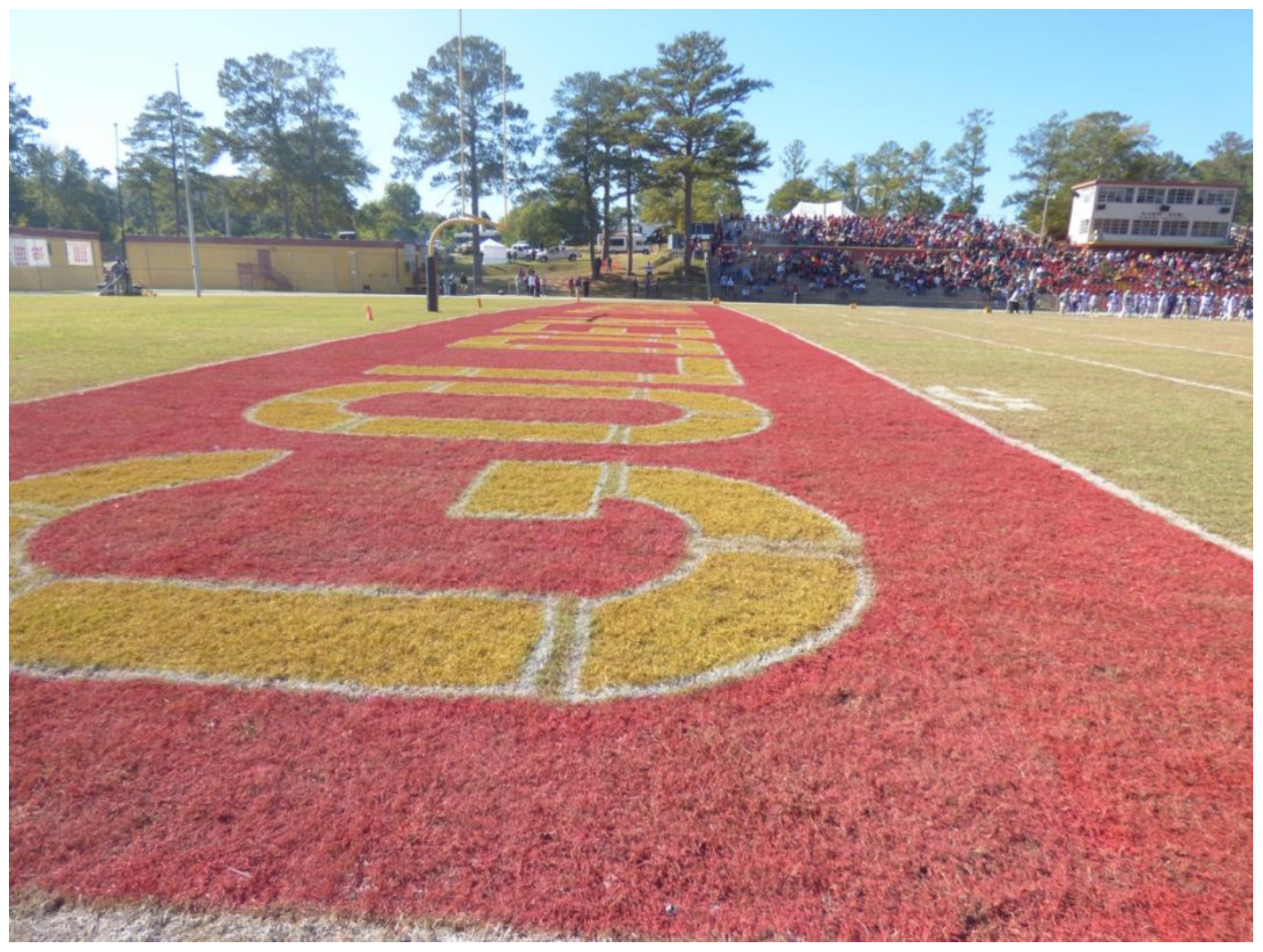

Figure 1. Field painted by university grounds crew

Swan stated that the most important resource that the HU athletic department has is its human resources. She discussed the importance of staff on ensuring student athletes have a valuable experience regardless of what other resources are available. Swan's perception of the value of human resources not only speaks to the way in which this resource is managed in the department, but also how important human resources are to the management of other resources. Swan noted, "You can have the information and finance, but you've got to have a human connection in order to make everything work together." Human resources is the "thinking resource" of this department in that staff, volunteers, and athletes perform both physical and cognitive functions for the organization. Human resources are both managed through satisficing 
and contribute to satisficing for other resource areas. The concept of satisficing will be discussed later in this chapter.

Jacob also stated that the most important human resource that HU has is students. As the video coordinator, he utilizes students to help produce video content. He also acknowledges students for their central role to the university stating:

"The most valuable resource we have on this campus is the students. The students pay tuition, which keeps the university running. More importantly, many students have workstudy jobs or volunteer their time to make the campus run smoothly. Especially events like Homecoming, which is probably the biggest money-making event and this event draws the largest crowd of any event all year."

Jacob's perspective of the important role that students play in the university as well as the department hints towards the scarcity of professional staff human resources which is often mitigated by student workers.

Professional development for employees is also affected by a lack of financial resources. When asked about specific departmental limitations affecting human resources, AD stated: "Like professional development, being able to go to, you know, go to conventions or conferences. We had some conferences that were a bit too much, too expensive for me to pay to go... So, we just had to not go. So, a lot of the football coaches didn't get to go to the football convention this past year."

AD further explained how not attending the football conference impairs his ability to recruit student athletes, stating:

“...you find leads on players in high school. You find leads on players from junior colleges. Whereas if you don't get to go, you don't even get to talk to those people. But 
that means somebody else is going to have an advantage over you because they got a chance to talk to the people that you would've gotten to talk to. And the person could be your, you know, like one of your good friends, but if I don't get there to talk to my good friend he is going to talk to his other friend."

Missing the coaching conference not only had consequences for professional development opportunities, but also for recruiting student athletes which are another valuable human resource for the department. Swan also explained the lack of professional development for administrators due to limited funds stating, "If you don't have the resources to attend, you can't attend." Thus, the lack of financial resources has limited the opportunity for professional development for both coaching and administrative staff.

Members of the HU athletics department staff stated that they feel that human resources are valuable and central to the athletics department. Limitations from a lack of financial resources are related to professional development and recruiting. These limitations affect both coaching and administrative staff for the HU department.

Physical Resources. Facilities and equipment are two of the primary physical resources managed by HU athletics. The HU department utilizes five facilities including a football stadium, basketball arena, tennis courts, softball field, and baseball field (Chart 2 in Appendix H). The condition of facilities is fair to poor and AD noted, "Nobody wants to use our facilities." Further, he stated that aside from the football field other facilities that are managed by athletics are not in good condition.

"We need to replace a lot of stuff... The track nobody can use unless they want to get a lot of shin splints. Basketball, we share the basketball arena with the ROTC and the 
armed forces and engineering... We're developing a baseball facility that hopefully we'll be able to use. We can't use it until we get a back stop up."

$\mathrm{AD}$ further explained that the arena is not under the management of the athletics department, but rather the engineering department that also holds classes and a museum inside of the arena facility. The Hill University athletic department is only responsible for the gym floor and athletic equipment such as volleyball nets, basketball goals, and the scoreboard in the arena. In short, the HU athletic department does not manage the arena space, but rather the basketball and volleyball equipment and floor for that particular facility. The only facilities that the athletic department has direct responsibility for and used for athletic competition are the football stadium, softball field (Figure 2), and tennis courts (Figure 3).

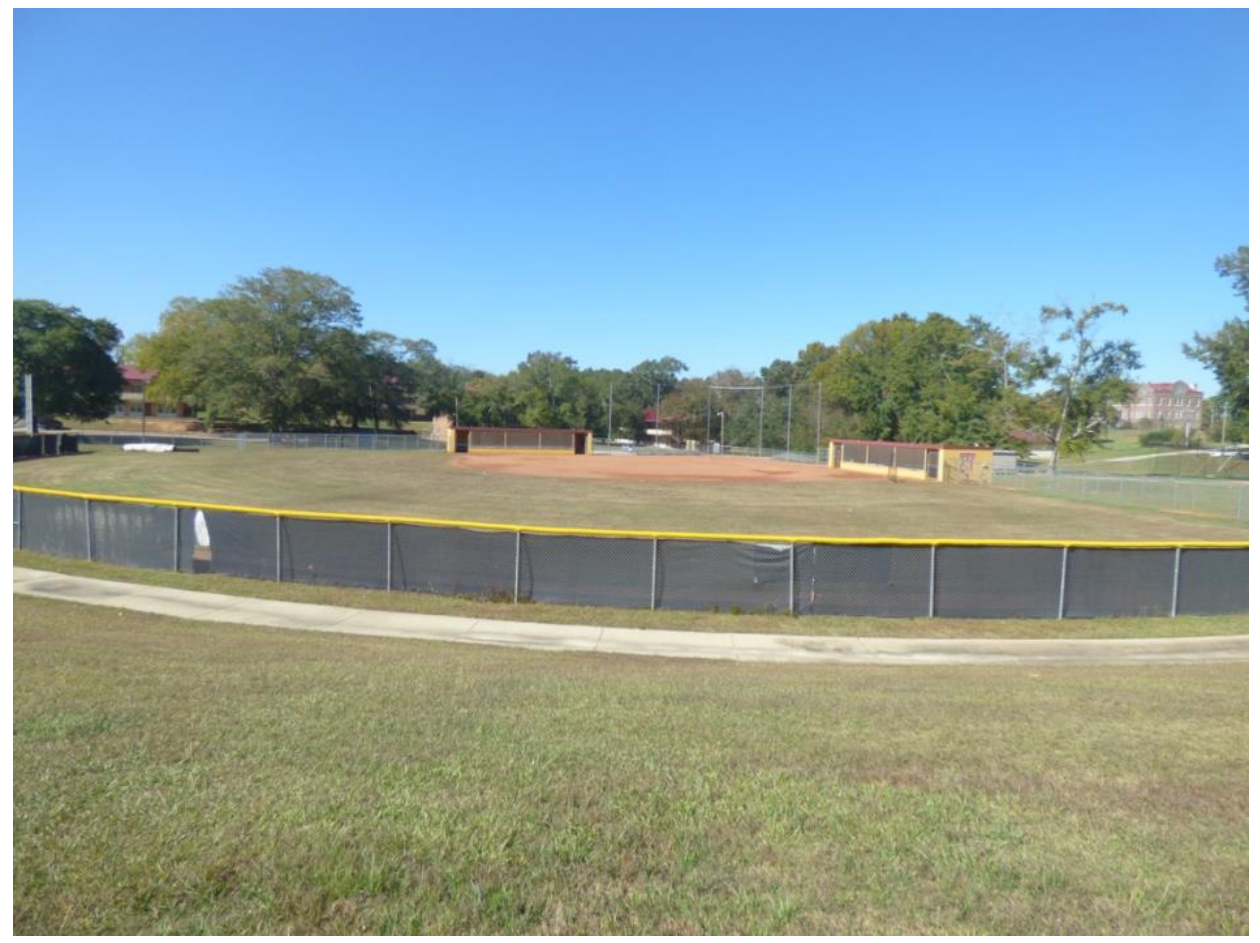

Figure 2. Softball Field 


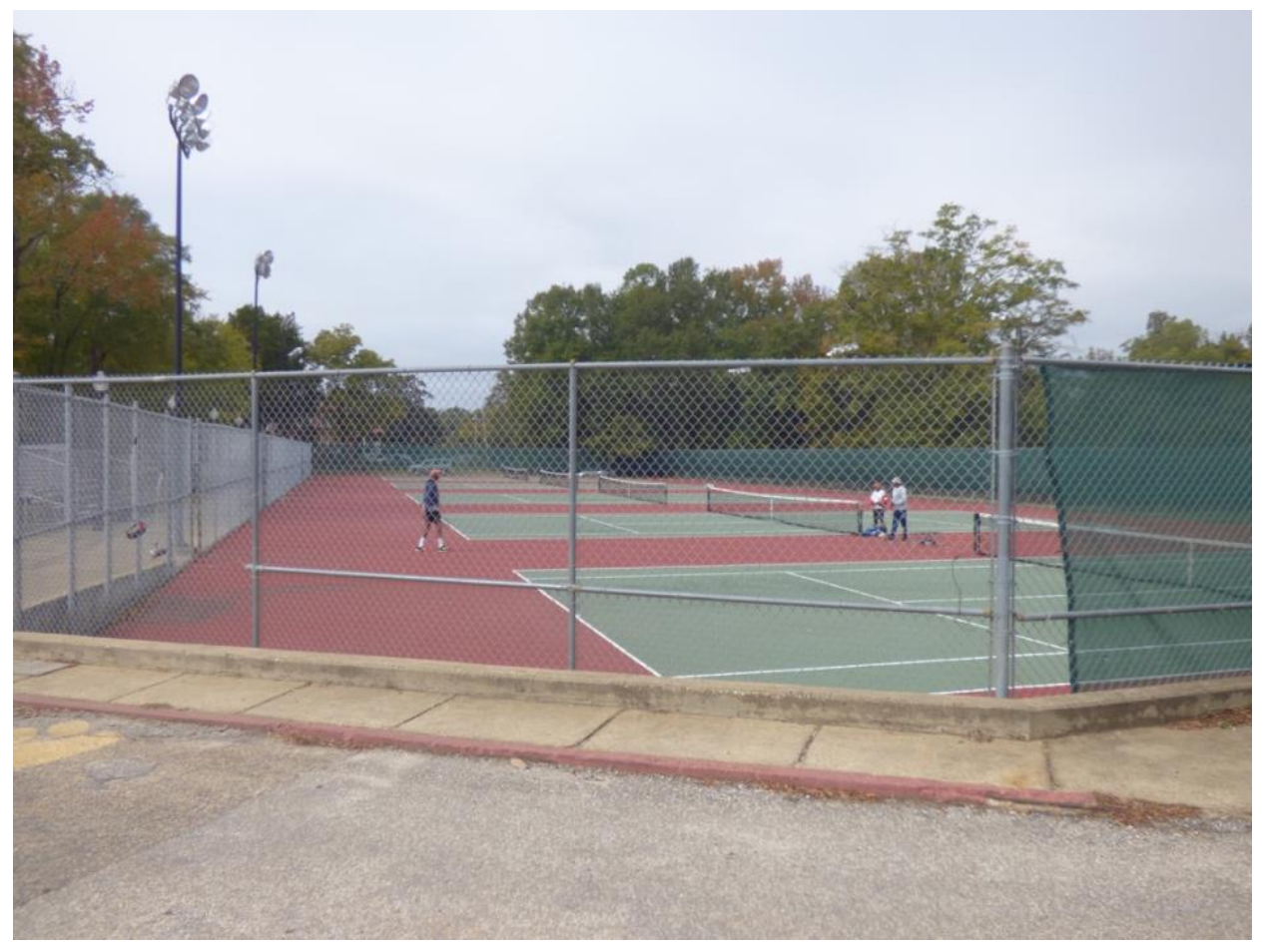

Figure 3. Tennis courts

Baldwin described the condition of facilities as being less than adequate and did not align with the nobility of the university and its reputation. Baldwin described the imbalance in athletic success and athletic facilities at Hill U noting:

"The football team is changing in double-wide trailers. If I were to tell you there's a program out there that's second in all-time wins, you wouldn't think those facilities exist. There's no way you should be second all-time with those kinds of facilities. They don't match."

In other words, Baldwin recognized the rich history not $\mathrm{HU}$ as well as the success of $\mathrm{HU}$ athletics. He expressed frustration that the facilities do not match the legacy of success. The football team locker room is located in a trailer behind the scoreboard of the stadium (Figure 4 and Figure 5). The worn, double-wide trailer was windowless. Inside, it was lined with bright red 
lockers. The locker room was formidable with a foul smell; worn uniforms and protective equipment were scattered across lockers and the floor.

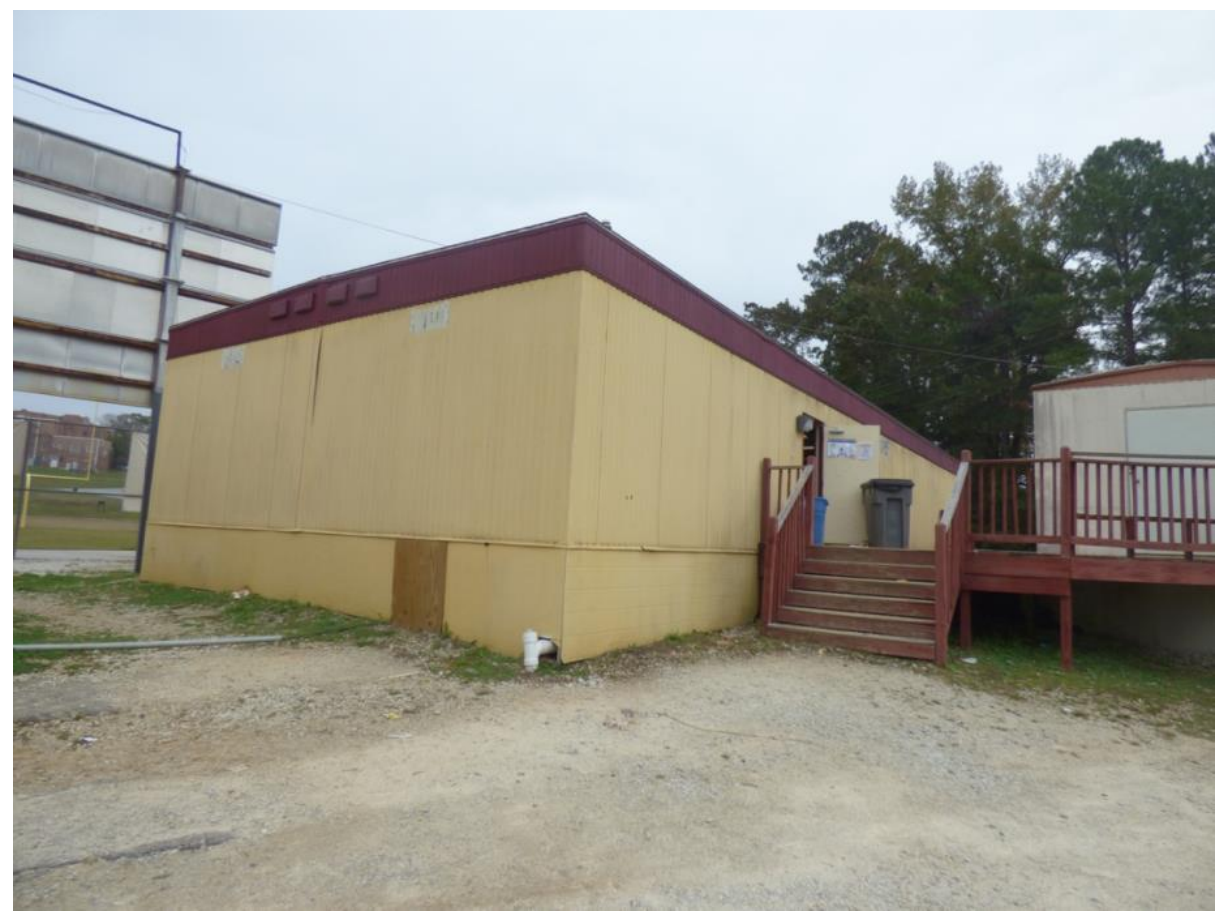

Figure 4. Exterior of the football locker trailer 


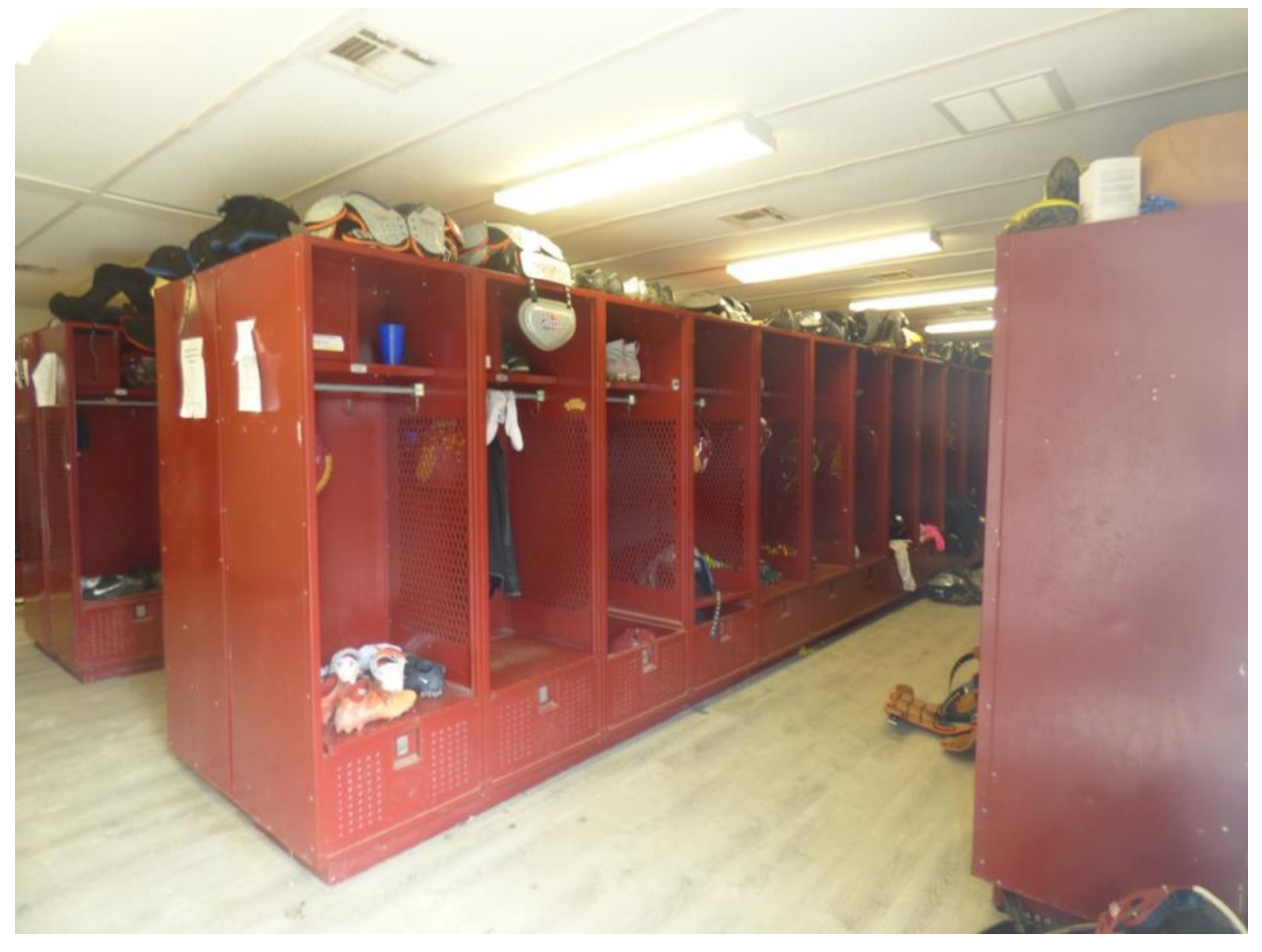

Figure 5. Interior of the football locker trailer 
Facilities in $\mathrm{HU}$ athletics are patched and painted for updates despite the looming need to replace and rebuild many of the facilities and much of the equipment. Though the current conditions are not adequate, Jacob perceived the football stadium as an important resource for HU athletics. Jacob noted: "The stadium is the key. The stadium is set up for tailgating during the game. The school makes money off parking, tailgating locations, concessions, and ticket sales. It wouldn't be possible without this facility." Though facilities have been named as a resource that the athletic department needs improvement for, the stadium was valuable to Jacob because of the revenue-generating opportunities and the experience that tailgating inside of the stadium gives to consumers (Copy of tailgate agreement explained in Appendix I). The tailgating structure (Figures 6 and 7) also add rarity to the potential competitive advantage of HU athletics.

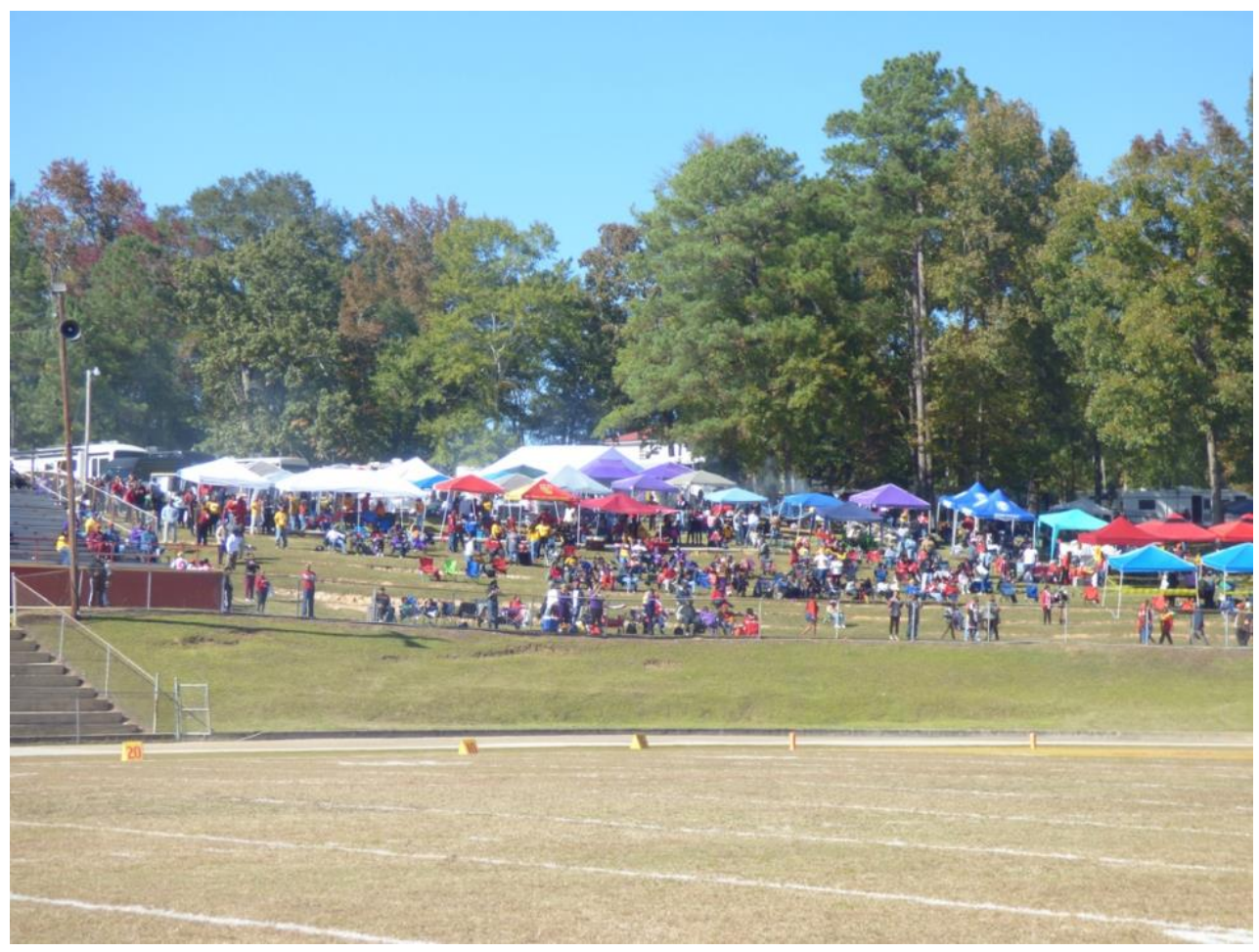

Figure 6. Photo of tailgating inside of the stadium taken by photovoice participant 


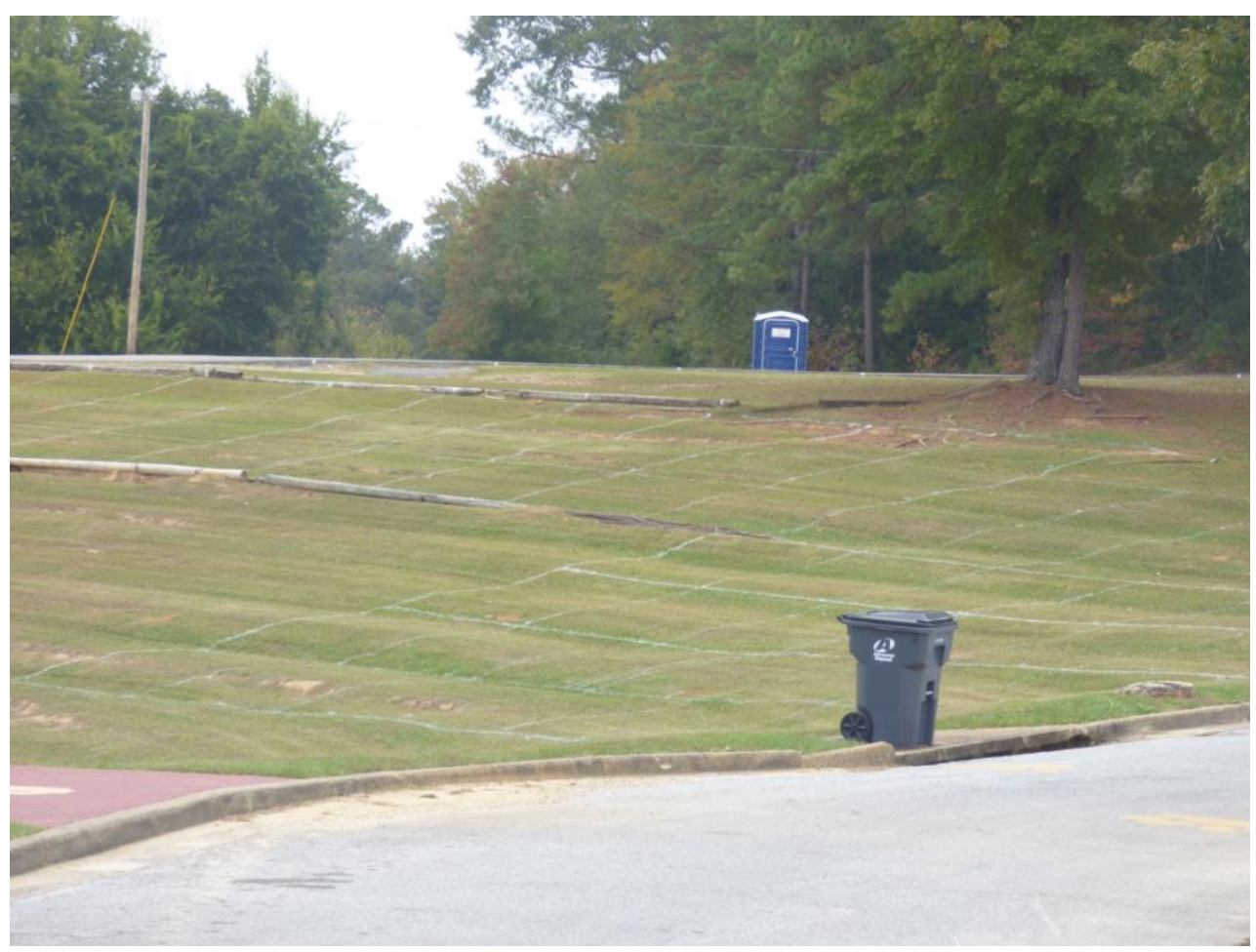

Figure 7. Tailgating markers for each section that is sold to customers

Physical Resources serve an important role in the operation of athletics programs. The current state of athletics facilities at HU are not in good condition. The use of the facilities that the department is responsible for (e.g., football stadium, softball field, baseball field, track, tennis courts) are used solely for athletic competition. The basketball arena which has shared responsibility with an academic unit is used for academic, athletics, and extracurricular purposes. The stadium has a unique opportunity for tailgating that makes the football stadium valuable and rare for the university.

Informational Resources. Informational resources are resources that an organization uses for operation that inform internal and/or external stakeholders or that provide information about the organization. Informational resources for HU athletics include the departmental mission statement, policies, procedures, and communications. All of the primary participants of the study manage informational resources. The mission statement for the HU athletics reads: 
"The mission of intercollegiate athletics at [Hill] is to provide athletic programs that contribute in an effective and meaningful manner to the achievement of the broader goals of the University. The Athletic programs should enhance the total educational experience of students, promote the retention and matriculation of students, and advance the reputation of [Hill], and cultivate loyalty and support of students, alumni and the community at large" (taken from the case site athletics' website).

The mission for the athletics department is strategically tied to the overall mission for Hill University. The mission states that cultivation of loyalty and support of students, alumni, and the community is the responsibility of athletics and for the university as a whole. Policies and procedures are not updated on a regular basis at HU. When asked about the development of policies and processes for the department, $\mathrm{AD}$ noted that he is becoming acclimated to being the athletic director for the first time in his career. AD stated "I'm just getting started as a... This is my first job as an athletic director, so we're constantly developing a process." He further discussed how he relies on Baldwin to assist with many administrative duties during the football season because of the amount of responsibility that comes with being the head football coach. AD is not absolved of his duties during football season, yet when he is away traveling with the team or actively coaching, Baldwin has administrative authority to make lower level decisions in AD's absence. Thus, formal procedures that have not been developed by leadership leaves room for a fluid management structure when $\mathrm{AD}$ is not available to make decisions, in that it allows for others in the department, particularly Baldwin, to step into a leadership role to make decisions when needed. However, this can also lead to confusion when decisions need to be made and a staff member is not clear about who has decision making authority and when. 
The dependence of human resources also calls for administrators to solicit volunteer work with managing their informational resources in the form of communications at HU. Baldwin has worked with volunteer announcers for audio streaming athletic competitions. Baldwin described the experience with having to use free labor, noting:

"We video stream all of our home events. When we're on the road we do an audio stream because again, wo don't own the rights to video stream in someone else's stadium. There was no budget when I arrived so in an effort to still give people what they want, we had to find announcers that were willing to do it for free and they did and have been doing it for three years now for free. But the downside to that, it's free, so it sounds like it in terms of quality so that was a decision that I had to make... at the end of the day there's no budget so the guys you're hearing, they're working for free. Unless you have another alternative for that, that's where we are."

The lack of human and financial resources has led to the need to outsource the production of informational resources. This is also true for the video coordinator for HU, Jacob, who manages informational resources on a regular basis. He also spoke about the importance of other resources such as human and financial to produce quality content. However, he also stated that the limitation of resources has not kept him from producing content and that he takes pride in his work. Jacob stated:

"Still my department is producing videos and other content that is valuable for teaching our student-athletes and recruiting new student-athletes through informative and entertaining videos. No one else in the [ ] conference is doing stuff like that, especially at the level and consistency that we have!" 
Jacob's optimism about the commitment to deliver a quality product despite limitations from a lack of resources hints at the thematic strategies that will further be explained in this chapter. Though limited, the HU athletics department manages financial resources that are subsidized by the HU general fund, human resources that face barriers to professional development opportunities, physical resources that are in need of repair and replacement, and informational resources that are also impaired by the scarcity of the aforementioned resources. The following content of this chapter will explain how the $\mathrm{HU}$ athletics department manages current resources as well as how administrators mitigate gaps in resources.

\section{RQ2: How are resources managed in $\mathrm{HBCU}$ athletic departments?}

Hill University currently manages aforementioned resources using several management strategies. The premise of resource dependence theory (RDT) is that organizations need resources to survive and when those resources are not available, they can obtain them from other organizations at the expense of their independence and organizational power. A secondary concept in RDT is a belief that whoever controls resources has leverage over an organization in need of those particular resources (Nienhüser, 2008). Contrary to RDT, which looks at the response to a deficit in resources, RBT examines the potential for a surplus of resources which can create or increase a competitive advantage in the market. RBT has a prescriptive nature in that it suggests that acquiring resources that are valuable, rare, and inimitable will lead to a competitive advantage for the organization. By applying RDT and RBT as frameworks of analysis, HU employed resource management strategies that emerged in the following themes: satisficing, personal attachment, and "village" benevolence (Figure 8). Each management strategy is further explained below. Each theme is supported by evidence collected on site for 
this case. This section is also divided by research question sub-questions with findings answering each question.
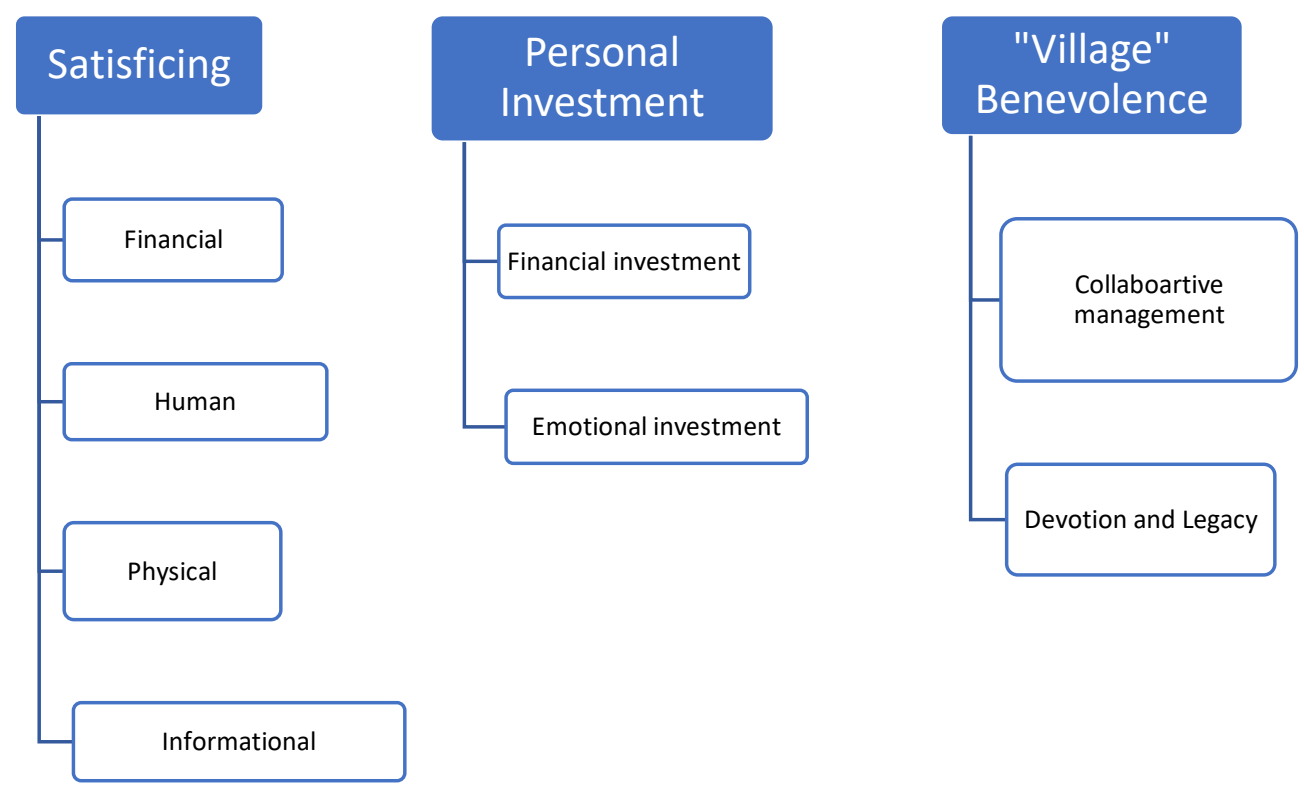

Figure 8. Three themes and elements of management strategies in this study

\section{Theme One: Satisficing}

Satisficing is a business decision making strategy in which decisions are made to reach a satisfactory outcome rather than an optimal outcome (Parker et al., 2007). Thus, this theme describes how the Hill University athletic department administrators make decisions to meet basic and immediate needs rather than strategizing for long-term optimization or a competitive advantage. Satisficing is present in the management of each of the four critical resources central to this study: financial, human, physical, and informational. Thus, this section will explore satisficing within these resource areas.

Financial Resources. The dependence on the university general fund for financial resources impacts the departmental fundraising decisions. AD described a specific time when fundraising efforts were not fruitful for the department due to the budget model that the university has set for the HU athletics department: 
"We have gotten some sponsorships, speaking about football. Like our homecoming game last year, we sponsored it out and we've used places like [redacted] and law offices here and all of those people donated money. But again, that money wasn't used for what it was raised for... We raised the money. We raised almost $\$ 40,000$ and we couldn't even use it."

Though the HU athletic department has secured sponsorships for small expenses (Figure 9), greater fundraising efforts have been thwarted by the budgeting model. Revenue generated through fundraising efforts are paid into the university general fund and then dispersed to various departments throughout the university. Money raised by the HU athletic department goes to the general fund. Rather than being able to access the funds, the department is limited to the funds allocated by the university at the beginning of the fiscal year. Because of this practice and the priority given to academics at Hill University, athletics does not receive the financial benefit of fundraising efforts. Further, the embezzlement of funds by a previous university president resulted in the athletic director advising the alumni athletic association to put a hold on fundraising for a new stadium. The controversy around money and how it is allocated has become an issue of trust between the athletics department and university leadership. 


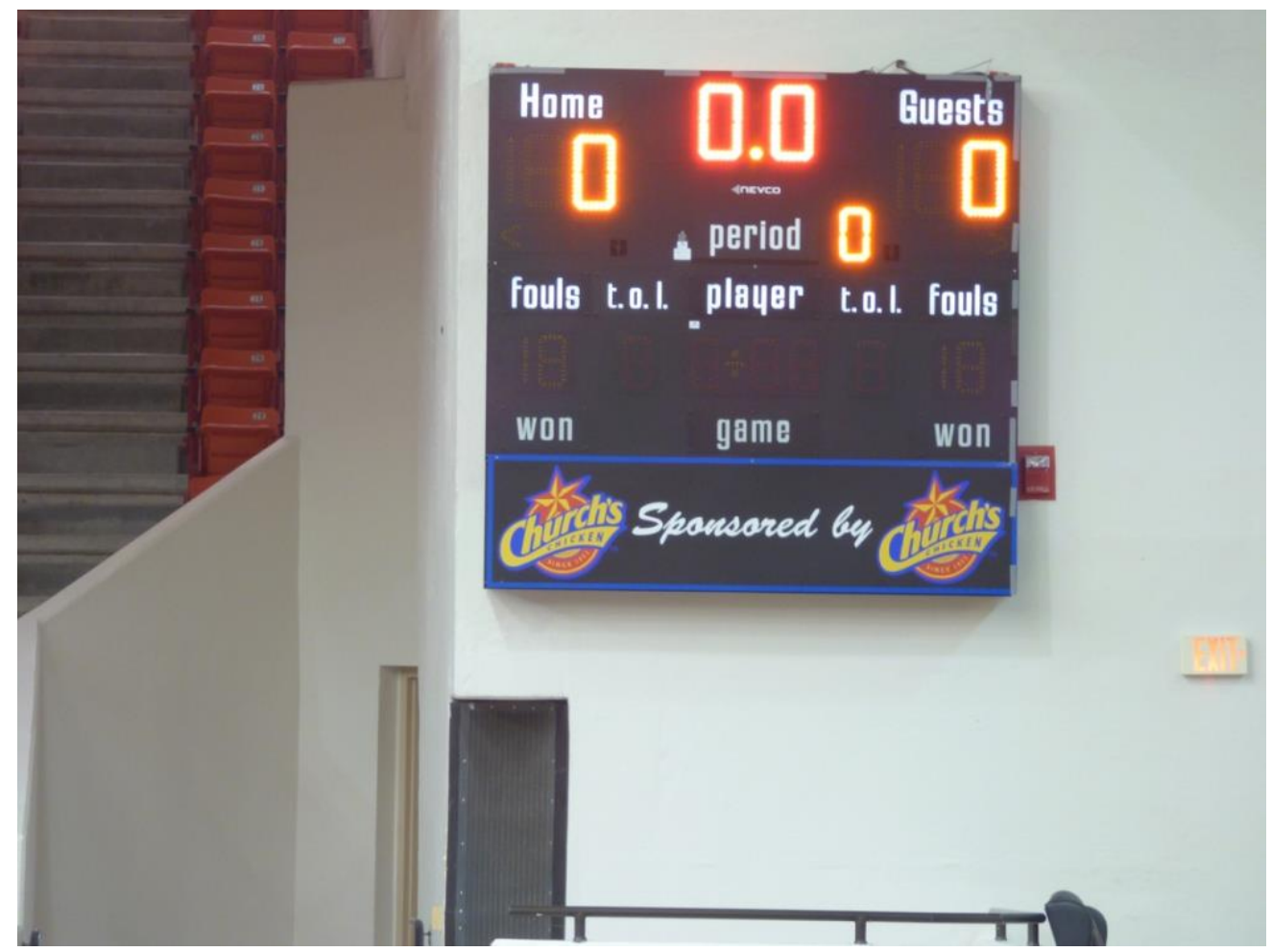

Figure 9. HU athletic sponsorship with a foodservice organization

Baldwin's role in the HU athletic department was originally focused on the marketing efforts of the department. Because of his role and the current funding model, Baldwin further explained that his role is impaired by limited financial resources. He noted, "A large percentage of what I do is affected by resources or lack thereof or trying to come up with makeshift ways in order to come to a common goal." Coming up with "makeshift" solutions to perform his role is influenced by the lack of available resources and a need to provide a satisfactory outcome rather than one that is best for the department. Financial resources in particular have influenced how Baldwin approaches his development efforts for the department which he explained by saying: "Initially it was hard because the exposure wasn't there so I had to build my own plans and come up with my own blueprints to tell people like, 'Here's your return on investment as a result of you partnering with us, here's what you can get.'... Then from a resources standpoint, you are competing against likes of an Auburn. [Hill University] 
hasn't been the high priority on that list when it's, when it's time to give monies away and partner with universities."

Baldwin's assessment of the difficulty of fundraising in a network that includes a Power Five athletic program displays the lack of competitive advantage in securing financial donations for Hill University athletics.

Human Resources. Human resources are also managed through satisficing. Staff positions are filled not based on need, but based on resources available to the department. Thus, rather than hiring more personnel, when a new need arises, HU has expanded job responsibilities of current staff. Baldwin's position has transitioned from managing marketing for the department to managing development and communications as well. When asked if the expansion comes with increased pay, Baldwin said that it does not.

Satisficing is also evident with limiting opportunities for professional development and attendance at industry conferences. When probed regarding how the lack of professional development opportunities affected the morale of the staff in the department, AD responded:

"Well, it affected us because you know, generally if we go to a football convention, we meet coaches from every level... You find leads on players from junior colleges. Whereas if you don't go, you don't even get to talk to those people. But that means somebody else is going to have an advantage over you because they got a chance to talk to the people that you would've gotten to talk to... It's really huge for us, and for us to miss it is, it's kind of a, it hurts the morale."

The decision not to attend professional development opportunities was evidence of satisficing because the satisfactory result is to save money, while a more optimal result would be the professional development of staff and the athletic programs. This satisficing strategy is 
influenced by the dependence of resources, and results in further limiting human resources capabilities.

Physical Resources. This theme of satisficing is also evident in managing physical resources such as the use and maintenance of buildings and equipment. Baldwin shared how facilities in this condition make it difficult to recruit talented student athletes who have opportunities to attend schools with nicer facilities. He noted:

"Any state school has a nice stadium. Even our rival has a nice stadium... If there was a kid on the fence between [redacted] and HU, they came to HU every time because [redacted] was playing at a stadium that belonged to the city that was a dump. Now you think you could sway that kid from [redacted] when they've got their brand new on campus stadium? No. Today's kid doesn't really know anything about history, nor do they care. They've got more bells and whistles than we do right now so that kid that's on the fence, whether he's going to [redacted] or HU, pretty good chance that he's going to [redacted]."

This strategy of satisficing not only affects the current state of facilities, but it also affects the ability to recruit talented athletes. This further affects the long-term stability of the HU athletic department.

Jacob's position with the athletic department involves the use of expensive equipment and typically also involves a team to capture and edit video content (Figure 10). He is the only full-time staff member who works in this role and he is also a part of the coaching staff for football. Jacob noted how the lack of financial resources affects the acquisition of physical resources such as video equipment and software and stated: "We do not have a lot of money to buy new equipment. By a matter of fact, we have not gotten new cameras in over six years.” 


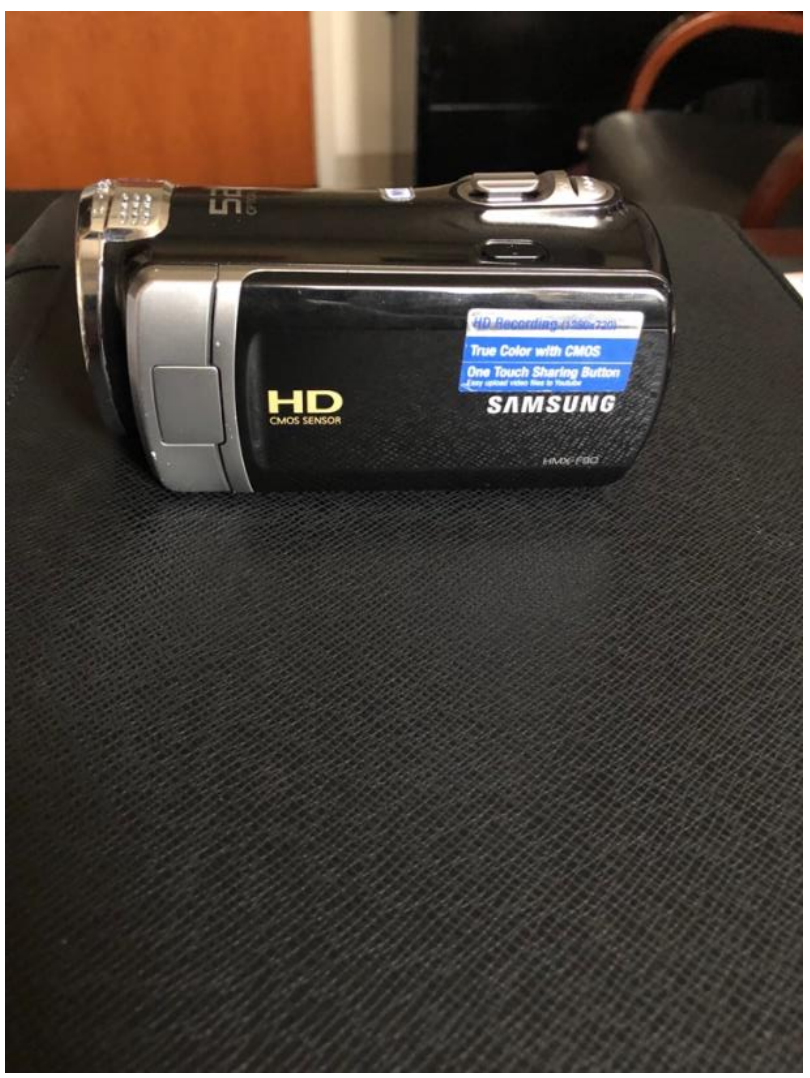

Figure 10. Currently outdated equipment taken by the photovoice participant

The lack of financial resources limits HU staff's ability to obtain updated equipment, and increases satisficing for other areas of video production such as editing. Jacob explained how he utilizes resources from academic units on campus to edit film and produce quality content.

Informational Resources. The strategy of satisficing influenced the decision to secure volunteer announcers to fill this gap in resources. Baldwin explained the decision stating, "at the end of the day there's no budget so the guys you're hearing, they're working for free. Unless you have another alternative for that, that's where we are." This quote is evidence of satisficing by making a decision to fill a gap in human resources to provide an informational resource for fans based on a satisfactory result. Baldwin was aware that the quality of the informational resource provided was not the best and stated, "the downside to that is that, it's free, so it sounds like it in terms of quality so that was a decision that I had to make." Further evidence of satisficing to 
mitigate gaps in informational resources was found in the area of innovation for the department. When asked about opportunities to incorporate new ideas for the department, Baldwin discussed his recent experiences with university leadership to update ticket sales; he suggested selling tickets online. Figures 11 and 12 show the current ticket booths for football stadium and arena ticket sales. Currently, in-person ticket sales are the only way to purchase football, basketball, and volleyball tickets. Baldwin stated:

“We need to sell football tickets online. You don't have to do it just for football. You can do it for men's and women's basketball. You can set up tickets for baseball and so forth. Do it. Just put them online. Build it and they will come. You never know who will buy it. Selling tickets online and the software, the equipment and the product itself was pricey, pretty expensive... bite the bullet, it'll pay for itself because you'll get it back in sales. It's just hard to convince them."

Baldwin's attempts at more updated practices within the department have been resisted by HU leadership who have the ability to approve changes of this nature. 


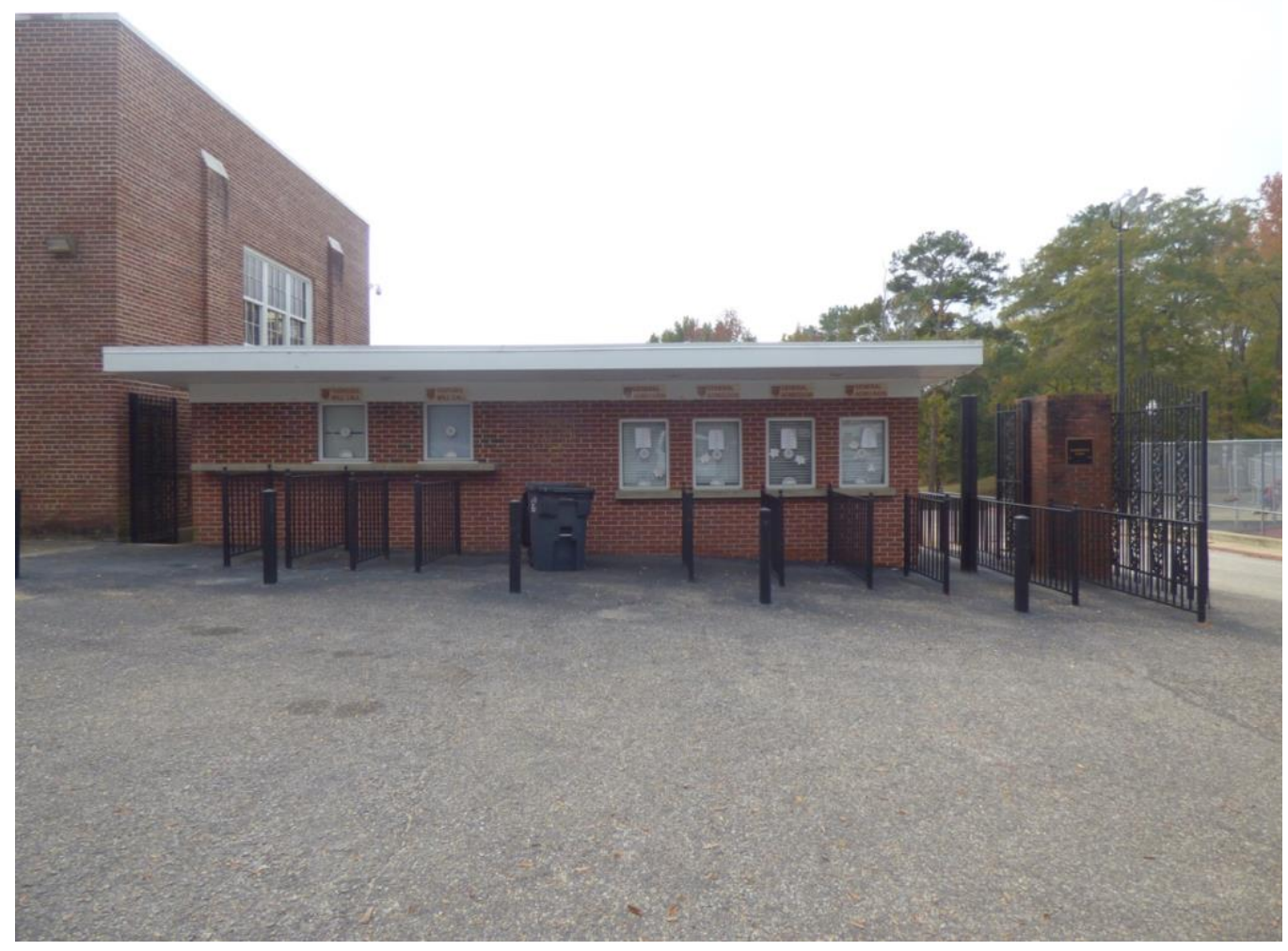

Figure 11. The current ticket box office for football ticket sales

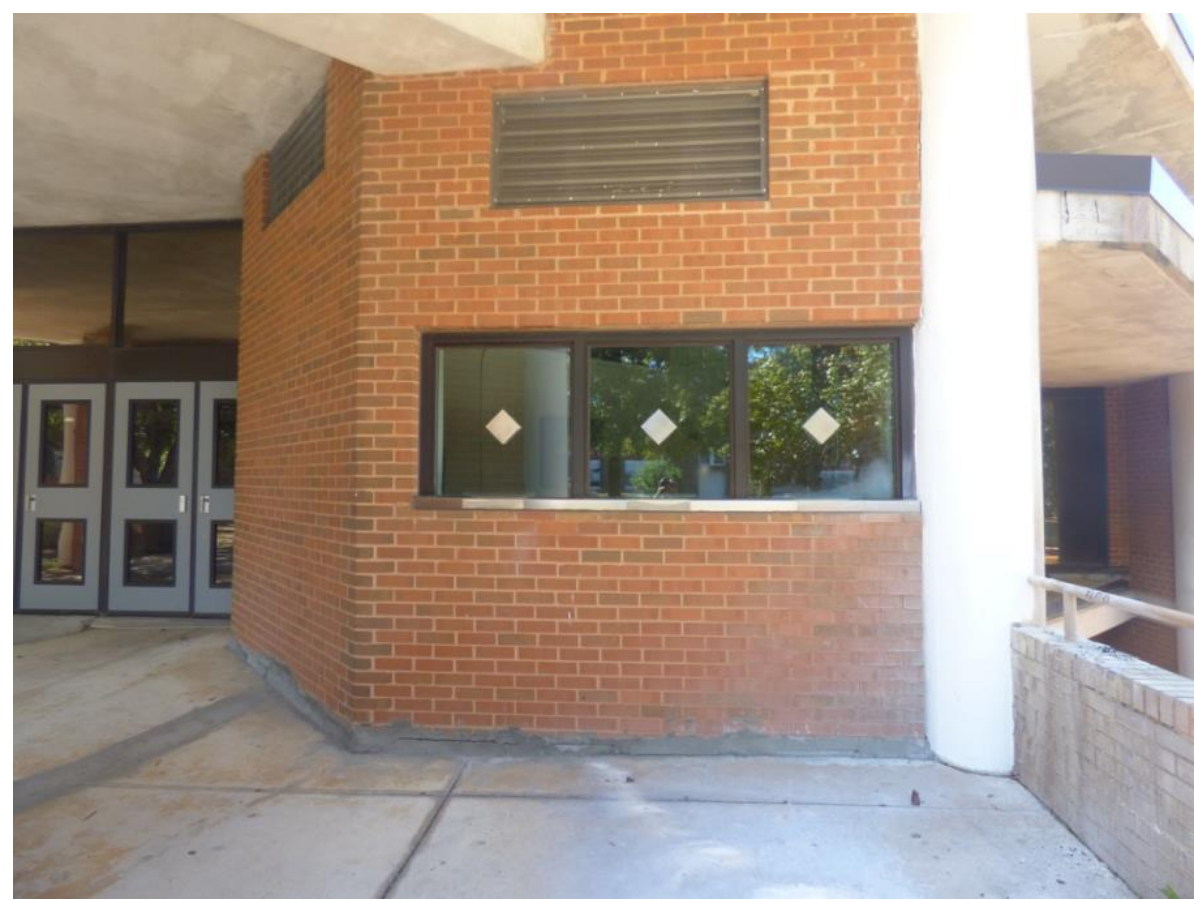

Figure 12. Photo of the ticket booth for basketball and volleyball ticket sales

Satisficing is a decision-making strategy in which a satisfactory outcome is sought rather than an optimal outcome and findings from this study show evidence of this strategy within HU 
athletics. Though satisficing is not necessarily a negative decision-making strategy, it does not consider long term needs of the organization. Thus, satisficing for the four critical resources that this department manages can impair the competitive advantage.

Theme Two: Personal Attachment. Personal attachment refers to the relationship an individual has with $\mathrm{HU}$. Often personal attachment to $\mathrm{HU}$ resulted in employment for the university. This is evidenced by the seven former student-athletes who returned to HU to coach or work in administrative positions; faculty and staff from across campus motivated to help when needed by the HU and the athletic department; and, the return of over 20,000 alumni and HBCU fans who attend $\mathrm{HU}$ homecoming every year. $\mathrm{HU}$ also had an average home football game attendance of 11,058 in 2018 ranking second of all Division II football programs in the NCAA with only three home games that season (NCAA 2018 Football Attendance Report). The largest corporate sponsor that $\mathrm{HU}$ athletics has secured is owned by an alumnus of the university. Though under-resourced, the HU athletics department serves as a hub of HBCU sport culture and has a long legacy of athletic success which can facilitate a competitive advantage in some respects. The personal attachment to the athletics department, when maximized, has helped in recruiting student athletes as well as retaining support from former student athletes.

The personal investment that was most evident in this study was the HU alumni population that works for and with the athletic department. Several coaches and administrators are alumni of HU. Many people who volunteer to work with the athletic department at HU are also alumni of the university who provide in-kind goods and services such as team meals, discounted dry cleaning services, summer football camps, and graphic design services to the athletic program. One alumni, in particular, coaches the baseball team and has used his personal funds to renovate the HU baseball field. AD describes this coach's dedication stating: 
"Well baseball is a unique situation because Coach played baseball here so he kind of... it's personal. So not only has he donated his time and his work efforts towards helping to improve the facilities so that we can practice on campus, he's also given his resources from him and his wife has given resources to also help do it."

The baseball coach's personal attachment to the university and athletic program influenced his decision to pay for improvements to the field out of his own pocket (Figure 13, Figure 14, \& Figure 15). His wife, also an alumna of HU, supported this decision because of her personal attachment to $\mathrm{HU}$, as well.

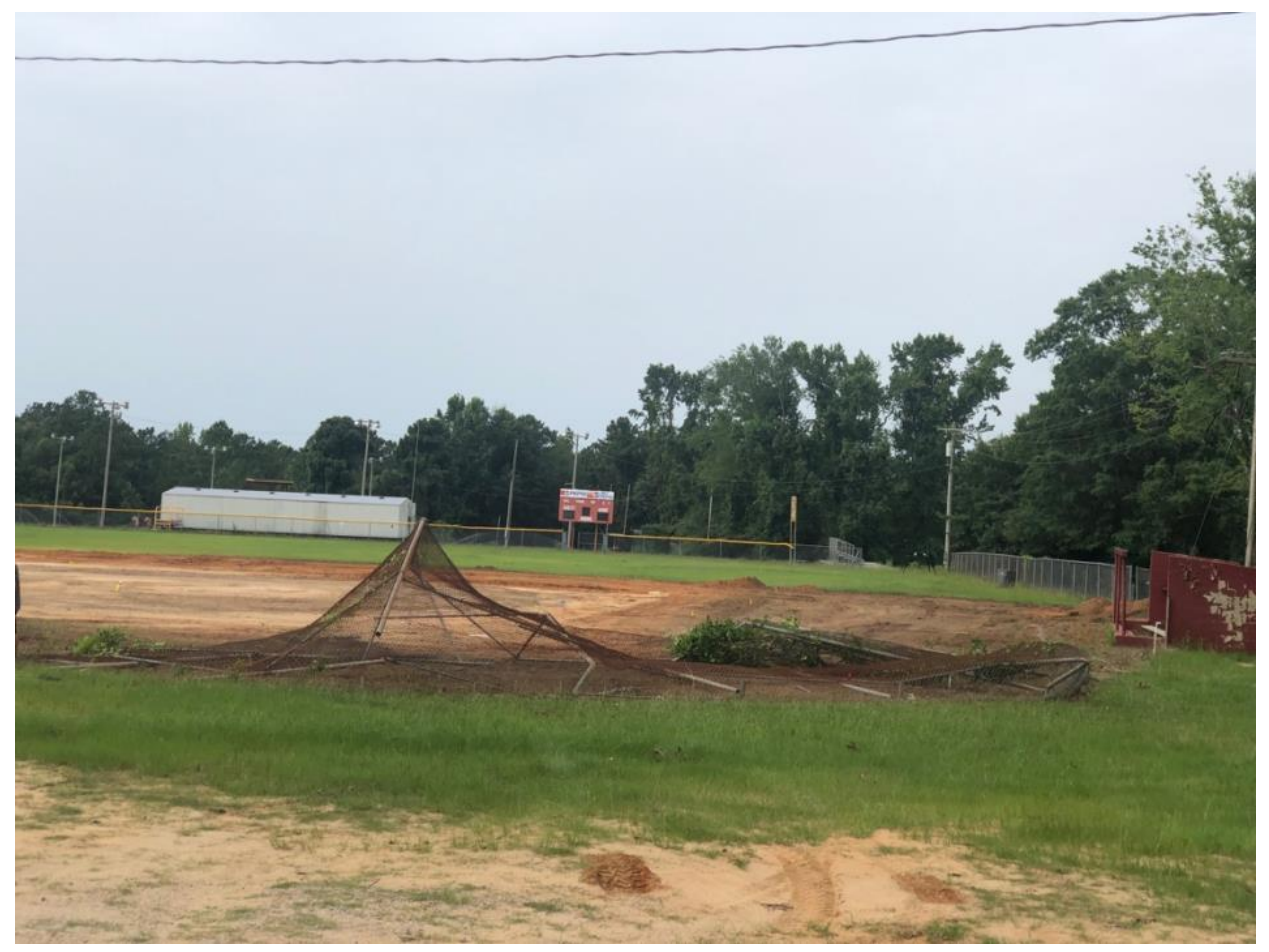

Figure 13. Prior condition of the baseball field 


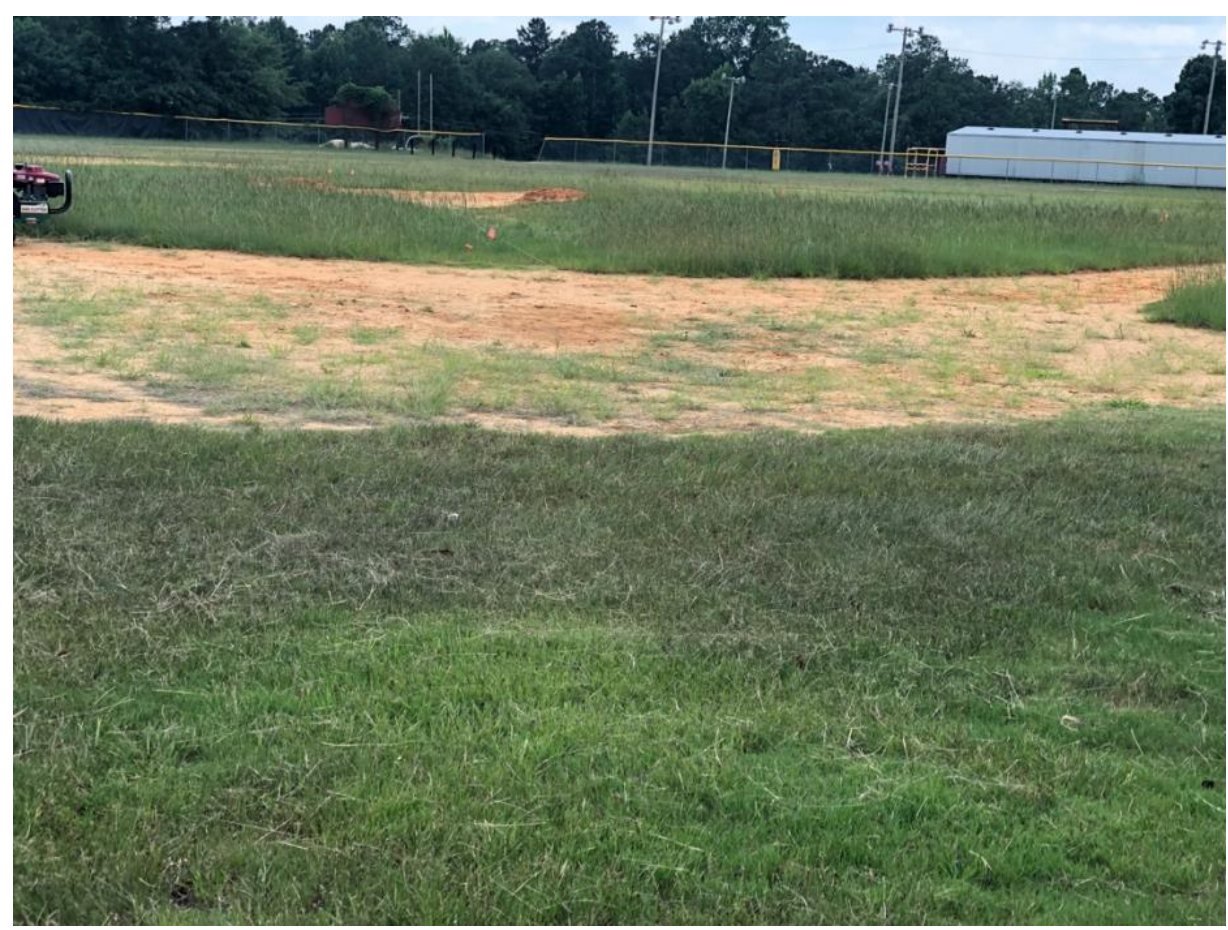

Figure 14. Baseball field prior to renovations

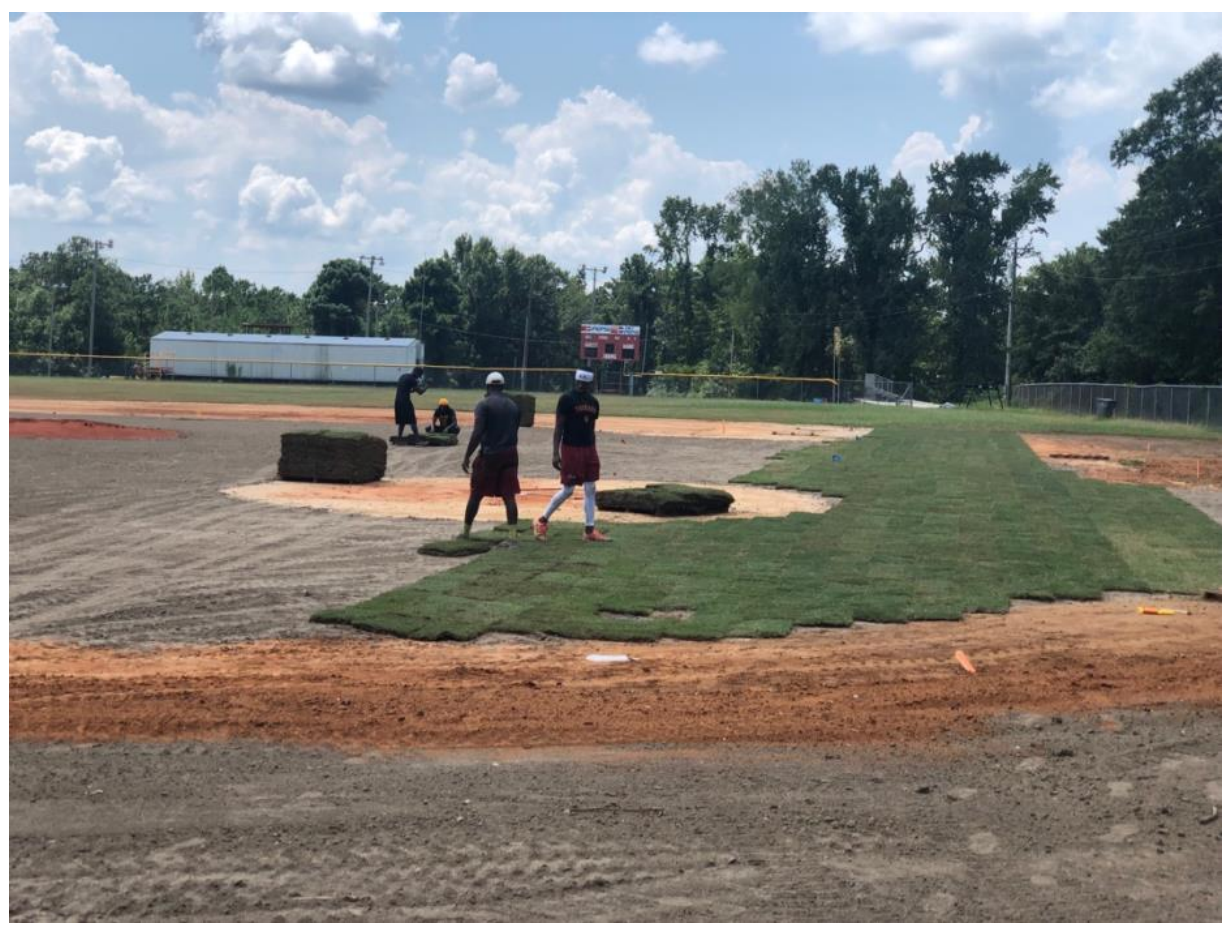

Figure 15. Staff and volunteers working to rebuild the baseball field

Baldwin further supports the theme of personal investment by acknowledging that many people have a personal attachment to HU which helps in soliciting assistance for the athletic department. Baldwin affirms, "I think we have enough people on campus that are willing to help, 
even if it's simply volunteering their time, and that's a good thing because they are people that are really passionate about this school." Many faculty and staff at HU decide to help with the athletic program because of their personal attachment to the university and the athletic department. This passionate relationship with HU is also evidenced in the attendance numbers for the HU homecoming game. Though the university student enrollment is under 1,800 , yet more than 23,000 alumni and fans attended the homecoming football game in 2019. The prior year, HU attendance was over 30,000.

Swan's father and mother graduated from Hill University. This influenced her decision to apply to work with the HU athletic department. Her attraction to work for this organization started with the legacy of her parents attending the university. She also described growing up in the same city where $\mathrm{HU}$ is located and becoming personally attached to the university at an early age. Though she did not attend the university due to affordability, she still has personal devotion to the success of the university and the athletic department because of this personal attachment to the university. Swan described her personal investment in the HU athletic department when she explained how she has had to finance fundraising efforts for the SAAC organization herself: "And so then that comes out of my pocket. And then of course I have to give what I have put into out... to reimburse myself." She spoke of this in a matter that suggests that personal financial investments in the department are a regular occurrence. She further stated, "Sometimes you have to pay out of pocket to help." This matter-of-fact statement is further evidence of her personal investment in the HU athletic department.

This theme also provides insight into the ways in which Hill University athletic administrators manage existing resources (Research Question 2a). The personal attachment of employees and stakeholders in the HU network further influences their investment of time and 
finances to the continuation of operations for the athletic department is evident throughout the data.

The HU athletics department manages four critical resources (financial, human, physical, and informational) by satisficing to meet immediate needs. This strategy is accompanied by personal attachment to the university and the athletic department which encourages employees and stakeholders to invest time, money, and other resources in the department to also meet the immediate needs of the athletics department. Personal investment and satisficing illustrated that when resources are not available for the HU athletics department, the administrators utilize what is available within their network to complete tasks and meet the needs of the department.

\section{RQ 2b: How do HBCU athletic departments mitigate gaps in resources?}

HU mitigates gaps by working with other departments and various stakeholders within the HU network when resources are not available within the department. This is evidence of resource dependence theory which states that when resources are not available within an organization, the organization utilizes external sources to fill those gaps (Pfeffer \& Salancik, 1978).

Theme Three: "Village" Benevolence. The theme of "village" benevolence is reflected in the collaborative style of management in HU athletics where members of the athletics department and external network work together to provide resources for the department. This theme provides insight into the strategy in which Hill University athletic administrators mitigate the gaps in resources. The "village" in this theme refers to employees, students, and members of the surrounding community of Hill University. This form of collaborative engagement explains the nature of collective management and supplication of resources in the department. However, elements related to the legacy of the university and the athletics department suggest an 
underlying motivation for the collaborative management of resources. The legacy referenced in the data also refers to the use of the university's legacy in order to obtain resources such as human resources or financial resources.

Legacy. AD spoke about how the legacy of Hill University is a great tool to leverage for student athlete recruitment. He uses this the legacy of HU to attract potential football players in his role as Head Coach. He described this use of the legacy of the university noting:

"Yeah we draw from the legacy and the name. And then we also draw from the student experience and student ability to get good jobs once they graduate from here. So that's what we sell. We sell all of the positive things that we can sell... we try to sell the school, the name, and the ability to get really good jobs."

$\mathrm{AD}$ uses the network of former students and football players' ability to find stable employment after graduation to attract players who would be swayed by post-eligibility opportunities. He also uses the prominence of the $\mathrm{HU}$ name to attract players who would be influenced by the prestige of the university.

Baldwin also explained his position on the use of legacy for the HU athletic department. His perspective of using legacy as an effective method to reach student athletes and potential sponsors became difficult as other institutions within the same state updated their facilities. This lag in physical updates has left legacy as a less effective way to promote the HU athletic department. This alternative perspective gives credence to how legacy may be effective until other organizations become more competitive in terms of physical resources. The historic presence of the university is not enough to attract top talent according to Baldwin. However, as stated with $\mathrm{AD}, \mathrm{HU}$ still relies on the prominence of its name and history to continue to maintain a position in the market. 
Swan described her legacy as motivation for her passion for the university. This influenced her decision to apply to work with the HU athletic department. Her attraction to work for this organization started with the legacy of her parents attending the university. She also described growing up in the same city where $\mathrm{HU}$ is located and becoming emotionally attached to the university at an early age. Though she did not attend the university due to affordability, she still has personal devotion to the success of the university and the athletic department because of this personal tie to the university.

The legacy of the university and the athletics department has been used as a tool to recruit student-athletes. Legacy has also attracted Swan to seek employment at HU. However, it is unknown how often legacy is used to attract new employees who do not have direct or personal ties to the university. It is also unknown how often using legacy is successful for soliciting donations and sponsorships.

Collaborative management. In his role as the athletic director, $\mathrm{AD}$ uses collaborative management by entrusting many decisions to Baldwin during the football season. Due to the current budgeting model for the $\mathrm{HU}$ athletic department, $\mathrm{AD}$ also collaborates often with university administration to achieve the objectives of the department. AD works with the HU leadership cabinet to ensure a great experience for student athletes and meet the needs of department personnel. AD also collaborates often with Baldwin to ensure that administrative operations run smoothly while his time is devoted to football season. AD described the collaboration stating, "Baldwin has really been the guy that's been working on that because the football part takes so much, takes so much of my time at this point." Baldwin has stepped in to cover more of the administrative tasks needed to operate on a day to day basis such as coordinating meetings, logistics, and travel arrangements in addition to his primary role of 
managing informational resources such as marketing and communications. Baldwin has served in multiple roles within the HU athletic department. As the Assistant Director for Marketing, he collaborates often with HU leadership and other staff across campus. Baldwin also collaborates with the director of marketing for Hill University to give ideas regarding athletic marketing and promotions that meet the needs of the university as well. Baldwin described one marketing collaboration and stated:

"I'll come together with the people on the university side and if there's something that I'm trying to achieve, whether it's a good idea or not or what else should we do moving forward. For example, Saturday they were naming a new mascot... so when I inquired about it, guess a light bulb came on with others and said 'Maybe we should push it out.' It's been really interactive. They asked for ideas via social media, what should we name him. People submitted names, and they put a handful of them in the pool and from that they voted on it so it's been a pretty cool gesture for them to do that."

The university received thousands of votes for the new name of the mascot. The new name was revealed at the Homecoming pre-game show and the response to the reveal was exciting. Students and fans screamed and chanted in approval of the name.

Swan's perspective of collaboration was evident in the value she placed on human resources. She stated:

"The most valuable resource I would have to say it would have to be human, because we all work together as a team to try to make everything cohesive and work... you've got to have a human connection in order to make everything work together."

The collaborative culture of the HU athletic department aligns with Swan's explanation. Many aspects of operations are possible because of how staff works together to reach a common goal. 
This strategy of management is also how HU mitigates gaps in resources in the athletics department.

As previously stated, Swan explained how she has mitigated gaps in financial resources by contributing her own personal finances. Swan has spent her personal funds to support her role as advisor for this student athlete group. She spoke about how this was a regular occurrence to pay for various supplies needed for her primary role in Compliance as well as her role as advisor. Further, Swan stated,

"Finances influence decisions that were made, because there are certain things that if you're not financially able, you cannot, we just can't fulfill... [decisions] are made on financial needs and limitations in this department. Probably on a day to day basis." This acknowledgement of the importance of finances and the lack thereof is evidence of decisions being made with a satisficing strategy.

Baldwin collaborates with departments across campus to assist with tutoring services, marketing efforts, and other logistical needs for the HU athletic department. Baldwin explained the collaboration for academic tutoring services and stated, "We've got people that provide academic services for us, whether that's tutoring student athletes, because we don't have that here anyway, so we have to rely on the university to help maintain study hall, things of that nature." In the absence of human and financial resources to support an athletic tutoring program, Baldwin collaborates with other departments across campus to mitigate that gap in resources for the HU athletic department.

Jacob works with student employees, volunteers, and other departments on campus to mitigate gaps in resources for his role as the video coordinator with HU athletics. Because he is also a part of the football coaching staff, collaborating to produce video content is important to 
his limited time and the available financial and physical resources. Jacob collaborates with students and other departments on campus to mitigate gaps in physical and human resources in the HU athletic department. He described this collaboration and said:

"Using work-study resources to pay for the labor and delivery of a great video product is unique. Like I stated before, no one else in our conference is doing this. Video Coordinators from around the league ask me how I get it done. It is as simple as getting creative with the work study group, teaching and training the students how to use the cameras and getting the post-production film editing software from a department on campus. It's a great use of university resources."

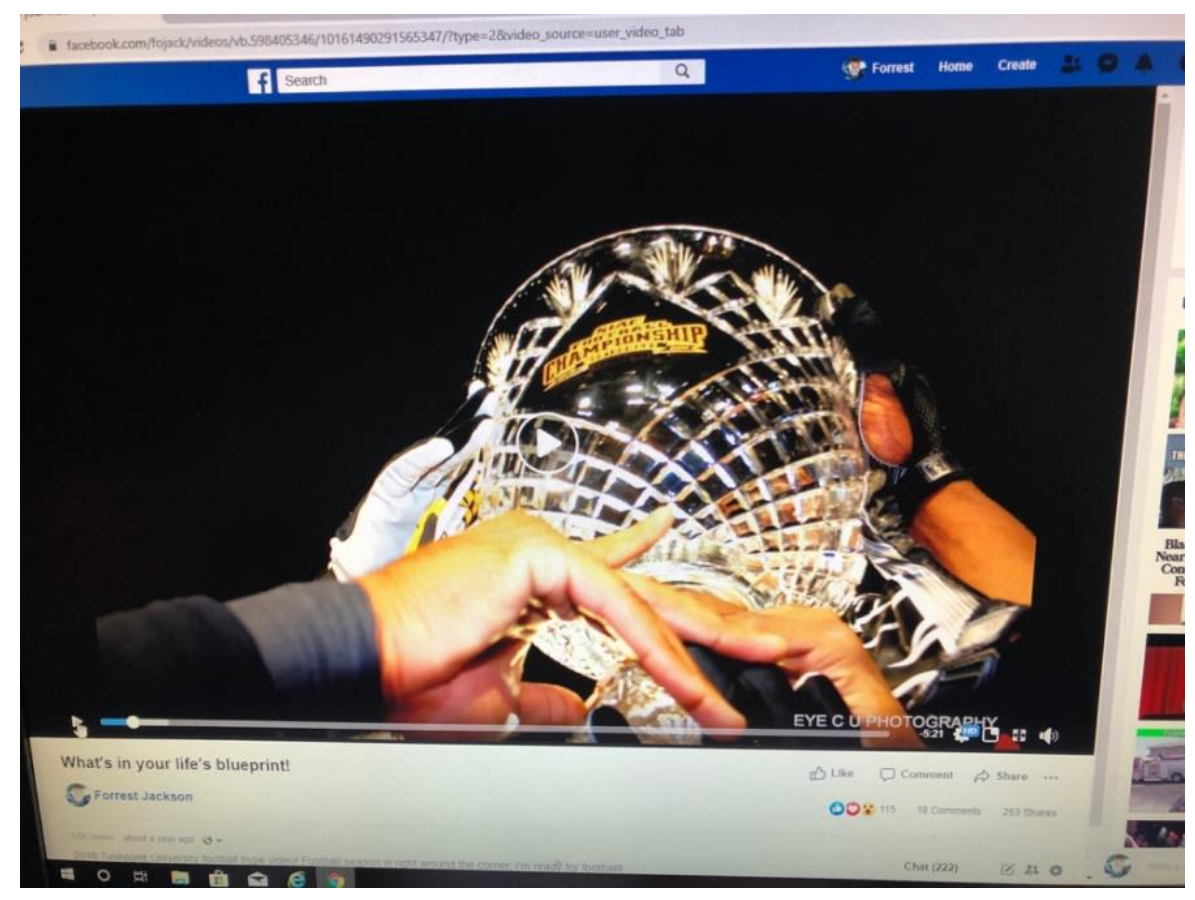

Figure 16. Photo of video content take by the photovoice participant

Jacob's description of this collaboration with students for human resources and other departments on campus for equipment is depicted in his photographic representation of a completed video product that he believes would not be possible without using the resources that are available within his environment at HU (Figure 16). 
"Village" benevolence is a management strategy that has helped HU athletics fill gaps in resources for an unknown number of years. The department has done well collaborating with several departments on campus for equipment and volunteers as well as throughout the local community and alumni network. The major assumption of RBT is that organizations rely on tangible and intangible resources to operate. This management strategy has integrated HU's tangible and intangible resources to fill gaps and continue to operate as an athletics department.

\section{Summary}

The findings from this study suggest that the availability of resources or lack thereof influences management strategies for the HU athletics department. Hill University is faced with a predicament of extremely limited financial resources that also contribute to the limitation of other critical resources for the department. The themes that emerged related to this analysis of the HU athletic department are satisficing, personal investment, and "village" benevolence. Each theme gave a glimpse into the inner workings of the $\mathrm{HU}$ athletic department, the management of existing resources, and the acquisition of resources that are not available within the department.

$\mathrm{HU}$ athletics department is responsible for the management of the four critical resources - financial, human, physical, and informational. Of those four critical resources, financial resources influence the management of the other three resources. To manage those resources, participant responses suggested satisficing as the decision-making strategy. That is, decisions are made to maintain the day to day operations of the department, but may not be ideal decisions for student athletes or other athletic department personnel, facilities, or in cultivating informational resources. Personal attachment to the university and/or athletics department compelled staff and volunteers to invest their time, resources, and personal finances to meet the immediate needs of the HU athletics department. In order to mitigate gaps in financial, human, informational, and 
physical resources, a collaborative culture is used in which people within the university network work together to meet the needs of the department. Findings from this study confirm the resource dependency theory in that it clearly shows that an organization needs resources to survive and when those resources are not available within, the organization will seek resources outside of the organization. This study also confirms the second tenet of RDT with evidence of a loss of organizational power due to a dependence on the HU general fund to operate.

The following is an excerpt from observations gathered from the researcher while on the campus of Hill University in November 2019:

On the day before the data collection process ended, I watched the clock run down in the fourth quarter of the homecoming game between $\mathrm{HU}$ and a rival $\mathrm{HBCU}$. Though $\mathrm{HU}$ was losing, the fans and students did not seem to be troubled, but instead laughed and hugged while holding red cups and plates of food from various tailgates. I realized that I did not witness fans watching a rival game, but a family that was proud of each other even in failure. The presence in the stadium was not of football fans, but of cousins and aunts and uncles who shared pride in the same institution and returned simply to bask in the familiarity of a place that felt like home with people who shared the same culture and experiences. Though lacking in most of their critical resources, one resource remained strong at $\mathrm{HU}$, the culture. 


\section{CHAPTER V}

\section{DISCUSSION}

Many HBCU athletic departments, including the one examined in this case study, have managed to remain somewhat stable despite the limited resources that they have available to operate. The growth of HBCUs in the opposition of Jim Crow Laws and unequal government funding was difficult but successful. Their focus on the cultural experience has branded them exciting and inviting to many Black sport consumers. However, competing with larger and better funded athletic programs for athletic talent halted much of their rapid growth (Cavil, 2015). Along with "new" and unbalanced competition, came the stress of balancing annual budgets with a minimal influx of financial resources. Therefore, the purpose of this study was to explore resource limitations, allocations, and decision-making practices of HBCU athletic departments stemming from a shortage of critical resources.

For this study resource was defined as "inputs to the production process" (Grant, 2001, p.118). For the purpose of this study, the collection of productive resources in management was divided into four main categories: financial, human (administrative and coaching staff), physical (facilities) and information (policies and knowledge). This study employed two theoretical frameworks: resource dependence theory (RDT) and resource based theory (RBT). RDT was used to analyze the strategies and practices stemming from a lack of resources. RBT was used to analyze the existing resources, strategies, and gaps in resources in order to develop better strategies. This investigation explored the relationship between resources and how HBCU athletic departments operate with limitations or an abundance of resources. This qualitative study 
sought to answer the following research questions: 1) What resources does a HBCU athletic departments manage? 2) How are resources managed in HBCU athletic departments? To further analyze how resources are managed in HBCU athletic departments the following sub-questions were developed:

a. How do HBCU athletic departments manage existing resources?

b. How do HBCU athletic departments mitigate the gaps in resources?

The themes that emerged from the data came in the form of management strategies that HU uses including Satisficing, personal attachment, and "village" benevolent management. This final chapter includes a discussion of these major findings related to the management of critical resources for HBCU athletics, as well as implications of the results from both a theoretical and practical lens. Also included is a discussion about the connections to this study and RDT and RBT theories. This chapter concludes with a discussion of the limitations, recommendations for future research, and a brief summary.

\section{Interpretation of the Findings}

RQ 1: What resources do HBCU athletic departments manage? The resources that the Hill University athletics department manage are financial, human, physical, and informational. While it is not unique for an organization to manage these resources, the ways in which HU manages said resources, as well as the dependence on certain resources, is specific to this particular case. HU athletics administrators have found ways to extend limited resources which is further discussed in response to research question one.

Financial Resources. For the purpose of this study, financial resources consisted of all monetary capital that the athletics department was responsible managing, including but not limited to: monetary donations, budget allocations, payments received for participating in 
guarantee contracted games, and operating expenditures. $\mathrm{HU}$ athletics has a zero-dollar operating budget; they are 100 percent subsidized by the HU general fund. All departmental salaries and expenses are paid from the HU general fund. Though this is not uncommon for an athletics department to be fully subsidized, the ways in which allocations are made back to the department are of great concern. A private institution which depends more heavily on donations and fundraising efforts may prioritize other university units before athletics more often than public institutions because those areas may be perceived as having high importance to the stability of the institution (Pfeffer \& Davis-Blake, 1987). The allocation of funding from the general university budget can possibly be tied to how important a university deems its athletics programs. This may explain the allocation of funding for HU's athletic programs.

All of the financial resources that the athletic department receives from external donors, sponsors, and guarantee contracts for classics are submitted to the general fund and then reallocated to the department based on need. It is important to note, however, that financial resources secured by the athletic department are not necessarily reallocated in total. In other words, if a donor makes a contribution of $\$ 40,000$ to the athletic department, the athletic department may only receive a portion of those funds. This limits the athletics department not only from a financial standpoint, but if donors give funds for a specific purpose and that purpose is not fulfilled, the donor relationship can become strained (Cohen, 2008; Stinson \& Howard, 2004). Thus, it is important not only for the athletics department but also for the university to honor the commitments made when soliciting all donors for the university. Also of concern for the university and athletics department alike is the potential to maintain the prestigious brand and legacy that HU has managed to build since its inception. This includes the condition of all aspects of operations not just academics. The HU football program is ranked second in 
attendance at the NCAA Division II level. Many patrons attend games and the conditions of athletics facilities is a part of the larger HU brand that many external stakeholders have more immediate access to than academic units on campus. Thus, it should be of more priority to reallocate funds to the athletics department. Finally of concern, is the lack of trust that has emerged from the current budgeting model in which athletics has worked to raise funds and then not seen those funds reallocated back to the department. The lack of trust has affected the AD's perception of the university's leadership. AD stated that not seeing the money that is raised for athletics be used for athletics purposes has made him not want to raise any more money. It has even halted the support he has given to the alumni association who started a capital campaign to raise money for a stadium. This lack of trust in the financial system in place at HU has now rippled to alumni donors who have organized to help increase financial resources. Thus, the current allocation model creates an issue for both the athletics department and university as a whole.

Though they do not manage financial resources directly, administrators in HU athletics manage requests that are submitted for additional funds. For example, when teams must travel for athletic competition, the coaches submit travel requests which are organized by the department's Office Manager and then sent to the CFOs office for approval and disbursement of funds for each specific travel expense such as hotel accommodations, buses, and meals. Thus, financial resources are managed indirectly through the office manager who reconciles with the CFO of the university all requests that are made for the operation of the athletics department. Saidel (1991) referenced three conditions of resource dependence between the organizations and the governing agency: importance, availability of alternatives, and "ability to compel provision" of resources. In terms of the availability of alternatives, dependence decreases when there was an 
alternative available in the exchange network. However, for $\mathrm{HU}$ athletics, administrators have found alternative sources of financial resources, and the university leadership has reinforced dependency by creating a budgeting model in which all accounts receivable go into the general fund rather than to the department. Thus, in this case with this particular budgeting structure, it is much more difficult for the HU athletics department to lessen dependence on the university general fund.

The concern with this budget model is the centralized management structure which has limited decision-making for the athletics department. This model has also caused disregard for the organizational structure of the athletics department as evidenced with the office manager who stated that she reports to the $\mathrm{CFO}$ and not the $\mathrm{AD}$ who is her actual direct supervisor. While the disadvantages of the current budgeting model presented itself in the data, there is an opportunity to better exploit this structure. For example, the AD currently does not have trust that the $\mathrm{CFO}$ will prioritize the athletics department in financial allocation decisions. However, should the relationship between the $\mathrm{AD}$ and the $\mathrm{CFO}$ become more collaborative in nature rather than an ask and receive relationship, there is opportunity for athletics to increase priority in allocation decisions. This will also allow the athletics department to increase the organizational power that they currently lack (Hillman, Withers, \& Collins, 2009)

The zero-dollar operating budget was implemented when the new president came to HU in 2018. This relatively new model for the HU athletics department has caused a ripple effect of limitations for other resources as seen with the conditions of athletics facilities, limited human resources, and professional development opportunities. While this model has created limitations for athletics, it has provided more financial resources for other areas of the university when revenue is generated. Pfeffer (1987) suggested that organizations attempt to decrease their 
dependencies or work to increase another organization's dependence on them. In this case, Hill University is dependent on the revenue of the athletics department. In other words, they use money generated by the athletics department to support other areas of HU. This, in turn, makes the athletic department more dependent on the University. Rather than decreasing dependencies, HU has developed a structure in which the University at-large and the athletic department must depend on each other for survival.

In an effort to reduce costs associated with athletics, Albany State University, a Division II member institution in the same region as $\mathrm{HU}$, recently moved to a similar budget realignment model and expects to save $\$ 600,000$. According to the 2019 NCAA Division II Census, 36 percent of athletic administrators believe that their institution has allocated adequate financial support for the athletic department to operate effectively. Thus, HU is not in an extraordinary position with the lack of financial resources available to them from the general fund nor with their current budget model. Still, the HU athletics department must rely on the HU general for its budget. This does not allow the $\mathrm{HU}$ athletic director to be proactive in reducing the unreliability of dependencies on the University as suggested by Malatesa and Smith (2014). That is, the athletic director is at the mercy of the financial managers at $\mathrm{HU}$ to make decisions for the University, which also includes the athletics department. Any financial mismanagement at the university-level could be catastrophic for the HU athletics operating budget.

The limitations of financial resources and authority over financial decisions also affects management of other resource areas including human, physical, and informational. Consequently, finances became central to this study due to effects on the acquisition and management of other resources. This also confirms much that is believed about HBCU athletic programs lacking financial resources; however, the creative ways to manage resources that are 
available shed new light on how HBCU athletic programs continue to survive in the NCAA when revenue is scarce. Those creative ways to manage $\mathrm{HU}$ resources will be discussed later in the chapter. Though this limitation of financial resources has created difficulties in managing the athletics department at $\mathrm{HU}$, it has not yet impaired operations enough to create compliance or other legal issues like it has for other schools in a similar situation.

Human Resources. Human resources include all employees, volunteers, and athletes as well as their varying forms of human capital for the $\mathrm{HU}$ athletics department including their skills, judgement, and competencies. Black men and women make up 10 percent of Athletic Directors in the NCAA. Of that 10 percent, 40 percent are from HBCU athletic programs. NCAA affiliated HBCU athletic programs also employ 33 percent of all Black head coaches. The total representation of Black head coaches in across NCAA divisions is only nine percent; that percentage falls to 6 when excluding HBCUs. Though HBCUs offer great opportunities for career advancement for Black intercollegiate sport professionals (Cheeks \& Crowley, 2015), HBCUs have struggled to attract and retain top coaching and administrative talent. This is often due to lower wages, higher workloads, and less resources to complete tasks within roles (Cheeks \& Crowley, 2015). Hill University is no different in terms of higher workloads and less resources to complete tasks within their roles. HU's athletic department has seven administrators, 16 coaching staff members, and student athletes in 12 athletic programs (six men's teams and six women's teams). Human resources are dynamic in that they are able to both think and perform in their roles. Employee competencies and skills are important to an organization suggesting that human resources play a prominent role in operations for organizations (Pesic, Millic, \& Stankovic 2012). 
The primary limitation of managing this "thinking" resource was the lack of professional development opportunities. This particular resource is also considered human capital. Human capital is a concept that calls attention to the learning capacity for human resources within an organization which adds value to the organization through knowledge and skills (Nafukho \& Brooks, 2004). HU should consider human capital in the organization as an opportunity for improvement of the dynamic capability of the athletics department. Increasing opportunities for professional development in turn improves the viability of the athletics department as employees learn new skills and have a stronger knowledge base of current industry standards (Dobbs et al., 2008). This increase in skill development also contributes to productivity within the department (Dobbs et al., 2008). Thus, prioritizing professional development for the staff of the HU athletics department further increases the competitive advantage and stability of the department (Hatch \& Dyer, 2004).

The resource based perspective challenges us to consider how human resources create a competitive advantage by being valuable, rare, inimitable, and organized (VRIO) (Wright \& McWilliams, 1994). While it is difficult to specifically quantify the value of human resources, one would argue that human resources create value for the firm through their contributions (Wright \& McWilliams, 1994). Human resources also provide a competitive advantage through the rarity of their competencies and skills. While an individual employee may not have a set of unique skills, the combination of several employees can provide the rarity needed for an organization's competitive advantage (Barney \& Wright, 1998). HU has an opportunity for a competitive advantage because the ways in which they work together, varying experiences and expertise, and the combination of their skills can serve as a rare resource for the athletics department. Social complexities also provide the inimitability of human resources, particularly in 
HBCU athletics given the long history that they have in the United States of providing educational and athletic opportunities to Black athletes and career opportunities to Black sport professionals (Cavil, 2014). However, without continued professional development, HU athletics staff lack the organization principle of the VRIO (value, rarity, inimitability, and organization) model because they are not being cultivated in the best way. Therefore, professional development can help HU athletics staff members strengthen their skills creating a competitive advantage for the department.

Physical Resources. Facilities and equipment fall under the resource category of physical resources. The HU athletics department manages four athletic facilities and is responsible for athletic equipment and the floor for the university arena. The shared responsibility of managing the university arena has worked in favor of the athletic department in terms of having a facility that is mainly the responsibility of an academic unit on campus in terms of updates for such a large facility. However, the state of other athletic facilities is inadequate and limits HU's ability to compete with other athletic programs for recruiting student athletes. Huml et al. (2018) found that institutions benefit from direct improvements to facilities in terms of recruiting prospective student-athletes. The same study also found that the perception of athletic performance was connected to facility improvements. In the case of $\mathrm{HU}$ athletics, many improvements are needed to not only advance recruiting athletes but also to increase perceived value of the athletic program (Martinez et al., 2010).

Where HU was once able to recruit student athletes based on their legacy alone, the legacy is no longer enticing when many athletic programs have updated and better equipped facilities. Because HU is also at the Division II level of the NCAA, they have a limited number of athletic scholarships to serve as incentives for signing with their athletic programs. Thus, 
having nicer facilities may be an even more impactful way to entice student athletes who are influenced by such physical resources. The athletic alumni association which is organized by former student athletes understand the importance of facilities for the HU athletics department. This particular group has worked on a campaign to rebuild the football stadium and field house with better locker rooms. This effort has been thwarted by AD's frustration with the current budgeting model, however, because all monies that are raised and given to the athletic department goes into the general fund leaving little for the athletics department to afford the stadium renovation. Should more priority be given to the athletics department for this renovation, the opportunity for a competitive advantage can be restored for recruiting athletes in the one sport that generates revenue in the department.

Informational Resources. Informational resources for HU athletics include the departmental mission statement, policies, procedures, marketing, and communications. The shortage of human resources provides further limitations to the management of informational resources. The HU athletic department has one administrator responsible for marketing, development, and communications for the department. His role with multiple responsibilities aligns with previous findings that many HBCU athletic programs do not have a dedicated marketing professional on staff (Jackson, Lyons, \& Gooden, 2001). Branding for the athletic program at $\mathrm{HU}$ is primarily managed from the university's Office of Communications, Public Relations, and Marketing. The HU athletics department does not have a documented strategic plan, but this is not uncommon among athletic programs at the Division II level. The NCAA Division II Census also reported that 21 percent of athletic programs did not have a written or documented strategic plan for athletics. The strategic plan should serve as a guide for 
departmental goals and objectives. Thus, not having a guide can further confuse the strategic management of the HU athletic department.

Strategic planning plays an important role in obtaining a competitive advantage (Powell, 1992). The strategic planning process according to Forounzandel (2005) consists of reviewing the principles and mission of the organization, evaluating the expected versus actual results of activities in an organization, and then developing and executing reformed plans. Strategic planning in essence accounts for forecasting, evaluating, and adjusting the plans within an organization. The HU athletics department does not have a strategic plan. This impairs the department's ability to optimize activity and strengthen their resource management strategies (Abdalkrim, 2013). The department is essentially operating on a need to need basis rather than taking strategic action to perform in a more efficient and effective manner. Strategic planning also allows leadership to anticipate risks and opportunities for the department (Linn, 2008). AD has an opportunity to improve the department and obtain competitive advantage by developing a strategic plan with the department.

\section{RQ 2a: How do HBCU athletic departments manage existing resources? Hill} University's athletics department manage existing resources using the following strategies: Satisficing, Personal Investment, and "Village" Benevolent Management. The management strategies not only explain how resources are managed, but how the department is able to continue to operate with the scarcity of resources in the department.

Satisficing to manage existing resources. "Satisficing" is defined as "choosing an alternative that is 'good enough' rather than 'maximizing', selecting the option with the highest expected utility" (Parker, Bruin, \& Fischhoff, 2007). This decision-making behavior of satisficing is evident throughout the data collected. The data exposed that when Hill University 
athletic administrators must make decisions, the plan that leads to a satisfactory result is more often taken than a plan that will lead to an optimal result. For example, AD stated that when he realized that the athletics department fundraising efforts would not be for the financial benefit of the department due to the budgeting structure, he stopped putting efforts into fundraising. His decision was not to lead to the optimal result of raising needed funds for updating the football stadium. Instead, the decision was to put efforts into more immediate needs for the department in terms of operations. This evidence of satisficing was inspired both by the limitation of available resources as well as frustration with the limitation of available resources when great effort was previously given and did not return optimal results. Satisficing is also characterized by an HBCU motto "I'll find a way or make one" (Cohen, 2008). HBCU athletic departments have historically suffered from legal and intentional underfunding, low endowments, and competing for talent. The narrow budgets and limited resources that HBCUs face effects the decisions that these athletic departments make to survive (Cohen, 2008). This lack of resources and need to survive with such further influences satisficing to essentially make the best of what is available to them within the HU athletics department's network.

For the theme of satisficing, much of the data suggested that many of the management decisions in Hill University athletics department were influenced by searching for alternatives to survive rather than thrive in their environment. Lower tuition and smaller endowments strain operating budgets; an institution's financial structure is further strained by subsidies to support athletics departments. Physical, human, and financial resources are scarce in comparison to larger Power Five institutions (Cheeks \& Crowley, 2015). Much of the satisficing stemmed from a lack of financial resources. This has led to administrators in $\mathrm{HU}$ athletics to make do with the resources available. Rather than searching for the best possible alternative which could possibly 
set HU athletics in a better position as an organization, they are faced with a heavy dependence of resources that leads to satisfactory alternatives. Though this stems from the lack of financial resources, this theme of satisficing carried over into other resources such as human, physical, and informational. This decision-making behavior of searching for short cuts to survive does not lead to a competitive advantage, nor does it lead to long term stability. The short-sightedness of this strategy fails to assess the future needs of the organization which can cause administrators at HU to face the same challenges year after year. Internal influence is linked to the proximity and access to decision making for personnel (Inglis, 1991). For HU athletic administrators, their internal influence in making decisions for their department has been stifled due to the dependent nature of the university general fund. Decisions making control still lies with university leadership rather than within the department, particularly when deciding allocations and updates of resources. This heavy dependence and lack of power has also led to the HU athletic administrators to focus on activities that lead to acquiring resources that meet immediate needs rather than improving performance and efficiency similar to the Papadimitriou (1998) study.

With regard to human resources, HU athletics has faced limitations in hiring personnel. The athletic staff also have few opportunities for professional development. According to the $\mathrm{AD}$, this has affected the morale of the department and has likely also had an impact on the overall development of staff and athletic programs even though other staff members who were interviewed did not mention anything about their morale. This may be due to his role serving as both the athletic director and head football coach, as well as how limitations from missing conference has affected his coaching role. AD explained that $\mathrm{HU}$ athletics has missed opportunities to recruit talented athletes at their football coaching conference. A lack of professional development also affects the performance of an organization from missing 
opportunities to learn new and innovative skills and methods to face common challenges which professional development offers employees (Hatch \& Dyer, 2004). Stifling human capital in this way further limits the development of the HU athletics department due to the lack of exposure to evolving industry standards. Limiting professional development also affects the value and that human resources are able to create within the department.

For physical resources, satisficing has led to patching and painting structures and facilities that are in need of extensive repair. This limitation of improvement of facilities has had an impact of different athletic programs' ability to recruit talented athletes as well. As Baldwin discussed in detail, $\mathrm{HU}$ athletics has seen that if a student athlete is unsure about which university to attend, having outdated facilities has become the determining factor for that student to attend a different university, thus taking their athletic talent with them. Intercollegiate athletic programs are in what is being referred to as an "arms race" to build new facilities in hopes to attract top talent through lavish facilities (Gaul, 2015). Athletics facilities currently serve as a way to attract top athletic talent for colleges and universities in the NCAA (Redd, 2018). The University of Alabama currently has a development campaign to raise $\$ 600$ million in ten years in order to improve athletics facilities (McNair, 2019). While Goff (2014) has argued that this is not the most effective way to spend money for a university, Huml et al. (2018) found that the promotion of future facilities was an effective recruiting tool for football programs. Alabama State University, an $\mathrm{HBCU}$ in the same region as $\mathrm{HU}$, spent $\$ 62$ million on a new football stadium (Poe, 2012). Though HU competes at the Division II level in the NCAA, their competition for athletic talent are at both the Division I and Division II levels. Thus, it is still vital for HU's athletic facilities to be updated. The athletic facilities also do not match the rich historic athletic success of $\mathrm{HU}$ athletics. Should $\mathrm{HU}$ athletics update facilities, there would be a 
competitive advantage with both the legacy of the university and its facilities. The structural school of thought for RBT examines the resources that are surplus-generating and how they influence and create a competitive advantage for an organization (Peteraf, 1994). In terms of physical resources, HU does not have a surplus; however, the structure of the football stadium can generate a surplus. This is due to the structure that allows for tailgaters to enjoy the game inside of the stadium. Improvements to the stadium are still needed such as updated concessions, announcing equipment, and parking. However, with improvements to the stadium, HU athletics can obtain a competitive advantage for their football and track and field programs.

Informational resources such as processes are an important part of strategic management (Slack \& Hinings, 1992). Informational resources have suffered as well due to the limitation of financial resources. Baldwin, who is responsible for the management of informational resources in the $\mathrm{HU}$ athletic department discussed how he has satisficed in his role by securing volunteer media announcers at the expense of the product that volunteer work has constructed. Though volunteer announcers are what is feasible for the HU athletic department, they may not be what is best for the organization and its brand that can be tarnished due to low quality experiences for consumers. Baldwin explained that consumers complained about the quality of the radio broadcasts. In a 2008 study, Armstrong also found that sport consumers of color were significantly motivated by the event promotions, family appeal, entertainment, social interactions, and event culture more than Caucasian consumers of sport (Armstrong, 2008). Armstrong (1999) proposed that Black sport consumers are also highly impacted by various streams of media. Thus, the quality of marketing and communications is important for $\mathrm{HBCU}$ athletic programs. This resource limitation further places HU behind in terms of a competitive advantage because consumers set the demand and value for a product. Consistent complaints 
about the quality of these informational resources further affects the value of the core product as well for Hill University athletics. However, from a strength perspective, volunteer announcers allow for an alleviation of a gap in human resources for the communications of the department. This also allows volunteers to build attachment to the university and the athletic program through their involvement and contribution to the continuation of programs.

With the current budgeting structure, Baldwin is responsible for marketing, communications, and development within the department. The triad of his role is tied to satisficing to fill needs for the department while utilizing the budget that is available for one position. His role in marketing and communications is somewhat alleviated by opportunities to collaborate with the HU Office of Communications, Public Relations, and Marketing. Baldwin has also strategized to secure volunteer announcers for streaming away games. The quality of the volunteer workers' outputs has generated complaints which affects the brand of the athletics department. However, the recommendations from Stoldt, Miller, and Comfort (2001) encourage collaborating with the public, students, and stakeholders to improve relationships with external groups. Thus, the use of volunteer announcers is a great opportunity to increase personal attachment for external members of the HU athletics network, but this is most effective with a stronger vetting process for securing announcers.

Personal Investment to manage existing resources. This theme provides insight into the ways in which Hill University athletic administrators manage existing resources answering RQ2a. The personal investment of employees and members of the community adds to the stability of operations for the athletic department, and is evident throughout the data. Participants discussed, in detail, their emotional and financial investments in HU athletics. For example, staff and students ensured the success of HU athletics with regard to financial, human, and 
informational resources because of their personal ties to the university, as well as financial investment of staff and stakeholders who have given from their personal finances to ensure that the needs of the HU athletic department are met. This is a particularly unstable way to manage resources because it is capricious and based on the present state of commitment from external sources.

This personal investment hints toward building social capital for members of the organization. Social capital relates to "the norms and networks of cooperation, reciprocity and trust that facilitate collective action for the achievement of a mutual benefit" (Christoforou, 2013). The network of cooperation for HU athletics extends beyond employees to other staff across campus, alumni networks, current students, and members of the local community. Social capital in this context also highlights the shared identity of members of the network which further influences their devotion to the success of the university and thus, the HU athletics department. Social capital itself is also a resource for the management of other resources within the context of this case. Strong ties to the university create the "mutual benefit" aspect of the social capital relationship which is evident with an alumnus, who is also the head baseball coach, personally financing repairs and updates to the baseball field. Further, his wife who is also a member of the social capital network as an alumna, was also supportive of investing in the field improvements project.

Much of the personal attachment to HU further implies organizational identity as the common factor of contributing to the department in this way. Organizational identity which stems from social identity theory and suggests that an "individual defines himself or herself in terms of their membership in a particular organization" (Mael \& Ashforth, 1992). Antecedents that contribute to this definition of self in relation to an organization are the distinctiveness and 
prestige of an organization as well as the perceived competition between the organization and others within the same category. For HU, the history of the university contributes to the prestige of the organization and the distinctiveness can be attributed to prominence of the institution within the HBCU category of higher education institutions. Thus, this belonging to a prestige and distinct institution further influences the level of commitment that alumni and staff have to the HU athletic department.

For staff in particular, organizational identity influences their retention and job satisfaction even with a dearth of resources to best perform in their roles. Employees who strongly identify with their organization are more likely to be retained and tend to have a more confident attitude towards the organization as well (Van Dick et al., 2007). Organizational identification also contributes to an increase of pride and bonding between staff members and the athletic department (Cremer et al., 2006).

The HU athletics department manages four critical resources (financial, human, physical, and informational) by satisficing to meet immediate needs. The use of satisficing for decisionmaking in the department has allowed the department to meet immediate needs; however, a more long-term decision-making strategy is needed to create a competitive advantage for the department. This strategy is accompanied by personal attachment to the university and the athletics department which encourages employees and stakeholders to invest time, money, and other resources in the department to also meet immediate needs of the athletics department. Personal investment is a dynamic strategy that has allowed the department to manage current resources, retain former athletes as staff as well as to attenuate gaps in resources. Personal investment and satisficing illustrated that when resources are not available for the HU athletics 
department, the administrators utilize what is available within their network to complete tasks and meet the needs of the department.

\section{RQ2b: How do HBCU athletic departments mitigate the gaps in resources? The Hill} University athletic department uses the same thematic strategies to mitigate gaps in resources that are used to manage existing resources.

Personal attachment. An emotional attachment is defined as "an individual's sense of belonging to a particular group and his or her feelings of morale associated with membership in the group" (Paxton \& Moody, 2003). The emotional attachment to an organization furthers the strength of its network (Lin, 1999). For HU, the personal attachment is strong with network members who have a sense of belonging and feeling of morale about HU as an institution (Paxton \& Moody, 2003). Position within a network (leader, member, or liaison) influences the member's sense of belonging and feeling of morale towards the organization (Paxton \& Moody, 2003). For example, a former student-athlete of HU will have a member position within a network and is likely to have a higher sense of belonging and morale toward the athletics department. The liaison position, perhaps an alumnus who works for HU, may also have a higher sense of belonging and morale towards the HU athletics department than an outsider without the personal connection or participation in the organization. This further explains the personal attachment of staff, students, and alumni who personally contribute to the mitigation of gaps in the HU athletics department.

For financial resources, staff contributing their personal finances to fill financial gaps in the athletics budget is a sound example of how personal attachment works to alleviate the deficit of financial resources. For human resources, alumni wanting to return to HU to work for the athletics department in administrative and coaching positions and sometimes as volunteers 
illustrates how a personal attachment fills gaps in human resources. Though personal attachment mitigates some gaps such as financial and human resources, facilities are a resource that personal attachment has not alleviated.

Strategy Theme Three: "Village" Benevolent Management. This theme provides insight into the strategy in which Hill University athletic administrators mitigate the gaps in resources thus answering RQ2b. The "village" in this theme refers to employees, students, and members of the surrounding community of Hill University. The communal management of the HU athletics resources further supports notions of both social capital and organizational identity of members of the organization. At the heart of social capital theory is the use of resources that are rooted in the social network (Lin, 1999). This ties in with resource dependence theory which says that a lack of resources will cause an organization to utilize resources within its network. The social capital present at HU combined with the resource dependence has created an environment where the members of the extended network share resources and work together for the survival of the athletics department. This is evident with volunteer support to fill gaps in human resources as well as the interdepartmental use of tutoring services for student-athletes. This is also evident in the shared responsibility of management for the basketball arena which is used by an academic unit, the Air Force ROTC, and the HU athletics department. Resourcesharing is central to social network analysis, which examines how individuals, groups, or organizations are connected by a social relationship and how those actors within the network work as partners for a common goal (Moliterno \& Mahony, 2011). For HU, the social relationship is tied to the organizational attachment and personal attachment to the university. Thus, there is a common goal of those actors within the social network to support the success of the university and its athletic programs. 
The village mitigates gaps. The shared responsibility for the HU athletics department also demonstrates collaboration as a cultural value. If culture is "a set of dominant values and norms of conduct for a given organization" (Kożuch, 2009) and collaboration is expected and accepted for the HU athletics department then this can serve as a model for the effective use of social capital within an organization that is limited by a shortage of critical resources. For example, the collaboration between employees in the HU athletics department observed in this study was natural in that there was not much debate about helping other staff with various aspects of the homecoming activities. The "all hands on deck" culture was evident when two staff members who work in academic advising for the department also assisted in passing out travel attire for football players, passing out credentials and parking passes for the football game, and training ticket booth volunteers the week of the homecoming game. This culture to transition from one role to helping with other tasks in the department makes for a positive resource for the HU department. HU also currently utilizes its social network well for gaps in human resources through effective use of volunteer support. The academic advisors also utilize tutoring from other academic units on campus to ensure that student athletes are able to receive the academic support needed for their courses. However, the social network for physical resources further limits the department in terms of utilizing public facilities for the baseball program. The facilities are located 30 minutes away from the campus which gives rise to other logistical issues from traveling for athletic competition even when HU is the "home" team. Thus, when the use of collaboration does not further hinder other areas of operation, the "village" culture is an effective management practice to fill gaps in resources.

"Village" benevolence is a management strategy that has helped HU athletics fill gaps in resources for an unknown number of years. The department has done well collaborating with 
several departments on campus for equipment and volunteers as well as throughout the local community and alumni network. The major assumption of RBT is that organizations rely on tangible and intangible resources to operate. This management strategy has integrated HU's tangible and intangible resources to fill gaps and continue to operate as an athletics department.

\section{Implications}

\section{Theoretical Implications}

The theoretical framework for this study consists of resource dependence theory (RDT) and resource based theory (RBT).

Resource Dependence Theory. Decreasing government subsidies and low alumni donations for Historically Black Colleges and Universities (HBCUs) increase the strain on institutional budgets (Palmer, 2010; Gasman, 2009; Cohen, 2008). Consequently, limited institutional budgets also strain budgets for HBCU athletic departments, which often depend on supplemental financial resources from the school's general budget (Cheeks \& Crowley, 2015). As a result, HBCU athletic departments have had to find unique ways to generate revenue to support the stability of their athletic programs. Resource dependence theory (RDT) was used as a framework to analyze the decisions made by athletic administrators at Hill University. RDT is primarily used in business to analyze intercorporate relations and organizational behavior stemming from a shortage of resources. A shortage of resources, typically financial, is often seen in non-profit organizations or public organizations (Malatesa \& Smith, 2014). Furthermore, RDT is useful to examine the interdependency of intercollegiate athletic programs because the NCAA is a non-profit organization and the HBCU- affiliated institutions are classified as non-profit as well. 
Assumptions of resource dependence theory. RDT seeks to explain the behavior of an organization based on the resources needed to survive. The central idea for RDT is that the control of resources is a form of organizational power (Hillman, Withers, \& Collins, 2009). When an organization is unable to obtain resources internally, they seek those resources from external organizations within their network. An organization's behavior is thus influenced by the abundance or lack of resources (e.g. financial, human, physical, and informational). The decision for either alternative is motivated by the lack of resources. Four primary concepts explain the basic argument of RDT and the relationships formed through a dependence of resources. The premise of RDT is that organizations need resources to survive and when those resources are not available, they can obtain them from other organizations at the expense of their independence and organizational power. For the HU athletics department, much of their decision-making power lies in the hands of university leadership that do not have any experience managing an athletics department. This is because of the nature of their heavily subsidized relationship in which the university general fund provides for the majority of the department's expenses. Thus, power in this context lies in the hands of the entity who holds the financial resources, the university general fund and those who have decision-making power for those funds. The president gave six priorities for HU in her State of the University Address and athletics was not on the list of priorities. Academics, residence life, and scientific research are the top priorities for the university according to the list and resource allocations going to departments other than athletics suggests the value that athletics currently holds for the institution.

A secondary concept in RDT is a belief that whoever controls resources has leverage over an organization in need of those particular resources (Nienhüser, 2008). Organizations strategize for resources through alliances with other organizations; in that process, they contract, merge, or 
join associations (Malatesa \& Smith, 2014). However, the dynamic of a dependent relationship gives the resource-granting entity a sense of power over the organization (Verschuere \& De Corte, 2014). The level of autonomy of the dependent organization is associated with the amount of resources provided to them. This suggests that increased funding is associated with a decrease in autonomy for the dependent organization. Thus, HU athletic programs have left themselves vulnerable to a loss of organizational power (e.g. decision making, facility expansions, departmental faculty expansions, recruiting top athletes, and retaining qualified personnel) due to the dependent relationship with the university general fund. This is further evident in the case of the HU athletics department because of the inability to make immediate decisions for the department due to the funding model. This has impacted the ability to make large facility updates and improvements thus affecting the ability to recruit top athletes. When funds have been raised to improve facilities, the money has gone into the general fund and not reallocated in full back to the athletics department. The lack of power to decide how funds are allocated is evidence of the loss of organizational power stemming from resource dependence.

This study revealed barriers that contribute to the limited acquisition of financial, human, physical, and informational resources for the Hill University athletic department and that the lack of resources further contributes to those barriers. HU athletics has a high level of resource dependence. Though much of the dependence stems from a lack of financial resources, the dependence is seen throughout all four critical resources. The lack of resources has motivated HU athletic administrators to become resourceful in their acquisition of resources and management of existing resources. Beyond satisficing to manage existing resources, $\mathrm{HU}$ athletic administrators rely on resources within its network to survive. 
The limitation of resources has presented many obstacles for the HU athletic department. Searching for resources within their network has been perceived as effective for HU athletic administrators. Baldwin has worked with other departments on campus to meet the immediate needs of the department such as tutoring and volunteers for ticket sales. The issue with this dependence on external resources to maintain stability is that they are not reliable long term. Thus, HU athletics has created further dependence while trying to ameliorate the lack of critical resources.

The resource that this study found to be most critical and in least abundance was financial. The current financial model for the $\mathrm{HU}$ athletic department has created an immense dependence on the general fund to continue operations. The HU athletic department currently relies on the general fund to subsidize 100 percent of departmental operations. This heavy dependence has removed much of the decision-making power that $\mathrm{HU}$ athletics formerly had as a department. The university leadership make final decisions for most of the athletic department's needs. This has caused difficulties with hiring new staff, opportunities for professional development, and even fundraising efforts for the athletic department. HU athletics has secured development funding and because of the dependent relationship with the university general fund, has not been able to use any of the funds that were raised. The university made the decisions to utilize the funds acquired through development for other university needs. This power dynamic further exacerbates the lack of financial resources for the department and other issues that stem from this limitation.

Mansoor and Naveed (2010) posited that when an organization has scarce resources, the management team takes uncertainty into consideration when making strategic decisions. A lack 
of resources also has an effect on board members' recruitment, production strategies, and external organizational links. The findings from the study suggest that organizations develop some strategies based on how they will need to use their internal resources, and other strategies related to external resources are developed to put the organization in a better position. Thus, the presence of resource dependence was evident for HU because the organization's behavior stemmed from the resources it had or needed. The gaps that were exposed in the study give insight to the practices that were formed by the department when faced with a shortage of resources. Though they were a response to a deficit as explained by RDT, the management strategies have an opportunity to create a competitive advantage as explained by the second theoretical framework for this study, resource based theory. The following section will further explain the role of resources and strategies can create a competitive advantage for the HU athletics department.

Resource Based Theory. The picture of Historically Black Colleges and Universities (HBCUs) athletics is often painted from a deficit perspective (Cavil, 2015; Cheeks \& Crowley, 2015; Gill \& Hart, 2015) it lacks the analysis of the resources and strategies that HBCUs have in place to combat the shortage of other resources. Resource based theory (RBT) is a framework used in strategic management that integrates both economic and behavioral perspectives of organizations.

RBT is separated into two "schools" of thought: structural and process (Peteraf, 1994). Structural examines the resources that are surplus-generating and how they influence and create a competitive advantage for an organization. Process examines the ways in which resources are generated, maximized, and preserved for an organization (Peteraf, 1994). Contrary to RDT, 
which looks at the response to a deficit in resources, RBT examines the potential for a surplus of resources which can create or increase a competitive advantage in the market. RBT has a prescriptive nature in that it suggests that acquiring resources that are valuable, rare, and inimitable will lead to a competitive advantage for the organization. Thus, RBT was useful for extracting practical implications for organizations to maximize their competitive advantage through efficient use of resources (Galbreath, 2005). The major assumptions of RBT are that organizations rely on tangible and intangible resources to operate.

Galbreath (2005) posited that all resources are interrelated to develop a competitive advantage. Thus, a competitive advantage is obtained through the use of both intangible and tangible resources. Numerous scholars of RBT presume that intangible resources lead to the strongest competitive advantage for an enterprise. However, Galbreath's study led to the revelation that tangible resources do play an active role in the success of an organization to some extent (2005). Three implications were developed from this study:

1. Organizational assets, such as culture, human resources management policies and corporate structure can significantly impact on a firm's success.

2. Reputational assets are among the most important the firm can develop.

3. Tangible assets, in contrast to traditional resource- based theory beliefs, may still have a viable place in the performance of firms (Galbreath, 2005, pg. 985).

Resources and the success of an organization are not linear in nature. They are interlinked to a combination of tangible and intangible resources. For this study, resources available to the HU athletic department were interlinked immensely due to the need to be resourceful to continue operations. Based on the implications from Galbreath's (2005) study, results from this study show that the corporate or organizational structure can significantly alter a firm's success. The 
current budgeting model has limited other areas of operations in the athletics department such as updating facilities. On a more positive note, the culture of collaboration that the department has provides a valuable asset which has been exploited to fill gaps in resources. The reputation of the university and athletics department has served as a valuable resource previously for recruiting. Now, it no longer holds the same value in terms of recruiting athletic talent. Thus, this particular case of HU shows that while reputation is important, it cannot be relied on solely for a competitive advantage. Tangible assets such as updated facilities and equipment would aide in producing a competitive advantage for $\mathrm{HU}$.

There is need for reputation, culture, finances, and physical resources to work together to create a competitive advantage. This is referred to as a heterogeneous use of resources. Heterogeneous refers to resources as well as the strategic use of those resources. Introducing heterogeneity to strategic uses of resources can increase revenue generation as well as alleviate the burden of cost for owning certain assets such as sport facilities and equipment. RBT posits that organizations create a competitive advantage with a mixture of resources (e.g., the combined use of appropriate physical, financial, and human resources needed to successfully host an athletic competition) or resources that can be strategically used for multiple purposes rather than reliance on a singular resource or use (e.g., a facility used for its primary purpose of athletic competition, as well as subsidiary uses such as leasing the space for public or private events) (Barney \& Clark, 2007). For HU athletics, many resources are not currently being used heterogeneously. All athletic facilities are used for the sole purpose of athletic competition. Even the Hall of Fame is only used for recognition purposes, though it is a great space to lease for private events. The condition of other facilities such as the football stadium prohibits further use of those facilities to possibly generate revenue or increase competitive advantage. 
The VRIO model of RBT refers to the value, rarity, inimitability, and organization of a department's resources. The VRIO model further assesses the value and potential of resources that are identified within the organization. Because value is subjective in nature, leadership within an organization may view a certain resource as holding greater value than someone with an outside perspective may have. For assessing the VRIO model at HU, the photovoice participant responded to prompts related to his perception of the value, rarity, inimitability, and organization of resources. His responses tell a story of the importance of perseverance and human resources in the department.

Findings from this study expose opportunities to create a competitive advantage through a strategic use of both tangible and intangible resources. This is an opportunity to further exploit resources that are immobile which are also essential for competitive advantage (Barney \& Clark, 2007). Immobile resources like the HBCU marching band style and culture tend to be intangible, therefore creating a stronger competitive advantage because competitors cannot purchase them easily and they are stable within the organization. Information and processes are also immobile and intangible and can further strengthen the ability of organizations to generate a surplus, thus, creating a competitive advantage. HU athletics are in need of stronger informational resources such as formal business and functional level management strategies and departmental policies. A mixture of improved physical resources and informational resources can help create a stronger competitive advantage as well as strengthen the brand of the athletics department.

Though RDT explained how the shortage of resources limits the department, RBT explains how the department can increase long term survival by developing strategies that fully exploit the resources that are available within the network. Creating more strategies that allow 
for heterogeneous use of resources as well as improving tangible resources for the department can create a competitive advantage for the HU athletics department.

Practical Implications. Hill University athletic department needs to acquire and protect resources. The shortage of financial, physical, and human resources creates a distraction for athletic administrators who could better spend their time developing richer strategies for operations. The purpose of this study was to identify the ways in which this shortage of resources influences the decisions and practices of athletic administrators in HBCU athletic departments and to identify resources that can lead to the long-term stability of the organization. This study can assist Limited Resource Institutions by providing insight for successful strategies and practices that meet the needs of their programs and become more sustainable through identifying strategic ways to allocate resources and maximizing existing resources. Because intercollegiate athletics research often focuses on the successes and issues of larger, well-financed athletic programs, this study was long overdue to focus on the inner workings of limited resource institutions. HU has offered a glimpse into the inner workings of athletic programs that struggle to maintain their athletic programs. This adds to empirical research and literature by increasing knowledge about the management of resources not often explored for HBCUs in the NCAA. Further, this extends literature within HBCU athletics research by focusing on a program at the Division II level of the NCAA.

HBCU athletic directors and university leadership should consider the importance of cultivating strong and dynamic human resources. Based on organizational identification theory, there is great opportunity to exploit the ways in which organizations build stronger human capital such as professional development. The cultivation of employees is important to the rarity and 
value that personnel are able to create in an organization. This can be done through providing or encouraging mentorship relationships with other professionals in athletic administration. Also of importance is prioritizing professional development as a necessity for staff rather than as a luxury. Developing the skills and competencies of staff members is not only of benefit to the individuals, but to the overall organization as staff begin to utilize those skills and competencies to build a competitive advantage for the department.

The current financial model for the $\mathrm{HU}$ athletics department could be effective if the lines of communication regarding decision-making are two-way. For example, the current budget model can be efficient if an increased priority is given to updating athletic facilities and increasing opportunities for professional development in the athletics department. Currently, the department has an "ask and receive" relationship with the leadership of the university rather than a partnership to move the university mission forward together. Changes in leadership dynamics can help the athletics department by meeting more of their immediate needs, but also the university as the athletics department can influence the overall brand of the university. Working together would be of great advantage for the university as a whole.

\section{Recommendations for Future Research}

The specific focus of this study was how resources affect strategies of HBCU athletic departments from both a deficit and surplus perspective. The case study method allowed for a more concentrated focus on one HBCU athletic department. The information gathered in this study will provide insight for athletic administrators of $\mathrm{HU}$ who seek to improve the success of their athletic programs and long-term stability of the department. Though the information gathered in this study provided an organizational assessment for one specific university's 
athletics department, there are many opportunities for further exploration in HBCU athletics. Areas of future research involving strategic management of resources include the following: human resources and organizational identification, human resources and personal investment into programs, and the role of physical resources in recruitment practices. Other areas of resource management that should also be examined are the prevalence of satisficing in HBCU athletics and the salience of the $\mathrm{HBCU}$ alumni identity as it pertains to athletic department personnel.

Human resources. This study revealed several opportunities to advance scholarship of human resources in HBCU athletics. Specific areas of interest for future research are how the reputation of an athletic program further influences the organizational identity of its employees. This includes both positive and negative aspects of a reputation. Also, because teachers also have reported paying for school supplies for their classes much like the employees of $\mathrm{HU}$ athletics, an investigation of how personal investment affects job satisfaction would possibly reveal interesting motivations and results from this type of relationship between staff and employees. Finally, exploring how satisficing can be both efficient and inefficient based on the resources available within an athletic department would further expose ways in which decisions can be advantageous or detrimental to an organization.

Physical resources. Empirical studies have examined the impact of newer facilities for recruiting student athletes and students for the university (Gumprecht, 2003; Huml et al., 2018; Martinez et al., 2010). However, little has been examined regarding the impact of not updating or building new facilities for athletics. The sport management industry could benefit from empirical evidence of what problems or benefits exist from not updating or building new facilities for athletic programs. 
Alumni support. The alumni athlete association for $\mathrm{HU}$ decided to band together to start a campaign to raise money for a new stadium. Though the campaign has not been able to move the project forward, this in addition to the alumni who volunteer their time, funds, and services to the athletic program suggests that alumni involvement is key to resource acquisition. A further exploration into the motivations and attachment of alumni, particularly alumni athletes, can provide strategy for solicitation for financial support.

\section{Conclusion}

The current state of HBCU athletic departments stems from historic and systemic issues regarding race in the United States of America. The limitations that arise from a lack of funding may be countered with a better understanding of the true extent of those limitations as well as how the strategies that have developed help or harm the long-term stability of the organization. This study sought to fill gaps in research that have not truly explored the strategic management of resources at athletic departments with meager budgets. The results from this study revealed that competitive advantage does not solely depend on wins or losses for an athletic program, but rather the ability to create management strategies that are forward-thinking and sustainable. This study also sought to fill gaps in practical knowledge for the athletic departments involved which may not have identified efficient ways to exploit resources due to a lack of time to focus on strategy. It is optimistic to consider that through an increase of resources HBCU athletic departments will be able to catch up to larger schools within the NCAA. Results from this study reveal that though finances are of great concern for administrators of $\mathrm{HBCU}$ athletic departments, other factors such as the level of dependence of resources, organization structures in place, and inhibitive decision-making strategies continue to create barriers to the long-term stability of these small and limited resource institutions. 
Though many of the results revealed counter-productive decision-making strategies, all

of the evidence did not present a case for pity for institutions and athletic departments like HU. A coach so dedicated to his alma mater and his current baseball players invested his time and finances to improve the conditions of the baseball field. A SWA who grew up just minutes from the university gave of her personal finances to help raise funds for a student-led organization. An athletic director with a great passion for football and coaching stepped into a role that has become overwhelming for him at times, but he still gives his best because of his love for the student-athletes. Numerous other stories, experiences, and observations were made over the period of one week that exposed the limitations that arise from a lack of resources. However, what was also revealed was a great deal of passion and love for the HU athletic department. Over time, with stronger strategies in place stemming from a better understanding of resources and how to optimize their use, HBCU athletic departments like Hill University will hopefully be able to no longer be categorized as a limited resource institution. 


\section{REFERENCES}

Abelman, R., \& Dalessandro, A. (2009). The institutional vision of Historically Black Colleges and Universities. Journal of Black Studies, 40(2), 105-134.

Amis, J., Pant, N., \& Slack, T. (1997). Achieving a sustainable competitive advantage: A resource-based view of sport sponsorship. Journal of Sport Management, 11, 80-96.

Anderson, O., \& Kheam, L.S. (1998). Resource-based theory and international growth strategies: An exploratory study. International Business Review, 7, 163-184.

Andrews, D., Sung, N., Powell, K., Rey, M.P., \& Yigletu, A. (2016). Historically Black Colleges and Universities' institutional survival and sustainability: A view from the HBCU business deans' perspective. Journal of Black Studies, 47(2), 150-168.

Arend, R.J. (2006). Tests of resource-based view: Do the empirics have any clothes? Strategic Organization, 4(4), 409-422.

Arend, R.J., \& Lévesque, M. (2010). Is resource-based view a practical organizational theory? Organizational Science, 21(4), 913-930.

Armstrong-Doherty, A.J. (1996). Resource dependence-based perceived control: An examination of Canadian interuniversity athletics. Journal of Sport Management, 10, 49-64.

Banks, M. (2007). Using visual data in qualitative research. London: Sage Publications Ltd.

Barney, J.B., \& Clark, D.N. (2007). Resource-based theory: Creating and sustaining competitive advantage. New York: Oxford University Press.

Barney, J.B., Ketchen, D.J., \& Wright, M. (2011). The future of resource-based theory: revitalization or decline? Journal of Management, 37(5), 1299-1315. 
Baxter, P., \& Jack, S. (2008). Qualitative case study methodology: Study design and implementation for novice researchers. The Qualitative Report, 13(4), 544-559.

Berkowitz, S., \& Schnaars, C. (2018). NCAA Finances. Retrieved from https://sports.usatoday.com/ncaa/finances/

Cardeal, N., \& António, N. (2012). Valuable, rare, imitable resources and organization (VRIO) resources or valuable, rare, inimitable resources (VRI) capabilities: What leads to competitive advantage? African Journal of Business Management, 6(37), 10159-10170.

Cheeks, G., \& Crowley, C. (2015). The economic state of HBCUs and their athletic programs: the financial relevance and viability of HBCU athletic programs. In B. Hawkins, J. Cooper, A. Carter-Francique, A., \& K. Cavil, The athletic experience at Historically Black Colleges and Universities: Past, present, and persistence (pp.167-179). Lanham, Maryland: Rowman \& Littlefield.

Cooper, J.N., Cavil, J.K., \& Cheeks, G. (2014). The state of intercollegiate athletics at Historically Black Colleges and Universities (HBCUs): Past, present, \& persistence. Journal of Issues in Intercollegiate Athletics, 7, 307-332.

Coupet, J., \& Barnum, D. (2010). HBCU efficiency and endowments: An exploratory analysis. International Journal of Educational Advancement, 10(3), 186-197.

Crawford, J. (2017). HBCUs: Accreditation, governance, and survival challenges in an everincreasing competition for funding and students. Journal of Research Initiatives, 2(3), 113.

Das, T.K., \& Teng, B. (2000). A resource-based theory of strategic alliances. Journal of Management, 26(1), 31-61. 
Filo, K., Cuskelly, G., \& Wicker, P. (2015). Resource utilisation and power relations of community sport clubs in the aftermath of natural disasters. Sport Management Review, $18,555-569$.

Fink, R., Edelman, L., Hatten, K., \& James, W. (2006). Transaction cost economics, resource dependence theory, and customer-supplier relationships. Industrial and Corporate Change, 15(3), 497-529.

Flores, S.M., \& Park, T.J. (2015). The effect of enrolling in a minority-serving institution for Black and Hispanic students in Texas. Research in Higher Education, 56, 247-276.

Fowles, J. (2014). Funding and focus: Resource dependence in public higher education. Research in Higher Education, 55, 272-287.

Galbreath, J. (2005). Which resources matter the most to firm success? An exploratory study of resource-based theory. Technovation, 25, 979-987.

Gallardo, F.O., \& Navarro, J.R. (2003). A model of strategic change: Universities and dynamic capabilities. Higher Education Policy, 00, 1-14.

Gill, E., \& Hart, A. (2015). Separate, unequal, and irrelevant: HBCU revenue sports. In Hawkins, B., Cooper, J., Carter-Francique, A., \& Cavil, K., The Athletic Experience at Historically Black Colleges and Universities: Past, Present, and Persistence (pp. 181-203). Lanham, Maryland: Rowman \& Littlefield.

Glesne, C. (2011). Becoming qualitative researchers: An introduction (4th ed.). Boston, MA: Pearson Education.

Grant, R.M. (1991). The resource-based theory of competitive advantage: Implications for strategy formulation. California Management Review, 114-135. 
Greenwell, T.C., Mahony, D.F., \& Andrew, D.P.S. (2007). An examination of marketing resource allocation in NCAA division I athletics. Sport Marketing Quarterly, 16, 82-92.

Hall, R. (1992). The strategic analysis of intangible resources. Strategic Management Journal, $13,135-144$.

Hancock, D.R., \& Algozzine, B. (2006). Doing case study research: A practical guide for beginning researchers. New York: Teachers College Press.

Harris, A.M. (2016). Video as a method: Understanding qualitative research. New York, NY: Oxford University Press.

Hillman, A.J., Withers, M.C., \& Collins, B.J. (2009). Resource dependence theory: A review. Journal of Management, 35(6), 1404-1427.

Hitt, M.A., Xu, K., \& Carnes, C.M. (2016). Resource based theory in operations management research. Journal of Operations Management, 41, 77-94.

Hodge, M.M., \& Piccolo, R.F. (2005). Funding source, board involvement techniques, and financial vulnerability in nonprofit organizations: A test of resource dependence. Nonprofit Management \& Leadership, 16(2), 171-191.

Inglis, S. (1991). Influence in and around interuniversity athletics. Journal of Sport Management, $5,18-33$.

Jensen, J.A., Cobbs, J.B., \& Turner, B.A. (2016). Evaluating sponsorship through the lens of the resource-based view: The potential for sustained competitive advantage. Business Horizons, 59, 163-173.

Johnson, R.S. (2017). Magic city classic generates millions: Who really benefits. Retrieved from https://www.al.com/news/2017/10/the_magic_city_classic_generat.html 
Kamboj, S., Goyal, P., \& Rahman, Z. (2015). A resource-based view on marketing capability, operations capability, and financial performance: An empirical examination of mediating role. Procedia - Social and Behavioral Sciences, 189, 406-415.

Kozlenkova, I.V., Samaha, S.A., \& Palmatier, R.W. (2014). Resource-based theory in marketing. Journal of the Academy of Marketing Science, 42, 1-21.

Kunc, M.H., \& Morecroft, J.D.W. (2010). Managerial decision making and firm performance under a resource-based paradigm. Strategic Management Journal, 31, 1164-1182.

Lillig, J.C. (2015). Financing HBCU athletics: Men's basketball - problems and opportunities. In B. Hawkins, J. Cooper, A. Carter-Francique, A., \& K., Cavil, The athletic experience at Historically Black Colleges and Universities: Past, present, and persistence (pp.167179). Lanham, Maryland: Rowman \& Littlefield.

Lockett, A., Thompson, S., \& Morgenstern, U. (2009). The development of the resource-based view of the firm: A critical appraisal. International Journal of Management Reviews, 11(1), 9-28.

Macedo, I.M., \& Pinho, J.C. (2006). The relationship between resource dependence and market orientation. European Journal of Marketing, 40(5), 533-553.

Mahoney, J.T. (2001). A resource-based theory of sustainable rents. Journal of Management, 27, 651-660.

Malatesa, D., \& Smith, C.R. (2014). Lessons from resource dependence theory for contemporary public and nonprofit management. Public Administration Review, 74(1), 14-25.

Merriam, S.B., \& Tisdell, E.J. (2016). Qualitative research: A guide to design and implementation. San Francisco, California: John Wiley \& Sons, Inc. 
Miles, M., Huberman, A.M., \& Saldana, J. (2014). Qualitative data analysis: A methods sourcebook. Los Angeles, CA: Sage Publications, Inc.

Mills, J., Platts, K., \& Bourne, M. (2003). Applying resource-based theory: Methods, outcomes, and utility for managers. International Journal of Operations \& Production Management, 23(2), 148-166.

Morrow, S., \& Robinson, L. (2013). The British Olympic Association initiative: A resource dependence perspective. Sport Management Review, 16, 413-423.

Morrow, S., \& Robinson, L. (2013). The FTSE-British Olympic association initiative: A resource dependence perspective. Sport Management Review, 16, 413-423.

NCAA APR report database (n.d.). Academic Progress Rate. Retrieved from https://web3.ncaa.org/aprsearch/aprsearch

Neinhüser, W. (2008). Resource dependence theory: how well does it explain behavior of organizations? Management Revue, 19(1), 9-32.

Nemati, A.R., Bhatti, A.M., Maqsal, M., Mansoor, I., \& Naveed, F. (2010). Impact of resource based view and resource dependence theory on strategic decision making. International Journal of Business and Management, 5(12), 110-115.

Newbert, S.L. (2008). Value, rareness, competitive advantage, and performance: A conceptuallevel empirical investigation of the resource-based view of the firm. Strategic Management Journal, 29(7), 745-768.

Omondi-Ochieng, P. (2018). Resource-based theory of college football team competitiveness. International Journal of Organizational Analysis.

Palmer, R. (2010). The perceived elimination of affirmative action and the strengthening of Historically Black Colleges and Universities. Journal of Black Studies, 40(4), 762-776. 
Pan, S.L., Tan, B.C.C., \& Poulsen, B. (2007). The development paths of non-strategic capabilities. European Management Journal, 25(5), 344-358.

Papadimitriou, D. (1998). The impact of institutionalized resources, rules and practices on the performance of non-profit sport organizations. Managing Leisure, 3, 169-180.

Penrose, E. (1959). The theory of the growth of the firm. Oxford University Press: Oxford, UK.

Pesic, M.A., Millic, V.J., \& Stankovic, J. (2012). Application of VRIO framework for analyzing human resources' role in providing competitive advantage. Book of Proceedings Tourism and Management Studies International Conference Algarve, 2, 575-586.

Peteraf, M. (1994). The two schools of thought in resource-based theory: definitions and implications for research. Advances in Strategic Management, 10A, 153-158.

Pfeffer, J. (1987), “A resource dependence perspective on interorganizational relations,” in M.S. Mizruchi, and M. Schwartz, Intercorporate relations: The structural analysis of business (pp. 25-55), Cambridge, UK: Cambridge University Press.

Pfeffer, J., \& Davis-Blake, A. (1987). Understanding wage structures: A resource dependence approach. The Academy of Management Journal, 30(3), 437-455.

Pfeffer, J., \& Salancik, G. R. (1978). The external control of organizations: A resource dependence perspective. New York: Harper \& Row.

Rivas, J.L. (2012). Co-opting the environment: an empirical test of resource-dependence theory. The International Journal of Human Resource Management, 23(2), 294-311.

Saidel, J. R. (1991). Resource interdependence: The relationship between state agencies and nonprofit organizations. Public Administration Review, 51(6), 543-553.

Saldana, J. (2013). The coding manual for qualitative researchers. Los Angeles, CA: Sage Publications, Inc. 
Sav, T. (2000). Tests of fiscal discrimination in higher education finance: Finding Historically Black Colleges and Universities. Journal of Education Finance, 26, 157-172.

Sav, T. (2010). Funding Historically Black Colleges and Universities: Progress toward equality? Journal of Education Finance, 35(3), 295-307.

Schriber, S., \& Löwstedt, J. (2015). Tangible resources and the development of organizational capabilities. Scandinavian Journal of Management, 31, 54-68.

Slack, T., \& Hinings, B. (1992). Understanding change in national sport organizations: An integration of theoretical perspectives. Journal of Sport Management, 6, 114-132.

Smart, D.L., \& Wolfe, R.A. (2000). Examining sustainable competitive advantage in intercollegiate athletics: A resource-based view. Journal of Sport Management, 14, 133153.

Stake, R. (2006). Multiple case study analysis. New York: The Guilford Press.

Stinson, J.L., Marquardt, A., \& Chandley, J. (2012). An empirical examination of university intercollegiate athletic expenditures. Sport Marketing Quarterly, 21, 104-114.

Stone, G.W., Cort, K.T., \& Nkonge, J. (2012). An exploratory model of the antecedent factors contributing to fan support/ attendance at HBCU basketball games. Atlantic Marketing Journal, 1(1), 15-30.

Travers, M. (2001). Qualitative research through case studies. London: Sage Publications Ltd. Ulrich, D., \& Barney, J.B. (1984). Perspectives in organizations: Resource dependence, efficiency, and population. The Academy of Management Review, 9(3), 471-481.

United States Senate (n.d.). Freedmen's Bureau Acts of 1865 and 1866. Retrieved from https://www.senate.gov/artandhistory/history/common/generic/FreedmensBureau.htm 
Verschuere, B., \& De Corte, J. (2014). The impact of public resource dependence on the autonomy of NPOs in their strategic decision making. Nonprofit and Voluntary Sector Quarterly, 43(2), 293-313.

Vos, S., Breesch, D., Késenne, S., Van Hoecke, J., Vanreusel, B., \& Scheerder, J. (2011). Governmental subsidies and coercive pressures. Evidence from sport clubs and their resource dependencies. European Journal for Sport and Society, 8(4), 257-280.

Voss, U., \& Brettel, M. (2014). The effectiveness of management control in small firms: perspectives from resource dependence theory. Journal of Small Business Management $52(3), 569-587$.

Wan, W.P., Hoskisson, R.E., Short, J.C., \& Yiu, D.W. (2011). Resource-based theory and corporate diversification: Accomplishments and opportunities. Journal of Management, $37(5), 1335-1368$.

Warnier, V., Weppe, X., \& Lecocq, X. (2013). Extending resource-based theory: Considering strategic, ordinary, and junk resources. Management Decision, 51(7), 1359- 1379.

Wicker, P., \& Breuer, C. (2011). Scarcity of resources in German non-profit sport clubs. Sport Management Review, 14, 188-201.

Wicker, P., Vos, S., Scheerder, J., \& Breuer, C. (2013). The link between resource problems and interorganisational relationships: a quantitative study of Western European sport clubs. Managing Leisure, 18, 31-45.

Won, D., \& Chelladurai, P. (2016). Competitive advantage in intercollegiate athletics: Role of intangible resources. PLOS ONE 11(1). 
Yang, Y., \& Konrad, A.M. (2011). Understanding diversity management practices: Implications of institutional theory and resource-based theory. Group \& Organization Management, $36(1), 6-38$.

Yin, R.K. (2003). Case study research: design and methods (3rd ed.). Thousand Oaks, CA: Sage Publications, Inc.

Yin, R.K. (2009). Case study research: Design and methods (4th ed.). Thousand Oaks, CA: Sage Publications, Inc.

Yin, R.K. (2018). Case study research and applications: Design and methods. Thousand Oaks, CA: Sage Publications, Inc. 


\section{Appendices}

\section{Appendix A. Interview Protocol}

1. What is your role with this athletic department?

a. Describe your responsibilities related to resource management.

2. How long have you been in your current role?

3. How long have you worked in intercollegiate athletics?

4. Describe your educational background.

5. How many administrative staff are employed with the department?

6. How many coaching staff are employed with the department?

7. How many staff members perform multiple roles within the department?

8. How would you describe the role of (physical, financial, human, or informational) resources within the department?

9. What would you say is the most valuable resource (financial, human, physical, or informational) for your department? Why?

10. What resources would you say your department has enough of? Why?

11. Describe a time when a limitation of resources (human, physical, or financial) influenced a decision that you made. What was the outcome?

12. How often do you evaluate available resources prior to making a decision? Give an example.

13. How often are decisions made based on financial needs or limitations? Give an example.

14. What resources do you have access to outside of your department? Give examples. 
15. How often do you utilize external sources (security, equipment, facilities, etc.) for the operation of your department or event? Give examples.

16. How have you found external resources for the department?

17. Describe the administrative focus of staff members within the department and their roles.

18. Describe how your athletic facilities are currently used.

19. Describe how marketing initiatives are developed within the department.

20. How often do you update procedures for the department? Why?

21. Describe how departmental needs are met through innovative procedures.

22. Describe a time when you wanted to implement a new idea but could not due to a lack of resources. What was the outcome?

23. How much of your role has been affected by seeking ways to acquire resources? 


\section{Appendix B. Case Study Protocol and Schedule}

\section{$11 / 4 / 2019$}

Introductions with staff and become familiar with the case site

Train individual participants for Photovoice

Collect all signed informed consent forms

Meeting with the Athletic Director

\section{1/5/2019}

Financial resources

- Budgets

- Collect budgets for three years prior - refused by the Business Office Manager

- Interview with the business manager - Refused to participate

- Field observations- general

○ Video journaling

\section{1/6/2019}

Human resources

- Interviews with the Athletic Director and Associate AD for Marketing

- Send interview recordings to be transcribed

- Organizational Charts

- Field observations- personnel

$\circ$ Video journaling

\section{1/7/2019}

Physical Resources (facilities, equipment)

- Tour athletic facilities

- Stadium, gymnasium/arena, tennis courts, softball \& baseball fields

- Field observations- facilities

$\circ$ Video journaling

\section{1/8/2019}

Informational Resources (marketing, procedures, organizational culture)

- Interview with the Director of Marketing and the Director of the Marching Band - Send interview recording to be transcribed

- Review departmental marketing portfolio

- Collect photos or pdf of any marketing material or agreements

- Field observations

11/9/2019

Informational Resources (HBCU sport culture)

- Field Observations - Culture and Legacy

11/10/2019

Debrief with the Athletic Director 
- Follow-up questions

- Photovoice photos and descriptions

- Next steps of the process

- Review of what was collected and why 


\section{Appendix C. PhotoVoice Training Guide}

PhotoVoice Training Guide

I. Welcome

a. Introduce yourself

b. Have participants introduce themselves and tell their role within the department

c. Give a quick ice breaker to create a positive environment so that training can begin

II. Set Ground Rules

a. Share and agree on common conditions regarding the method

b. Encourage participants to fully participate and take ownership of their role in the method

III. Set Expectations

a. Explain the purpose of the study

b. Explain expectations of their participation

c. Set clear deadlines for taking and submitting photos and descriptions

IV. Basic concepts of PhotoVoice

a. Explain what PhotoVoice is

b. Explain how PhotoVoice will help with the purpose of the study

c. Explain how PhotoVoice will work within the context of this study

V. PhotoVoice Prompts

a. Explain all prompts given so that they are clear

VI. Photovoice Practice

a. Practice on mock prompts to show clear understanding of their role in the method

b. Show a mock prompt and response for further clarification 


\title{
Appendix D. Photovoice Prompt
}

\author{
Photovoice Prompt \\ HBCU Resources Study
}

Based on your experience in this department, what resources do you think that your department use well?

Based on your experience in this department, what are your most valuable resources?

Based on your experience in this department, what resource makes your department most unique?

What use of resources is unique to your department? 


\section{Appendix E. Data Collection Chart}

\begin{tabular}{|l|l|l|l|}
\hline Data Collected & & $\begin{array}{l}\text { Date of } \\
\text { Collection }\end{array}$ & $\begin{array}{l}\text { Means of } \\
\text { Collection }\end{array}$ \\
\hline Interview & $\begin{array}{l}\text { Athletic Director/ } \\
\text { Head Football Coach }\end{array}$ & $11 / 6 / 2019$ & In person \\
\hline Interview & $\begin{array}{l}\text { Director of } \\
\text { Compliance/SWA }\end{array}$ & $11 / 5 / 2019$ & In person \\
\hline Interview & $\begin{array}{l}\text { Assistant AD for } \\
\text { Marketing and } \\
\text { Communications }\end{array}$ & $11 / 8 / 2019$ & In person \\
\hline Photovoice & Video Coordinator & $11 / 6 / 2019$ & In person \\
\hline Photos & & $11 / 4 / 2019-$ & In person \\
\hline Tailgating Agreement & Document analysis & $11 / 9 / 2019$ & Online \\
\hline Vending Agreement & Document analysis & $11 / 6 / 2019$ & Online \\
\hline $\begin{array}{l}\text { Season ticket pricing } \\
\text { form }\end{array}$ & Document analysis & $11 / 6 / 2019$ & Online \\
\hline $\begin{array}{l}\text { Game Day Advertising } \\
\text { Rates Form }\end{array}$ & Document analysis & $11 / 6 / 2019$ & Online \\
\hline $\begin{array}{l}\text { Athletic Association } \\
\text { website }\end{array}$ & Document analysis & & Online \\
\hline $\begin{array}{l}\text { Athletics Mission } \\
\text { Statement }\end{array}$ & Document analysis & & Online \\
\hline $\begin{array}{l}\text { Field Observation } \\
\text { Notes }\end{array}$ & Written and video & $11 / 4 / 2019-$ & $11 / 10 / 2019$ \\
\hline $\begin{array}{l}\text { State of the University } \\
\text { Address Video }\end{array}$ & $\begin{array}{l}\text { Private Youtube link } \\
\text { for alumni }\end{array}$ & & In person \\
\hline
\end{tabular}




\section{Appendix F. Participant Schedule}

\begin{tabular}{|l|l|l|l|}
\hline Participation Type & Position & Interview Date & $\begin{array}{l}\text { Meeting/Interview } \\
\text { Time }\end{array}$ \\
\hline Meeting & $\begin{array}{l}\text { Athletic } \\
\text { Director/Head } \\
\text { Football Coach }\end{array}$ & $11 / 4 / 2019$ & $12: 00 \mathrm{pm}$ \\
\hline Interview & $\begin{array}{l}\text { Athletic Director/ } \\
\text { Head Football } \\
\text { Coach }\end{array}$ & $11 / 5 / 2019$ & $1: 30 \mathrm{pm}$ \\
\hline Interview & $\begin{array}{l}\text { Director of } \\
\text { Compliance/SWA }\end{array}$ & $11 / 5 / 2019$ & $9: 00 \mathrm{am}$ \\
\hline Interview & $\begin{array}{l}\text { Assistant AD for } \\
\text { Marketing and } \\
\text { Communications }\end{array}$ & $11 / 7 / 2019$ & $1: 30 \mathrm{pm}$ \\
\hline Photovoice & $\begin{array}{l}\text { Video } \\
\text { Coordinator }\end{array}$ & $11 / 6 / 2019$ & $10: 00 \mathrm{am}$ \\
\hline
\end{tabular}




\section{Appendix G. Participant Profiles}

\begin{tabular}{|c|c|c|c|}
\hline Participant & Title & $\begin{array}{l}\text { Role in } \\
\text { Study }\end{array}$ & Description \\
\hline AD & $\begin{array}{l}\text { Athletic Director } \\
\text { (2.5 years) } \\
\text { Head Football } \\
\text { Coach } \\
\text { (14.5 years) }\end{array}$ & & $\begin{array}{l}\text { AD is both the athletic director and the head } \\
\text { football coach. He served as Interim Athletic } \\
\text { Director for one year after the departure of the } \\
\text { previous athletic director in 2017. His } \\
\text { experience in intercollegiate athletics has been } \\
\text { primarily in coaching until his appointment as } \\
\text { Interim Athletic Director. He has coached } \\
\text { football at Predominantly White Institutions } \\
\text { (PWIs) prior to starting his role as Head } \\
\text { Football Coach at HU in 2005. AD tends to } \\
\text { focus on football as the head coach during the } \\
\text { football season. He is highly aware that } \\
\text { football is the only revenue producing sport } \\
\text { that HU offers. AD participated in a formal } \\
\text { interview and served as the guide for my site } \\
\text { visit }\end{array}$ \\
\hline Baldwin & $\begin{array}{l}\text { Assistant AD for } \\
\text { Marketing and } \\
\text { Communications } \\
\text { (2.5 years) }\end{array}$ & & $\begin{array}{l}\text { Baldwin, the Assistant Athletic Director, has } \\
\text { over } 15 \text { years of experience working in athletic } \\
\text { administration and works closely with the } \\
\text { Athletic Director in decision making. His } \\
\text { athletic administrative experience has been at } \\
\text { the intercollegiate, conference, and governing } \\
\text { body levels. Much of that experience was in } \\
\text { the area of communications. AD depends } \\
\text { heavily on Baldwin's role as the liaison } \\
\text { between the athletic department and the HU } \\
\text { President's office during football season. } \\
\text { Baldwin participated in a formal interview for } \\
\text { this study. }\end{array}$ \\
\hline Swan & $\begin{array}{l}\text { Director of } \\
\text { Compliance/SWA } \\
\text { (8 years) }\end{array}$ & & $\begin{array}{l}\text { Swan is the Director of Compliance for the } \\
\text { HU athletic department. She has eight years of } \\
\text { experience working in intercollegiate athletics } \\
\text { setting and began her career at HU. She is a } \\
\text { graduate of a nearby university but grew up in } \\
\text { the same town as HU and knows the history } \\
\text { and culture of the university extensively. She } \\
\text { is also the senior-most ranking woman in the } \\
\text { athletic department. Swan participated in a } \\
\text { formal interview for this study. }\end{array}$ \\
\hline Jacob & $\begin{array}{l}\text { Assistant football } \\
\text { coach } \\
\text { (7years) } \\
\text { Video } \\
\text { Coordinator } \\
\text { (5 years) }\end{array}$ & & $\begin{array}{l}\text { Jacob serves as both an assistant coach with football } \\
\text { and the video coordinator for HU athletics. He has } \\
\text { mainly coaching experience; however, his } \\
\text { educational background is in communications and } \\
\text { he enjoys coordinating the video content for the } \\
\text { department. He has put together a team of student } \\
\text { workers to support his role as well as teach students } \\
\text { how to develop video content in sport. Jacob } \\
\text { participated in the Photovoice data collection } \\
\text { process for this study. }\end{array}$ \\
\hline
\end{tabular}




\section{Appendix H. Facilities Chart}

Athletic Facilities Chart

\begin{tabular}{|l|l|l|l|}
\hline Facility & Year Built & Major Renovation & Capacity \\
\hline Football Stadium & 1924 & 1991 & 10,000 \\
\hline Baseball Field & 1890 & $2019-2020$ & 250 \\
\hline Softball Field & N/A & None & N/A \\
\hline Tennis Courts (5 courts) & 1928 & 2001 & 200 \\
\hline Arena (shared responsibility) & 1987 & court - 2018 & 5,000 \\
\hline
\end{tabular}




\section{CURRICULUM VITAE}

Brigitte M. Burpo, M.Ed.

1481 S. 3rd Street, Apt. 2, Louisville, KY 40208 | brigitteburpo@gmail.com | (205)790-6588

\section{EDUCATION}

Ph.D. Leadership, Evaluation, and Organizational Development, University of Louisville Louisville, KY Completed - May 2020

M.Ed. Administration of Higher Education, Auburn University Minor: Sport Management Auburn, AL Completed - Dec 2015

B.S. Sales and Marketing, Tuskegee University Tuskegee, AL

\section{TEACHING EXPERIENCE}

University of Louisville, Louisville, KY January 2018-Present

Instructor, Health \& Sport Sciences

- Teaching undergraduate and graduate level courses averaging 70-160 students per semester with a $4 / 4$ teaching load, covering the following topics:

$\circ$ Leadership \& Management of Sport (SPAD 382)

- Sport Marketing (SPAD 383)

- Sport Governance (SPAD 390)

- Career Development in Sport (SPAD 401)

- Sport Facilities Management (SPAD 405 - distance education course)

- Senior Seminar in Sport (SPAD 490 - distance education course)

$\circ$ Women in Sport (SPAD 529 - distance education course)

- Sport for Development \& Peace (SPAD 571)

- Developed lectures, quizzes, exams, hallmark assessment tasks, and other assignments

- Developed syllabi to meet accreditation standards

- Managed grading of all assignments and final course grades

\section{Student Course Evaluation Feedback}

"The instructor was fun and engaging throughout all lectures and she made the class interesting. I do not have any suggestions for improvement."

"Excellent professor who did a great job of increasing my knowledge about the marketing world."

"Very nice having her as a professor, made everyone want to come to class on a regular basis." "Professor Burpo was excited and kind!" 
"She was very energetic and it made an 8 am go by much easier."

"The professor always came to class with a positive attitude and gave off a relaxing yet professional atmosphere."

"I enjoyed the material a lot and Burpo was able to apply it directly to us, which is more helpful than most college courses."

"The instructor taught relevant information that was very helpful to my success in and out of the classroom."

"Style was fitting to my learning tendencies, so I really enjoyed the course."

\section{RESEARCH}

"It's Personal": A case study analysis of the strategic management of resources for an HBCU athletic department, University of Louisville

Committee: Meg Hancock, Ph.D. (chair), Meera Alagaraja, Ph.D., Mary Hums, Ph.D., Marion Hambrick, Ph.D., and Ishwanzya Rivers, Ph.D.

- Qualitative case study dissertation that explores the strategic management of resources in HBCU athletic departments using resource dependence theory and resource based theory

- Anticipated completion, April 2020

Outsiders Within: Barriers affecting the retention of Black faculty in sport and leisure studies, University of Louisville

Co-Investigator, Dr. Marion Hambrick

- Qualitative phenomenological study that explored the common barriers and facilitators of retention of Black faculty in sport and leisure studies at predominantly White institutions (PWIs)

- Presented initial findings at NASSM 2018 Conference in Halifax, Nova Scotia

- Manuscript in progress

\section{GRANTS AND FUNDING}

2019 Multicultural Assoc. of Graduate Students Research Grant - Dissertation research University of Louisville; Funded $\$ 500$

2019 Graduate Student Council Research Grant - Dissertation research funding University of Louisville; Funded \$500

\section{ACADEMIC PUBLICATIONS}

Murfree, J., Burpo, B., \& Hambrick, M. (2020). Nike and the Balancing Act between Social Justice and Selling Products. Sage Business Cases (in publication).

\section{CONFERENCE PRESENTATIONS}

Oral Presentation, Burpo, B. "'It's personal': a strategic management case study of the acquisition and management of resources for HBCU athletics", Graduate Student Regional Research Conference, February 2020. 
Poster Presentation, Cintron, A. \& Burpo, B. "Stadium development: A Trojan Horse for urban imperialism", Urban Affairs Association Conference, April 2019.

Oral Presentation, Burpo, B. "For the culture: An analysis of attraction, identification, and retention of HBCU Classic Consumers", College Sport Research Institute (CSRI), April 2019.

Oral Presentation, Burpo, B. "Sacrificial lamb games: An analysis of the growing reliance on guarantee games for HBCU athletics”, Black Student Athlete Summit, January 2019.

Oral Presentation, Burpo, B. "Barriers affecting retention of Black faculty in sport and leisure studies academic programs", North American Society for Sport Management (NASSM) Conference, June 2018.

Oral Presentation, Burpo, B. "The Outsider within: Barriers affecting retention of Black female faculty at predominantly White institutions, CEHD Spring Research Conference, March 2018.

\section{PROFESSIONAL EXPERIENCE}

\section{Instructor}

August 2019 - Present

University of Louisville Department of Health and Sport Sciences

Louisville, $K Y$

Develop and teach undergraduate and graduate level courses for Sport Administration according to COSMA standards including Sport Marketing, Sport Management \& Leadership, Career Development in Sport, and Sport Governance; Serve on departmental, college, and university committees related to recruitment and retention activities, Co-Advise Sport Administration students with the SPAD Association

\section{Graduate Assistant}

August 2017 - July 2019

University of Louisville Department of Health and Sport Sciences

Louisville, $K Y$

Developed and taught undergraduate level courses as the instructor on record for Sport Administration according to COSMA standards; Conducted research in the Department of Health and Sport Sciences in the College of Education and Human Development; Participate in departmental and university related recruitment activities; Led experiential learning opportunities for undergraduate and masters students.

Athletics Tutor

University of Louisville Department of Athletics

April 2018 - August 2019

Louisville, $K Y$

Tutor student-athletes for the football, men's golf, baseball, rowing, men's basketball, and women's basketball teams; Use practical methods to ensure student comprehension in subject matter from the communications, sport finance, sociology, and business management areas of study.

\section{Residence Hall Director}

University of Georgia Department of Residence Life and Housing

February 2016 -July 2017

Athens, GA

Live-in and on-call position; Coordinated programmatic and academic initiatives; Advised student groups; Supervised Resident Assistants and Desk Assistants including interviewing, hiring, and schedule management; Managed the residence hall budget and reported expenses, Managed Key and Access Control for residence hall; Facilitated staff trainings and meetings; and 
Served as a University hearing officer for students involved in housing and/or university policy violations.

Administrative Intern

2014-2015

Tuskegee University Department of Athletics

Tuskegee, AL

Developed and managed promotional activities for all athletic programs; Supervised student volunteer workers for game day and promotional activities; Secured in-kind donations as prizes for promotional activities; Developed marketing initiatives including designing marketing materials, creating marketing campaigns, and securing corporate sponsors; Developed the "Partnering with Champions" corporate sponsorship program.

Go Red Event Coordinator

2013-2014

American Heart Association

Birmingham, $A L$

Planned and executed logistics for large fundraising events; Managed budget and finances for the Go Red for Women campaigns including the Go Red Luncheon, Red Dress Dash, and other peripheral Go Red activities leading to the Go Red Luncheon; Prepared media releases and initial grass-roots campaigns; Exceeded fundraising goals for three major campaigns.

Foodservice Operations Specialist

2011-2012

General Mills, Inc.

Southeast District

Business to business sales and account management; Managed email marketing campaigns as well as promotional and swag materials; Responsible for product trainings and local promotions; Managed logistics for trade shows with high level opportunities for product demonstrations and customer recruiting.

Account Manager

2010-2011

Coca Cola Refreshments

Montgomery, $A L$

Outside sales and territory management; Created marketing and promotional materials; Business to business sales involving promotional strategy and cross-selling from an extensive brand portfolio; Exceeded sales goals consistently.

Marketing Territory Manager

2008-2010

RJ Reynolds Tobacco Company

South Alabama District

Managed contract negotiations for discount pricing and in-store presence; Developed promotions and pricing strategies; Managed compliance of contracts; Increased share of market for my territory by $14 \%$ in my first year.

\section{HONORS AND AWARDS}

SIGS Presidential Diversity Fellow

2017 - Present

School of Interdisciplinary and Graduate Studies Presidential Diversity Fellows are nominated by faculty, selected by SIGS leadership, and receive full academic funding as well as professional development funding for up to four years while studying at the PhD level.

\section{Faculty Women of Color in the Academy Conference}


Two female doctoral students with aspirations to become tenure track faculty in their careers are selected each year to attend the conference on behalf of the School of Interdisciplinary and Graduate Studies.

\section{M. Celeste Nichols Award Recipient}

This award is given to UofL graduate students according to how well their intended use of the award for research or professional development supports the mission of the U of L Women's Center. It is named in honor of M. Celeste Nichols who was the first African American to receive a Ph.D. from UofL's English Department.

\section{PROFESSIONAL DEVELOPMENT AND TRAINING}

\section{PLAN Professional Development Workshops}

Time Management

Grant Writing

Presenting at Academic Conferences

Developing a Teaching Philosophy

Entrepreneurship

DELPHI U Certification for online teaching 2017

Completed course training for effective online course teaching and management

\section{PROFESSIONAL SERVICE \\ Department}

Co-Advisor for the SPAD Association

2019-2020

SRLA Conference Planning Committee

2019-2020

International Service-Learning Program Assistant

2019-2020

SPAD - Central High School Outreach Program Coordinator

2018-2019

SPAD Graduate Program Masters candidate interviews

2018-2020

2019 NFL Draft Green Team experiential learning trip coordinator

2019

\section{College}

College of Education and Human Development Diversity Committee

2019-2020

CEHD Marketing Manager Search Committee member

\section{University}

SIGS Search Committee for Director of Graduate Diversity and Retention

\section{Industry}

Tuskegee University Golf Classic Fundraiser

\section{Community}


Jefferson County Public Schools TAPPS Career Day Panelist

\section{INTERESTS AND INVOLVEMENT}

International Service-Learning Program - Ghana 2019

Tuskegee University Alumni Association

Delta Sigma Theta Sorority, Inc.

North American Society for the Sociology of Sport

Sport Marketing Association

North American Society for Sport Management

Individual Sports (Tennis)

\section{REFERENCES}

Dr. Meg Hancock

Associate Dean for Student Success and Academic Affairs

(502)852 3237

mghanc01@ louisville.edu

Dr. Marion Hambrick

Assoc. Dean of Investment and Strategy

(502)767 7154

marion.hambrick@louisville.edu

Dylan Naeger - Department Chair, Health and Sport Sciences

University of Louisville

College of Education and Human Development

(502)852-5050

Dylan.naeger@louisville.edu

Sylvia W. Bowen

Executive Administrator

City of Birmingham, Mayor's Office

(205)254 2283

sylvia.bowen@birminghamal.gov

Calida McCampbell Craddock

Corporate \& Gov. Affairs Manager

Alabama Power Company

(334)312-6175

cjmccampbell@gmail.com 